\title{
Mechanisms of proton translocation in Methanosarcina mazei Gö1
}

Dissertation

Zur Erlangung des Doktorgrades

Der Mathematisch-Naturwissenschaftlichen Fakultäten

Der Georg-August Universität zu Göttingen

Vorgelegt von

Sebastian Andreas Bäumer

Aus Münster

Göttingen 2001 
Die vorliegende Arbeit wurde in der Arbeitsgruppe von PD Dr. Uwe Deppenmeier in der Abteilung Allgemeine Mikrobiologie von Herrn Prof. Dr. Gerhard Gottschalk des Institiuts für Mikrobiologie und Genetik der Georg-August Universität Göttingen angefertigt.

Teile dieser Arbeit wurden veröffentlicht in:

1) Brodersen, J.,Bäumer, S.,Abken, H.J.,Gottschalk, G.,Deppenmeier, U. (1999) Inhibition of membrane-bound electron transport of the methanogenic archaeon Methanosarcina mazei Gö1 by diphenyleneiodonium. Eur. J. Biochem. 259, 218-224

2) Ide, T.,Bäumer, S.,Deppenmeier, U. (1999) Energy conservation by the $\mathrm{H}_{2}:$ Heterodisulfide Oxidoreductase from Methanosarcina mazei Gö1: Identification of Two Proton Translocating Segments. J. Bacteriol. 181 (13), 4076-4080

3) Bäumer, S., Ide, T., Jacobi, C., Johann, A., Gottschalk, G., Deppenmeier, U. (2000) The $\mathrm{F}_{420} \mathrm{H}_{2}$ Dehydrogenase from Methanosarcina mazei is a Redox-driven Proton Pump Closely related to NADH Dehydrogenases. J. Biolog. Chem. 275 (24) 17968-17973

4) Beifuss, U., Tietze, M., Bäumer, S., Deppenmeier, U. (2000) Methanophenazine: Structure, Total Synthesis and Function of a New Cofactor from Methanogenic Archaea. Angew. Chem. Int. Ed. 39 (14) 2470-2472

5) Bäumer, S., Lentes, S., Gottschalk, G., Deppenmeier, U. (2001) Identification and Analysis of proton-translocating Pyrophosphatases in the methanogenic archaeon Methanosarcina mazei. Archaea 1 (1), in Press.

D7

Referent: Prof. Dr. G. Gottschalk

Korreferent: PD Dr. U. Deppenmeier

Tag der mündlichen Prüfung: 22.06.2001 


\section{Table of Contents}

$\begin{array}{ll}\text { Summary } & 1\end{array}$

Introduction 4

Chapter 1:

Inhibition of membrane-bound electron transport of the methanogenic archaeon Methanosarcina mazei Gö1 by diphenyleneiodonium

$\begin{array}{lr}\text { Abstract } & 10 \\ \text { Introduction } & 11 \\ \text { Materials and Methods } & 12 \\ \text { Results } & 15\end{array}$

$\begin{array}{lr}\text { Discussion } & 23\end{array}$

$\begin{array}{ll}\text { References } & 26\end{array}$

Chapter 2:

Energy conservation by the $\mathrm{H}_{2}$ :heterodisulfide oxidoreductase from

Methanosarcina mazei Gö1: identification of two proton-translocating segments

$\begin{array}{ll}\text { Abstract } & 30 \\ \text { Introduction } & 31 \\ \text { Materials and Methods } & 32 \\ \text { Results } & 34 \\ \text { Discussion } & 40 \\ \text { References } & 44\end{array}$

Chapter 3:

The $\mathbf{F}_{\mathbf{4 2 0}} \mathrm{H}_{2}$ Dehydrogenase from Methanosarcina mazei is a Redox- $\quad 48$ driven Proton Pump Closely Related to NADH Dehydrogenases

$\begin{array}{lr}\text { Abstract } & 48 \\ \text { Introduction } & 49 \\ \text { Materials and Methods } & 50 \\ \text { Results } & 51 \\ \text { Discussion } & 62 \\ \text { References } & 67\end{array}$

Chapter 4:

Methanophenazine: structure, total synthesis and function of a new cofactor from methanogenic archaea 
Introduction

Synthesis Report 71

Results

References

Chapter 5:

Identification and analysis of proton-translocating pyrophosphatases

in the methanogenic archaeon Methanosarcina mazei

$\begin{array}{ll}\text { Abstract } & 79 \\ \text { Introduction } & 80 \\ \text { Materials and Methods } & 81 \\ \text { Results } & 83 \\ \text { Discussion } & 89 \\ \text { References } & 94 \\ \text { clusions } & 97\end{array}$

Curriculum vitae 


\section{Summary}

Methanogenesis from methanol and $\mathrm{H}_{2}$ plus $\mathrm{CO}_{2}$ is coupled to the generation of a transmembrane ion gradient, which is the driving force for ATP formation from ADP plus Pi.

In this work three proton-translocating enzyme systems from the methanogenic archaeon Methanosarcina mazei Gö1 were analyzed: The $\mathrm{F}_{420} \mathrm{H}_{2}$ :heterodisulfide oxidoreductase, the $\mathrm{H}_{2}$ :heterodisulfide oxidoreductase and a proton-translocating pyrophosphatase.

It was shown, that the $\mathrm{H}_{2}$ :heterodisulfide oxidoreductase from Methanosarcina mazei Gö1 catalyzed a $\mathrm{H}_{2}$ dependent reduction of 2-hydroxy phenazine and the dihydro2-OH phenazine dependent reduction of the heterodisulfide CoM-S-S-CoB. The electron carrier is a water soluble analogon of the physiological electron carrier, methanophenazine. Washed inverted vesicles of this organism were able to couple each partial reaction with the transfer of protons across the cytoplasmic membrane The maximal $\mathrm{H}^{+} / 2 \mathrm{e}^{-}$was found to be 2.0 for each reaction.

The electrochemical proton gradient thereby generated was used for ATP synthesis by an A- type ATP synthase. Using the protonophor SF 6847 and ATPase inhibitor DCCD in the presence or absence of ADP, the energy conserving systems showed a stringent coupling, which resembles the phenomenon of respiratory control.

It was found, that 2-OH phenazine-dependent reactions as catalyzed by the $\mathrm{H}_{2}$ :heterodisulfide oxidoreductase, and the $\mathrm{F}_{420} \mathrm{H}_{2}$ :heterodisulfide oxidoreductase were inhibited by diphenyliodoniumchloride (DPI) indicated by $\mathrm{IC}_{50}$ values of $20 \mathrm{nmol} \mathrm{DPI} / \mathrm{mg}$ protein for the $\mathrm{F}_{420} \mathrm{H}_{2}$ :heterodisulfide oxidoreductase and $45 \mathrm{nmol} / \mathrm{mg}$ protein for the $\mathrm{H}_{2}$ dependent enzyme system. Further analysis revealed that DPI inhibited heterodisulfidedependent oxidation of reduced membrane bound cytochromes as well as $\mathrm{H}_{2}$-dependent cytochrome reduction. Membrane bound and purified $\mathrm{F}_{420} \mathrm{H}_{2}$ dehydrogenase was directly inhibited by DPI: The $\mathrm{K}_{\mathrm{m}}$ value for $2-\mathrm{OH}$ phenazine increased from $35 \mu \mathrm{M}$ to $100 \mu \mathrm{M}$ in 
the presence of DPI leading to the hypothesis that DPI reacts as a competitive inhibitor due to ist structural similarity to $2-\mathrm{OH}$ phenazine.

The $\mathrm{F}_{420} \mathrm{H}_{2}$ :heterodisulfide oxidoreductase was found to catalyze a $\mathrm{F}_{420} \mathrm{H}_{2}$ dependent 2-OH phenazine reduction and a dihydro-2-OH phenazine dependent reduction of the heterodisulfide similar to the $\mathrm{H}_{2}$ dependent system. Both partial reactions contribute to the generation of an electrochemical proton gradient with $\mathrm{H}^{+} / 2 \mathrm{e}^{-}$ratios of 2.0 each. These findings indicate that the $\mathrm{F}_{420} \mathrm{H}_{2}$ dehydrogenase functions as a novel proton pump in methanogenic archaea.

Sequence data from the genome sequencing project of Ms. Mazei Gö1 revealed the existence of a gene cluster comprising 12 genes which were referred to as fpo $\left(\underline{\mathrm{F}}_{420} \mathrm{H}_{2}\right.$ :phenazine oxidoreductase) A B C D H J K L M N O. Each gene is preceeded by at least one putative ribosome binding site and starting with codon ATG or GTG and termiated by stop codons TAA or TGA. Upstream from fpo A an archaeal promoter sequence was identified. Nothern blot analysis revealed an $11 \mathrm{~kb}$ signal, when RNA from methanol grown cells was hybridized with a fpoH specific probe, which indicates that the genes fpo A-O were organized in one operon.

The deduced primary sequences of the Ms. mazei $\mathrm{F}_{420} \mathrm{H}_{2}$ dehydrogenase subunits were compared with those from other organisms. For eleven proteins encoded by fpo A to $\mathrm{N}$ homologues exist in bacterial NDH-1 and the mitchondrial Complex I (NADH:ubiquinone oxidoreductase). The current working model divides the bacterial Complex I into three subcomplexes or modules: The NADH dehydrogenase input module as a peripheral device for the oxidation of $\mathrm{NADH}$, the membrane associated connecting module which channels the electrons to the third, large membrane integral module which is adapted to the reduction of the membrane integral electron acceptor, the quinone. The membrane integral and associated part of the $\mathrm{F}_{420} \mathrm{H}_{2}$ dehydrogenase complex showed high similarities to the corresponding module of the bacterial Complex I with the exception that the gene product from fpoO has no similarity to Complex I-like enzymes as well as to any known protein. A NADH dehydrogenase module does not exist in $M s$. mazei, Gö1, instead a polypeptide with high homologies to $\mathrm{F}_{420}$ dependent hydrogenases 
was copurified with the $\mathrm{F}_{420} \mathrm{H}_{2}$ dehydrogenase leading to the assumption that this protein serves the dehydrogenase as an $\mathrm{F}_{420} \mathrm{H}_{2}$ oxidizing input module. The corresponding gene to this subunit, fpoF was not located in the operon, but on a different part of the chromosome.

The structure and chemical synthesis of methanophenazine, the first phenazine from archaea, was reported. Experiments on the function of the new cofactor in Ms. mazei Gö1 demonstrated that it is also the first phenazine whatsoever involved in the membrane bound electron transport in biological systems. Experiments combining the chemically synthesized cofactor with washed membranes of Methanosarcina mazei Gö1 clearly indicated that methanophenazine serves as an electron acceptor to both the membranebound hydrogenase and the $\mathrm{F}_{420} \mathrm{H}_{2}$ dehydrogenase if $\mathrm{H}_{2}$ and $\mathrm{F}_{420}$ were added, respectively. In addition, the heterodisulfide reductase uses the reduced form of methanophenazine as an electron donor for the heterodisulfide reduction. Therefore, methanophenazine is able to mediate the electron transport between the membrane-bound enzymes.

Further bioinformatical studies showed the existence of two open reading frames in the Ms. mazei genome encoding proton translocating pyrophosphatases. The corresponding polypeptides were referred to as Mvp1 and Mvp2 each representing an extremely hydrophobic membrane integral protein with 15 transmembrane segments. Northern blot analysis using RNA from mid growth phase harvested methanol grown cells revealed that only Mvp2 was produced under these conditions. Washed membranes showed a specific pyrophosphatase activity of $0.34 \mathrm{U}$ per $\mathrm{mg}$ membrane protein and inverted vesicles were found to couple a translocation of one proton to the hydrolysis of one molecule of pyrophosphate. These findings indicate that this type of enzyme might contibute to the energy conservation processes in Ms. mazei Gö1. 


\section{Introduction}

Biological methanogenesis has received much attention because it plays a major role in the carbon cycle on Earth and represents the terminal step in the anaerobic breakdown of organic matter in many anaerobic habitats. The methanogenic Archaea are able to produce methane from $\mathrm{H}_{2}+\mathrm{CO}_{2}$, formate, methanol, methylamines or acetate. They represent one of the most prominent group of archaea. Furthermore, it is to note that $\mathrm{CH}_{4}$ released to the atmosphere acts as an important greenhouse gas (Thauer, 1998).

\section{The process of methanogenesis}

Methanogenic Archaea are strictly anaerobic organisms that can be divided into two major groups (Boone et al., 1993). The substrate spectrum of obligate hydrogenotrophic organisms of the orders Methanobacteriales, Methanococcales and Methanomicrobiales is restricted to $\mathrm{H}_{2}+\mathrm{CO}_{2}$ and formate. A limited number of species is able to use secondary alcohols as electron donors. Methylotrophic methanogens of the order Methanosarcinales utilize simple $\mathrm{C}_{1}$-components such as methanol and methylamines. Some of them are also able to grow on $\mathrm{H}_{2}+\mathrm{CO}_{2}$ and on acetate.

The metabolic pathways leading to the formation of methane have been elucidated in recent years (Thauer, 1998; Deppenmeier et al., 1999; Heddrich et al., 1999; Ferry, 1999). Methanogenesis from $\mathrm{H}_{2}+\mathrm{CO}_{2}$ proceeds according to the following equation:

$\mathrm{CO}_{2}+4 \mathrm{H}_{2} \longrightarrow \mathrm{CH}_{4}+2 \mathrm{H}_{2} \mathrm{O} \quad\left(\Delta \mathrm{G}_{0}{ }^{\prime}=-130 \mathrm{~kJ} / \mathrm{mol}\right) \quad$ [eq. 1]

The pathway starts with the $\mathrm{H}_{2}$ - and MF-dependent reduction of $\mathrm{CO}_{2}$ to formyl-MF. The endergonic reaction is catalyzed by a formyl-MF dehydrogenase and is driven by an electrochemical ion gradient (Kaesler und Schönheit, 1989, Winner und Gottschalk, 1989). The formyl group is then transferred to $\mathrm{H}_{4} \mathrm{MPT}$ and the resulting formyl- $\mathrm{H}_{4} \mathrm{MPT}$ is stepwise reduced to methyl- $\mathrm{H}_{4} \mathrm{MPT}$. The electrons are derived from reduced $\mathrm{F}_{420}$ $\left(\mathrm{F}_{420} \mathrm{H}_{2}\right)$ which is produced by the $\mathrm{F}_{420}$-reducing hydrogenase (Vaupel und Thauer, 1998). The methyl-group of methyl- $\mathrm{H}_{4} \mathrm{MPT}$ is then transferred to HS-CoM by the methyl-H4MPT:HS-CoM methyltransferase. The exergonic reaction $\left(\Delta \mathrm{G}^{0^{\prime}}=-29 \mathrm{~kJ} / \mathrm{mol}\right)$ is coupled to the formation of an electrochemical sodium ion gradient $\left(\Delta \mu_{\mathrm{Na}^{+}}\right.$; Becher et al., 1992; Weiss et al., 1994; Lienard et al., 1996; Sauer und Thauer, 1998). The final step in methanogenesis is the reduction of $\mathrm{CH}_{3}-\mathrm{S}-\mathrm{CoM}$ to $\mathrm{CH}_{4}$, which can be divided into two partial reactions. First methyl-S-CoM is reductively cleaved by the methyl-S-CoM 
reductase using HS-CoB as reductant (Ermler et al., 1997). The reaction results in the formation of methane and a heterodisulfide (CoM-S-S-CoB) from HS-CoM and HS-CoB. In a second reaction CoM-S-S-CoB is reduced by the heterodisulfide reductase (Künkel et al., 1997; Simianu et al., 1998). The reducing equivalents are derived from $\mathrm{H}_{2}$ and channeled to the heterodisulfide reductase by a membrane-bound electron transport system (see below).

When cells grow on methanol, methylamines or methylthiols, the substrates undergo disproportionation to $\mathrm{CH}_{4}$ and $\mathrm{CO}_{2}$ (Keltjens und Vogels, 1993), e.g. methanol is converted according to the following equation:

$$
4 \mathrm{CH}_{3} \mathrm{OH} \longrightarrow 3 \mathrm{CH}_{4}+1 \mathrm{CO}_{2}+2 \mathrm{H}_{2} \mathrm{O} \quad\left(\Delta \mathrm{G}_{0}^{\prime}=-106 \mathrm{~kJ} / \mathrm{mol}\right) \text { [eq. 2] }
$$

In the oxidative branch of the pathway one out of four methyl groups is oxidized to $\mathrm{CO}_{2}$ by the reversed $\mathrm{CO}_{2}$-reduction route. The series of reactions starts with the formation of $\mathrm{CH}_{3}$-S-CoM and methyl-group transfer to $\mathrm{H}_{4} \mathrm{MPT}$ as catalyzed by the methyl$\mathrm{H}_{4} \mathrm{MPT}$ :HS-CoM-methyltransferase. The endergonic reaction $\left(\Delta \mathrm{G}^{\mathrm{o}^{\prime}}=29 \mathrm{~kJ} / \mathrm{mol}\right)$ is driven by an electrochemical sodium ion gradient (Müller and Gottschalk, 1992; Müller et al., 1993). The formation of methyl- $\mathrm{H}_{4} \mathrm{MPT}$ is followed by the stepwise oxidation to formyl$\mathrm{H}_{4} \mathrm{MPT}$. Reducing equivalents derived from these reactions are used for $\mathrm{F}_{420}$-reduction. After transfer of the formyl-group to MF the formyl-MF dehydrogenase catalyzes the oxidation of $\mathrm{CHO}-\mathrm{MF}$ to $\mathrm{CO}_{2}$ and $\mathrm{MF}$. In the reductive branch of the pathway three out of four methyl groups are transferred to HS-CoM by methanol-specific methyltransferases (Harms und Thauer, 1996). Again, the HS-CoB-dependent reduction of methyl-S-CoM leads to the formation of $\mathrm{CH}_{4}$ and CoM-S-S-CoB.

The major part of methane production in nature originates from the decomposition of acetate, which is carried out only by the genera Methanosarcina and Methanosaeta (Ferry, 1997)

$$
\mathrm{CH}_{3}-\mathrm{COO}^{-}+\mathrm{H}^{+} \rightarrow \mathrm{CH}_{4}+\mathrm{CO}_{2} \quad\left(\Delta \mathrm{G}^{\mathrm{o}^{\prime}}=-36 \mathrm{~kJ} / \mathrm{mol}\right)
$$

It is thought that in Methanosarcina strains acetate is activated by an acetate kinase and a phosphotransacetylase, in contrast to Methanosaeta species where an acetate thiokinase leads to the formation of acetyl-CoA. The C-C and C-S bonds of acetyl-CoA are cleaved by a $\mathrm{CO}$ dehydrogenase/acetyl-CoA synthase complex. In the course of the reaction enzyme-bound $\mathrm{CO}$ is oxidized to $\mathrm{CO}_{2}$ and the electrons are used for ferredoxin reduction. 
The methyl-moiety is transferred to $\mathrm{H}_{4} \mathrm{MPT}$. The resulting methyl- $\mathrm{H}_{4} \mathrm{MPT}$ is converted to methane by the catalytic activities of the sodium-translocating methyl-H 4 MPT:HSCoM methyltransferase and methyl-S-CoM reductase as described above (Ferry, 1999).

\section{Energy metabolism:}

The last reaction of all methanogenic pathways is the reduction of the heterodisulfide to HS-CoM and HS-CoB catalyzed by the heterodisulfide reductase. It has been shown for the methylotrophic methanogen Methanosarcina mazei Gö1 that reducing equivalents for the reductive process are provided by membrane-bound electron transport systems using $\mathrm{H}_{2}$ or $\mathrm{F}_{420} \mathrm{H}_{2}$ as electron donors (Deppenmeier et al., 1999). Electron transfer is coupled to proton translocation across the cytoplasmic membrane resulting in the formation of an electrochemical proton gradient. These systems are referred to as $\mathrm{H}_{2}$ :heterodisulfide oxidoreductase and $\mathrm{F}_{420} \mathrm{H}_{2}$ :heterodisulfide oxidoreductase, respectively (Deppenmeier et al., 1990 a/b; Deppenmeier et al., 1991). In the final step of the aceticlastic pathway again the heterodisulfide reductase reduces $\mathrm{CoM}-\mathrm{S}-\mathrm{S}-\mathrm{CoB}$ which derives electrons from reduced ferredoxin by a third membrane-bound electron transport system (reduced ferredoxin:heterodisulfide oxidoreductase; Hedderich et al., 1999).

All key enzymes of the electron transport chains have been isolated and characterized (Deppenmeier et al., 1996). The oxidation of molecular hydrogen by the F420nonreducing hydrogenase is the initial reaction of the $\mathrm{H}_{2}$-dependent system. This enzyme was isolated from Ms. barkeri (Kemner and Zeikus,1994) and Ms. mazei Gö1 (Deppenmeier et al., 1992). The purified proteins consist of two different subunits with molecular masses of approximately 60 and $40 \mathrm{kDa}$ and contain a redox active $\mathrm{Ni}$ ion and FeS clusters. Ms. mazei Gö1 contains two sets of genes (the vho and the vht operon) which code for $\mathrm{F}_{420}$-nonreducing hydrogenases (Deppenmeier et al., 1995). The vhoGAC-encoded enzyme is believed to be part of the $\mathrm{H}_{2}$ :heterodisulfide oxidoreductase. The deduced amino acid sequences revealed that the small (VhoG) and the large subunit (VhoA) of the protein are homologous to corresponding polypeptides of membranebound $\mathrm{NiFe}$ hydrogenases from several bacteria (Vignais and Toussaint, 1994). A third gene ( $v h o C$ ) belonging to the hydrogenase operon from strain Gö1 encodes a b-type cytochrome (cyt $\left.b_{1}\right)$ which probably functions as primary electron acceptor of the core enzyme consisting of VhoG and VhoA (Brodersen et al., 1999).

The $\mathrm{F}_{420} \mathrm{H}_{2}$ dehydrogenase from Ms. mazei Gö1 with a molecular mass of $115 \mathrm{kDa}$ contains iron-sulfur clusters and FAD (Abken and Deppenmeier, 1997). The enzyme is 
very similar to the corresponding protein from Methanolobus tindarius (Haase et al., 1992) and is composed of five different subunits with molecular masses of 40, 37, 22, 20 and $17 \mathrm{kDa}$. $\mathrm{A} \mathrm{F}_{420} \mathrm{H}_{2}$ dehydrogenase has also been isolated form the sulfate reducing archaeon Archaeoglobus fulgidus (Kunow et al., 1994).

The heterodisulfide reductase from Methanosarcina species is composed of two subunits (HdrDE) (Heiden et al., 1994). HdrE represents a membrane-integral b-type cytochrome (cyt $b_{2}$ ) and contains two distinct heme-groups. HdrD is the catalytic subunit of the heterodisulfide reductase and contains two $\mathrm{Fe}_{4} \mathrm{~S}_{4}$ clusters (Simianu et al., 1998).

The question rose which component mediates electron transport between the abovementioned enzymes. It is important to note that methanogenic Archaea do not contain typical quinones such as ubiquinone or menaquinone. Instead, there is strong evidence that methanophenazine fulfills this function. The hydrophobic, redox active component with a molecular mass of 538 Da was isolated from membranes of Ms. mazei strain Gö1. After purification the chemical structure was analyzed by mass spectroscopy and NMR studies. Methanophenazine represents a 2-hydroxyphenazine derivative, which is connected via an ether bridge to a pentaisoprenoid side chain (Abken et al., 1998). Since the cofactor is almost insoluble in aqueous buffers, the water-soluble analogon 2hydroxyphenazine was used for further experiments. It was shown that 2hydroxyphenazine could function as electron acceptor for both the $\mathrm{F}_{420} \mathrm{H}_{2}$ dehydrogenase and the membrane-bound hydrogenase in the presence of reduced $\mathrm{F}_{420}$ and $\mathrm{H}_{2}$, respectively. Furthermore, the membrane-bound heterodisulfide reductase was able to use reduced 2-hydroxyphenazine as electron donor for the reduction of CoB-S-S-CoM (Brodersen et al., 1999a, Bäumer et al. 1998). Thus, the electron transport processes can be divided into two partial reactions:

$$
\mathrm{H}_{2}+2-\mathrm{OH}-\text { phenazine }
$$

dihydro-2-OH-phenazine + CoM-S-S-CoB

$\mathrm{F}_{420} \mathrm{H}_{2}+2-\mathrm{OH}-$ phenazine

dihydro-2-OH-phenazine + CoM-S-S-CoB
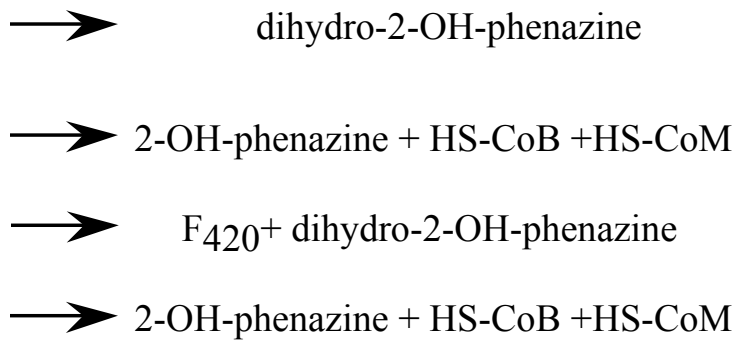

The goal of this thesis was to study the processes of proton translocation in Methanosarcina mazei strain Gö1 in detail. In the course of the experiments a novel membrane bound cofactor in methanogenic archaea was discovered, referred to as methanophenazine. It was demonstrated that the cofactor functions as the central electron 
carrier between the membrane bound enzymes that are involved in the anaerobic respiratory chain of Ms. mazei (Chapter 4). The composition of the $\mathrm{H}_{2}$ :heterodisulfide oxidoreductase and the mechanism of energy conservation was investigated (Chapter 2). A specific inhibitor of phenazine-mediated electron transport processes, diphenyliodoniomchloride (DPI) was discovered and its effect on the energy transducing enzymes was analyzed (Chapter 1). Furthermore, the composition of the $\mathrm{F}_{420} \mathrm{H}_{2}$ dehydrogenase was eludicated on the base of genetical and biochemical data and its function as an important proton pump was demonstrated (Chapter 3). Finally a membrane bound pyrophosphatase was discovered in Ms. mazei which coupled the hydrolysis of anorganic pyrophosphate with the transfer of $\mathrm{H}^{+}$across the membrane. (Chapter 5).

\section{References:}

Abken, H.J., Deppenmeier, U. (1997 FEMS Lett. 154, 231-237.

Abken, H. J., Tietze, M., Brodersen, J., Bäumer, S., Beifuss, U., Deppenmeier, U. (1998) J. Bacteriol. 180, 2027-2032

Bäumer, S., Murakami, E., Brodersen, J., Gottschalk, G., Ragsdale, S W. Deppenmeier, U. (1998) FEBS Lett. 428, 295-298

Becher, B., Müller, V., Gottschalk, G. (1992) FEMS Microbiol. Lett. 91, 239-244

Brodersen, J., Bäumer, S., Abken, H.J., Gottschalk, G., Deppenmeier, U. (1999a) Eur. J. Biochem. 259, 218-224

Brodersen, J., Gottschalk, G., Deppenmeier, U. (1999b) Arch. Microbiol. 171, 115-121.

Boone, D.R., Whitman, W.B., Rouviere, P.E. (1993) In: Ferry, J.G. (ed.), Methanogensis, Chapman \& Hall, New York-London, 35-80

Deppenmeier, U., Blaut, M., Mahlmann, A., Gottschalk, G. (1990 a) Proc. Natl. Acad. Sci. USA 87, 9449-9453

Deppenmeier, U., Blaut, M., Mahlmann, A., Gottschalk, G. (1990 b) FEBS Lett. 261, 199-203

Deppenmeier, U., Blaut, M., Gottschalk, G. (1991) Arch. Microbiol. 155, 272-277.

Deppenmeier, U., Blaut, M., Schmidt, B., Gottschalk, G. (1992) Arch. Microbiol. 157, 505-511

Deppenmeier, U. (1995) Arch. Microbiol. 164, 370-376

Deppenmeier, U., Müller, V., Gottschalk, G. (1996) Arch. Microbiol. 165, 149-163

Deppenmeier, U., Lienard, T., Gottschalk, G. (1999) FEBS Lett. 457, 291-297 
Ermler, U., Grabarse, W., Shima, S., Goubeaud, M., Thauer, R.K. (1997) Science 278, $1457-1462$

Ferry, J. G. (1999) FEMS Micobiol. Rev. 23, 13-38

Haase, P., Deppenmeier, U., Blaut, M., Gottschalk, G. (1992) Eur. J. Biochem. 203, $527-$ 531

Harms, U., Thauer, R.K. (1996) Eur. J. Biochem. 235, 653-659

Heddrich, R., Klimmel, O., Kröger, A., Dirmeier, R., Keller, M., Stetter, K.O. (1999) FEMS Microbiol. Rev. 22, 353-381

Heiden, S., Hedderich, R., Setzke, E., Thauer, R.K. (1994) Eur. J. Biochem. 221, 855-861

Kaesler, B., Schönheit, P. (1989) Eur. J. Biochem. 184, 223-232

Keltjens, J. T., Vogels, G. D. (1993) In: Ferry JG (ed) Methanogenesis. Chapman \& Hall, New York, London, 209-252

Kemner, J. M., Zeikus, J. G. (1994) Arch. Microbiol. 161, 47-54

Künkel, A., Vaupel, M., Heim, S. Thauer, R.K., Hedderich, R. (1997) Eur. J. Biochem. 244, 226-234

Kunow, K., Linder, D., Stetter, K.O., Thauer, R.K. (1994) Eur. J. Biochem. 223, 503-511

Lienard, T., Becher, B., Marschall, M., Bowien, S., Gottschalk, G. (1996) Eur. J. Biochem. 239, 857-864

Müller, V., Gottschalk, G. (1992) In: Acetogenesis (H. L. Drake, ed.), Chapman \& Hall, New York, USA, 127-156

Müller, V., Blaut, M., Gottschalk, G. (1993) In: Ferry JG (Hrgb) Methanogenesis. Chapman \& Hall, New York, 360-406

Reeve, J.N. (1993) In: Ferry, J.G. (ed.) Methanogenesis. Chapman \& Hall, New York, London, 493-527

Sauer, K., Thauer, R.K. (1998) FEBS Lett. 436, 401-402

Simianu, M., Murakami, E., Brewer, J. M., Ragsdale, S. W. (1998) Biochemistry 37, 10027-10039

Thauer, R.K. (1998) Microbiology. 144, 2377-2406

Vaupel, M., Thauer, R.K. (1998) Arch. Microbiol. 169, 201-205

Vignais, P.M., Toussaint, B. (1994) Arch. Microbiol. 161, 1-10

Weiss, D., Gärtner, P., Thauer, R.K. (1994) Eur. J. Biochem. 226, 799-809

Winner,C., Gottschalk, G. (1989) FEMS Microbiol. Lett. 65, 259-264 


\title{
Chapter 1
}

\section{Inhibition of membrane-bound electron transport of the methanogenic archaeon Methanosarcina mazei Gö1 by diphenyleneiodonium}

\begin{abstract}
:
The proton translocating electron transport systems $\left(\mathrm{F}_{420} \mathrm{H}_{2}\right.$ :heterodisulfide oxidoreductase and $\mathrm{H}_{2}$ :heterodisulfide oxidoreductase) of Methanosarcina mazei Gö1 were inhibited by diphenyleneiodonium chloride (DPI) indicated by $\mathrm{IC}_{50}$ values of 20 $\mathrm{nmol} \mathrm{DPI} / \mathrm{mg}$ protein and $45 \mathrm{nmol} \mathrm{DPI} / \mathrm{mg}$ protein, respectively. These effects are due to a complex interaction of DPI with key enzymes of the electron transport chains. It was found that 2-hydroxyphenazine-dependent reactions as catalyzed by $\mathrm{F}_{420}$-nonreducing hydrogenase, $\mathrm{F}_{420} \mathrm{H}_{2}$ dehydrogenase and heterodisulfide reductase were inhibited. Interestingly, the $\mathrm{H}_{2}$-dependent methylviologen reduction and the heterodisulfide reduction by reduced methylviologen as catalyzed by the hydrogenase and the heterodisulfide reductase present in washed membranes were unaffected by DPI, respectively. Analysis of the redox behaviour of membrane-bound cytochromes indicated that DPI inhibited CoB-S-S-CoM-dependent oxidation of reduced cytochromes and $\mathrm{H}_{2}-$ dependent cytochrome reduction. Membrane-bound and purified $\mathrm{F}_{420} \mathrm{H}_{2}$ dehydrogenase were inhibited by DPI irrespectively whether methylviologen + metronidazole or 2hydroxyphenazine were used as as electron acceptors. Detailed examination of 2hydroxy-phenazine-dependent $\mathrm{F}_{420} \mathrm{H}_{2}$-oxidation revealed that DPI is a competitive inhibitor of the enzyme, indicated by the $\mathrm{K}_{\mathrm{m}}$ value for 2-hxydroxyphenazine which increased from $35 \mu \mathrm{M}$ to $100 \mu \mathrm{M}$ in the presence of DPI. Since DPI and phenazines are structurally similar with respect to their planar configuration we assume that the inhibitor is able to bind to positions where interaction between phenazines and components of the electron transport systems take place. Thus, electron transfer from reduced 2-
\end{abstract}


hydroxyphenazine to cytochrome $b_{2}$ as part of the heterodisulfide reductase and from $\mathrm{H}_{2}$ to cytochrome $b_{1}$ as subunit of the membrane-bound hydrogenase is affected in the presence of DPI. In case of the $\mathrm{F}_{420} \mathrm{H}_{2}$ dehydrogenase electron transport from FAD or from FeS centers to 2-hydroxyphenazine is inhibited.

\section{Introduction}

The process of methanogenesis as performed by methanogenic archaea is coupled to energy conservation by electron transport phosphorylation (Deppenmeier et al., 1996). In Methanosarcina mazei Gö1 two membrane-bound electron transport systems have been discovered. The $\mathrm{F}_{420} \mathrm{H}_{2}$ :heterodisulfide oxidoreductase is involved in methanol degradation and consists of $\mathrm{F}_{420} \mathrm{H}_{2}$ dehydrogenase (Haase et al., 1992; Abken and Deppenmeier, 1997) and heterodisulfide reductase (Künkel et al., 1997). Electron transfer between the enzymes is probably mediated by methanophenazine, a membrane integral electron carrier which was recently isolated from Ms. mazei Gö1 (Abken et al., 1998). The $\mathrm{F}_{420} \mathrm{H}_{2}$ dehydrogenase catalyzes the oxidation of $\mathrm{F}_{420} \mathrm{H}_{2}$ which is formed during oxidation of one out of four methanol molecules. The remaining methyl-moities are transferred to 2-mercaptoethanesulfonate (CoM-SH). In the final step of methanogenesis the methyl-S-CoM reductase catalyzes the reduction of methyl-S-CoM using 7mercaptoheptanoylthreonine phosphate $(\mathrm{CoB}-\mathrm{SH})$ as electron donor thereby producing methane and a heterodisulfide (CoB-S-S-CoM) of CoB-SH and CoM-SH (Ermler et al., 1997). CoB-S-S-CoM serves as electron acceptor of the above mentioned energy conserving systems and is reduced by the heterodisulfide reductase (Heiden et al., 1994). The second electron transport system is referred to as $\mathrm{H}_{2}$ :heterodsulfide oxidoreductase and is involved in methanogenesis from $\mathrm{H}_{2}+\mathrm{CO}_{2}$ (Deppenmeier et al., 1991). It is known that a $\mathrm{F}_{420}$-nonreducing hydrogenase (Deppenmeier et al., 1992; Kemner and Zeikus, 1994), the heterodisulfide reductase (Heiden et al., 1994) and probably methanophenazine (Abken et al., 1998) are involved in electron transfer from $\mathrm{H}_{2}$ to the heterodisulfide. Both electron transport systems are coupled to the generation of an 
electrochemical proton gradient which is used for ATP synthesis from ADP $+\mathrm{P}_{\mathrm{i}}$ by an $\mathrm{A}_{1} \mathrm{~A}_{0}$-type ATP synthase (Deppenmeier et al., 1996; Ruppert et al., 1998).

Several inhibitors of mitochondrial and eubacterial electron transport systems were tested for their effect on the energy conserving oxidoreductases of methanogens (Kamlage and Blaut, 1992). Only those inhibitors that interact with íron-sulfur proteins were effective indicating that the mode of inhibition was unspecific. Here we present evidence that diphenyleneiodonium chloride (DPI; Fig. 1) specifically inhibits components of the $\mathrm{H}_{2}$ :heterodisulfide-oxidoreductase and of the $\mathrm{F}_{420} \mathrm{H}_{2}$ :heterodisulfide-oxidoreductase from the archaeon Ms. mazei Gö1.

\section{Materials and Methods}

\section{Strains and growth of organisms}

Ms. mazei Gö1 (DSM 3647) was obtained from the Deutsche Sammlung von Mikroorganismen (Braunschweig, Germany) and grown in a 100-1 fermenter as described (Abken and Deppenmeier, 1997).

\section{Preparation of washed membranes and purification of proteins}

Washed membranes and $\mathrm{F}_{420} \mathrm{H}_{2}$ dehydrogenase from $M s$. mazei were purified according to Abken and Deppenmeier (1997). The $\mathrm{F}_{420}$-nonreducing hydrogenase from Ms. mazei was purified under aerobic conditions. Washed membranes were solubilized by the addition of $1.5 \mathrm{mg}$ Chaps $/ \mathrm{mg}$ membrane protein. After stirring for $15 \mathrm{~min}$ the solubilized membranes were centrifuged at $120000 \mathrm{x}$ g for $30 \mathrm{~min}$. The supernatant was loaded onto a DEAE-Sephacel column $(5 \mathrm{~cm} \times 7 \mathrm{~cm}$, flow rate $3 \mathrm{ml} / \mathrm{min}$ ) equilibrated with $25 \mathrm{mM}$ Mops buffer, pH 7.0 containing $0.5 \mathrm{mM}$ Chaps (buffer A). The column was washed with $100 \mathrm{ml}$ of the above buffer followed by a linear gradient of 0 to $1 \mathrm{M} \mathrm{NaCl}$ in buffer $\mathrm{A}$ ( 2 x $300 \mathrm{ml}$ ). Active fractions were applied to a hydroxyl apatite column preequilibrated with $25 \mathrm{mM}$ Mops buffer, pH 7.0 containing $5 \mathrm{mM}$ Chaps buffer. The tightly bound 
hydrogenase was eluted with $60 \mathrm{mM}$ K-phosphate in the same buffer. Hydrogenasecontaining fractions were pooled and concentrated by ultrafiltration (YM 30 filter, Amicon, Witten, FRG). Finally purification was done by gel filtration (Superdex $200 \mathrm{HR}$, $1.6 \times 60 \mathrm{~cm}$, flow rate $1 \mathrm{ml} / \mathrm{min}$ ). The hydrogenase fractions were concentrated (YM 30 filter, Amicon, Witten, FRG) and stored at $-70{ }^{\circ} \mathrm{C}$. The procedure was also performed under anaerobic conditions. In this case all buffers were gassed with nitrogen and $4 \mathrm{mM}$ dithioerythritol was added. All purification steps were done in an anaerobic chamber (95 $\left.\% \mathrm{~N}_{2} / 5 \% \mathrm{H}_{2}\right) . \mathrm{F}_{420}$-nonreactive hydrogenase was assayed in 1.5-ml glass cuvettes gassed with $\mathrm{H}_{2}$ and filled with $0.5 \mathrm{ml}$ anaerobic $25 \mathrm{mM}$ Mops buffer, $\mathrm{pH}$ 7.0, containing $4 \mathrm{mM}$ dithioerythritol and $1 \mathrm{mg}$ resazurin/l. After addition of $0.2 \mu \mathrm{Ti}$ (III)-citrate $(0.2 \mathrm{mM}$ stock solution) the assay mixture was incubated for 1 min to reactivate the hydrogenases. The reaction was started by addition of $4 \mathrm{mM}$ methylviologen $\left(\varepsilon_{604}=13.9 \mathrm{~cm}^{-1} \mathrm{x} \mathrm{mM}^{-1}\right)$.

\section{Purification and synthesis of cofactors}

$\mathrm{F}_{420}$ was isolated from Ms. barkeri or Ms. mazei and reduced to $\mathrm{F}_{420} \mathrm{H}_{2}$ with $\mathrm{NaBH}_{4}$ as described (Deppenmeier et al., 1990). CoB-S-S-CoM was synthesized by the method of Noll et al. (1986) and Kamlage and Blaut (1992). 2-hydroxy-phenazine was prepared according to Abken et al. (1998) and was reduced as described by Bäumer et. al. (1998). Methylviologen was reduced by titration with Na-dithionite $(50 \mathrm{mM}$ stock solution in $\left.\mathrm{H}_{2} \mathrm{O}\right)$.

\section{Assay conditions}

Enzymatic activities of washed membranes $(20 \mu \mathrm{g}$ protein $)$ or purified proteins $(0.25 \mu \mathrm{g}$ protein) were measured in anaerobic cuvettes containing $1 \mathrm{ml} 25 \mathrm{mM}$ Mops, pH 7, $4 \mathrm{mM}$ dithioerithritol, $1 \mathrm{mg} / \mathrm{l}$ resazurine (buffer A). The assays were performed under an atmosphere of hydrogen when the activity of the $\mathrm{H}_{2}$ :heterodisulfide oxidoreductase was determined. The cuvettes were also gassed with $\mathrm{H}_{2}$ when the reduction of methylviologen or 2-hydroxyphenazine as catalyzed by washed membranes or by the purified hydrogenase was followed. All other assays were done under an atmosphere of molecular nitrogen. The final concentrations of the electron acceptors and donors in the 
assays were: $\mathrm{F}_{420} \mathrm{H}_{2}, 20 \mu \mathrm{M}$; CoB-S-S-CoM, $180 \mu \mathrm{M}$; methylviologen, $1 \mathrm{mM}$; 2hydroxyphenazine, $40 \mu \mathrm{M}$; methylviologen + metronidazole, $150 \mu \mathrm{M}$ and $250 \mu \mathrm{M}$, respectively. The oxidation of $\mathrm{F}_{420} \mathrm{H}_{2}$ was followed at $420 \mathrm{~nm}\left(\varepsilon=40 \mathrm{mM}^{-1} \mathrm{x} \mathrm{cm}^{-1}\right)$. Redox reactions with methylviologen and 2-hydroxyphenazine were measured at $604 \mathrm{~nm}$ $\left(\varepsilon=13.9 \mathrm{mM}^{-1} \mathrm{x} \mathrm{cm}^{-1}\right)$ and $425 \mathrm{~nm}\left(\varepsilon=4.5 \mathrm{mM}^{-1} \mathrm{x} \mathrm{cm}^{-1}\right)$, respectively. The $\mathrm{H}_{2^{-}}$ dependent reduction of CoB-S-S-CoM was quantified as described by Hedderich et al. (1988). In these experiments $25 \mathrm{mM}$ Mops-buffer, pH 7 was reduced by Ti-citrate titration until the red colour of the redox-indicator resazurine had disappeared. Dithioerythritol was omitted. DPI was solved in dimethylsulfoxide and added as indicated in Fig. 2 and 3.

\section{Redox difference spectroscopy}

Washed membranes were prepared under anaerobic conditions as described by Abken et al. (1998) except that $25 \mathrm{mM}$ Mops buffer, $\mathrm{pH} 7$ was reduced with Ti-citrate $(20 \mu \mathrm{M}$ final concentration). Dithioerythritol and resazurine were omitted. The kinetics of redox reactions of cytochromes present in washed membranes were followed by redox difference spectra and were recorded at room temperature with a Kontron spectrophotometer (model Uvicon 810) in the double beam mode. When the $\mathrm{H}_{2^{-}}$ dependent reduction of cytochromes was measured, washed membranes were titrated with aerobic $\mathrm{H}_{2} \mathrm{O}$ until $95 \%$ of the total heme groups of were in the oxidized state. The reaction was started by flushing the sample cuvettes with molecular hydrogen and was followed by repeated wavelength scans $(600-400 \mathrm{~nm} ; 20 \mathrm{~nm} / \mathrm{cm} ; 500 \mathrm{~nm} / \mathrm{min})$ against an $\mathrm{H}_{2} \mathrm{O}_{2}$-oxidized reference cuvette. For the analysis of the CoM-S-S-CoB dependent cytochrome oxidation $95 \%$ of the heme groups in the sample cuvette were reduced with $\mathrm{Na}$-dithionite and the reaction was monitored as described above after addition of 180 $\mu \mathrm{M}$ heterodisulfide under an atmosphere of molecular nitrogen. 


\section{Results}

In order to elucidate the energy- conserving systems of Ms. mazei Gö1 in more detail we tested diphenyleneiodonium chloride (DPI) for its effect on membrane-bound electron transport. DPI is a potential inhibitor of flavoproteins and low potential cytochromes (Ragan 1976; Majander et al., 1994).

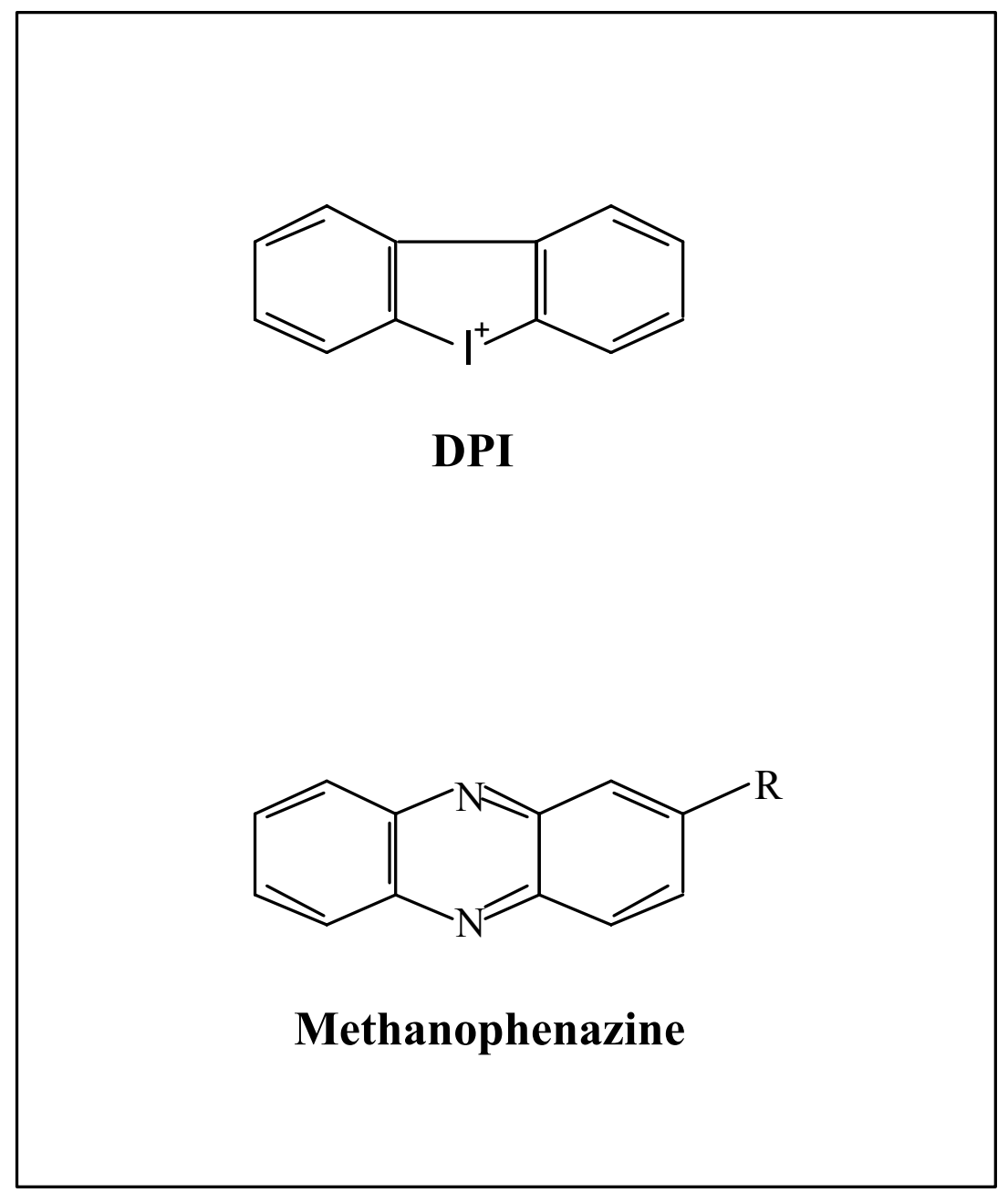

FIG. 1. Comparison of the chemical structures of diphenyleniodenioum chloride and phenazine derivatives.

Methanogenesis from methanol plus $\mathrm{H}_{2}$, methanol or acetate as catalyzed by resting cell suspensions of Ms. mazei Gö1 was almost completely abolished by DPI when the inhibitor was added to a final concentration of $50 \mathrm{nmol} / \mathrm{mg}$ protein (not shown). Experiments with washed membranes revealed that both the $\mathrm{F}_{420} \mathrm{H}_{2}$ :heterodisulfide 
oxidoreductase and the $\mathrm{H}_{2}$ :heterodisulfide oxidoreductase were inhibited by DPI indicated by $\mathrm{IC}_{50}$ values of $20 \mathrm{nmol} \mathrm{DPI} / \mathrm{mg}$ protein and $45 \mathrm{nmol} \mathrm{DPI} / \mathrm{mg}$ protein, respectively (Table 1).

The question arose which components of the electron transport chain interacted with DPI. Therefore, the activities of the key enzymes of electron transfer were checked in the absence and presence of DPI. As is evident from Table 1 the membrane-bound $\mathrm{F}_{420} \mathrm{H}_{2}$ dehydrogenase was inhibited by DPI when methylviologen + metronidazole or 2hydroxyphenazine were used as electron acceptors. In contrast, the membrane-bound heterodisulfide reductase was only affected by DPI when reduced 2-hydroxyphenazine $\left(\mathrm{IC}_{50}=125 \mathrm{nmol} \mathrm{DPI} / \mathrm{mg}\right.$ protein $)$ served as electron donor for heterodisulfide reduction. Interestingly, the enzyme remained active when reduced methylviologen was used for CoB-S-S-CoM reduction. A similar situation was found when the $\mathrm{F}_{420}$-nonreducing hydrogenase as present in washed membranes was analyzed. Inhibition of the enzyme was only observed when 2-hydroxyphenazine served as electron acceptor $\left(\mathrm{IC}_{50}=60\right.$ nmol DPI/mg protein). DPI did not influence $\mathrm{H}_{2}$-dependent methylviologen-reduction.

To elucidate the mechanism of inhibition, the $\mathrm{F}_{420}$-nonreducing hydrogenase was isolated from washed membranes of Ms. mazei Gö1 (Deppenmeier et al., 1992). The purified enzyme (Deppenmeier et al., 1995) consisting of the two subunits VhoG and VhoA (referred to as core enzyme; see Fig. 5) was able to catalyze $\mathrm{H}_{2}$-dependent methylviologen reduction but was unable to reduce 2-hydroxyphenazine (Table 2) in contrast to the membrane-bound form which used both electron acceptors. Like the membrane-bound hydrogenase the methylviologen reducing activity of the purified enzyme was not inhibited by DPI (Table 1 and Table 2). A reasonable explanation for these findings is that the core enzyme transfers electrons from $\mathrm{H}_{2}$ via iron-sulfur clusters to methylviologen. This reaction is obviously not effected by DPI. Besides the genes coding for VhoG and VhoA the hydrogenase operon contains a third open reading frame which codes for a b-type cytochrome (cyt $b_{1}$; see Fig. 5). It is most likely that this subunit of the membrane-bound hydrogenase is responsible for electron transfer to 2hydroxyphenazine. 


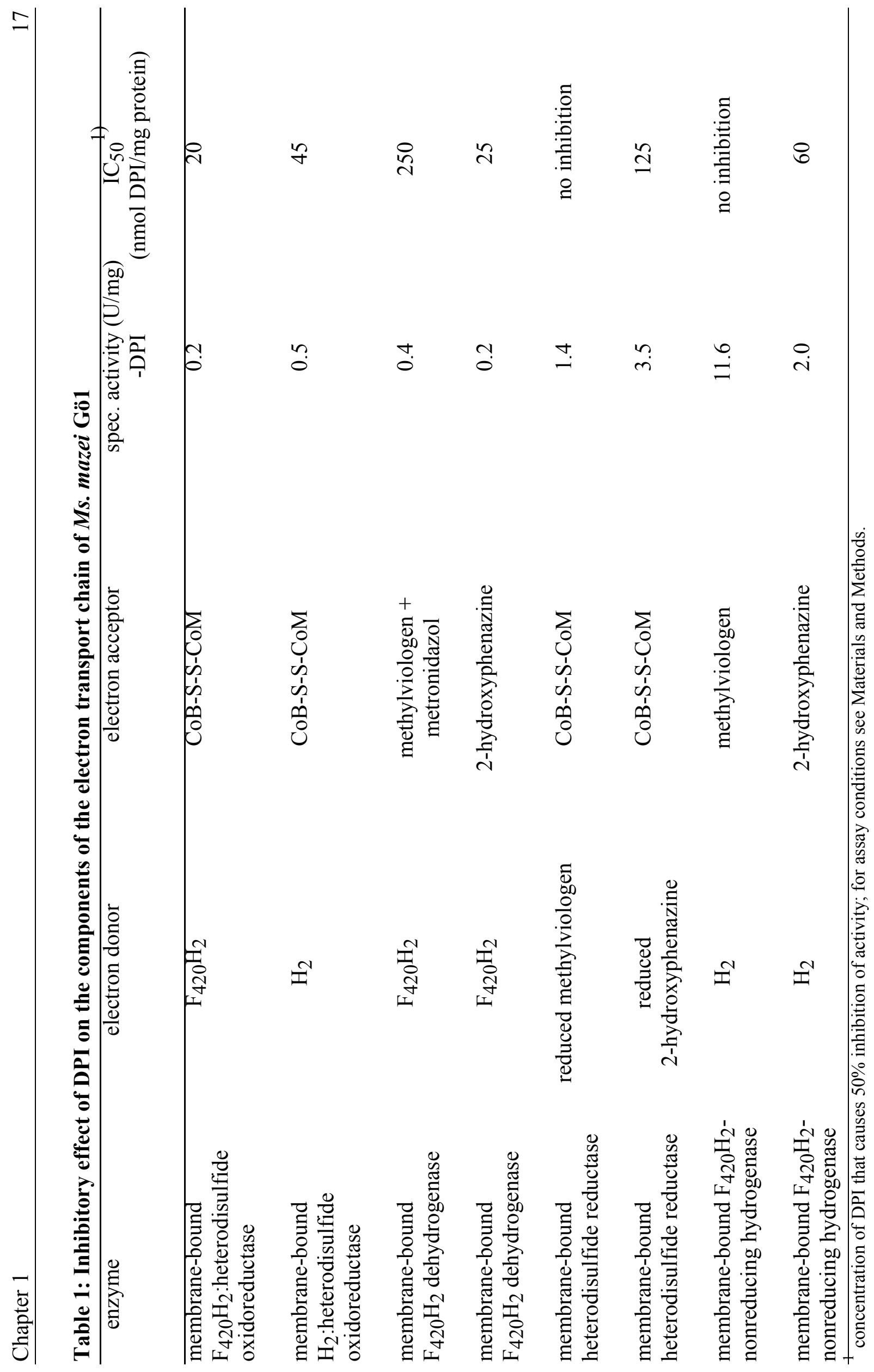


for the assumption that DPI inhibits electron transfer from the core enzyme to cytochrome $b_{1}$ the $\mathrm{H}_{2}$-dependent reduction of heme groups in the membrane was followed in the presence and absence of DPI. For this purpose washed membranes were titrated with aerobic $\mathrm{H}_{2} \mathrm{O}$ until $95 \%$ of the total content of heme groups were oxidized. When the preparation was gassed with molecular hydrogen $90 \%$ of the membrane-bound cytochromes converted from the oxidized to reduced state within 3 minutes (Fig. 2) and the reaction was complete after $7 \mathrm{~min}$. It is also evident from Fig. 2 that increasing amounts of DPI led to a decrease in the rate of cytochrome reduction. From the slope of the curves a $\mathrm{IC}_{50}$ value of $42 \mathrm{nmol} \mathrm{DPI} / \mathrm{mg}$ protein was calculated (Fig. 2, inset). These results clearly indicate that electron transfer from the core enzyme to cytochrome $b_{1}$ was affected by the inhibitor.

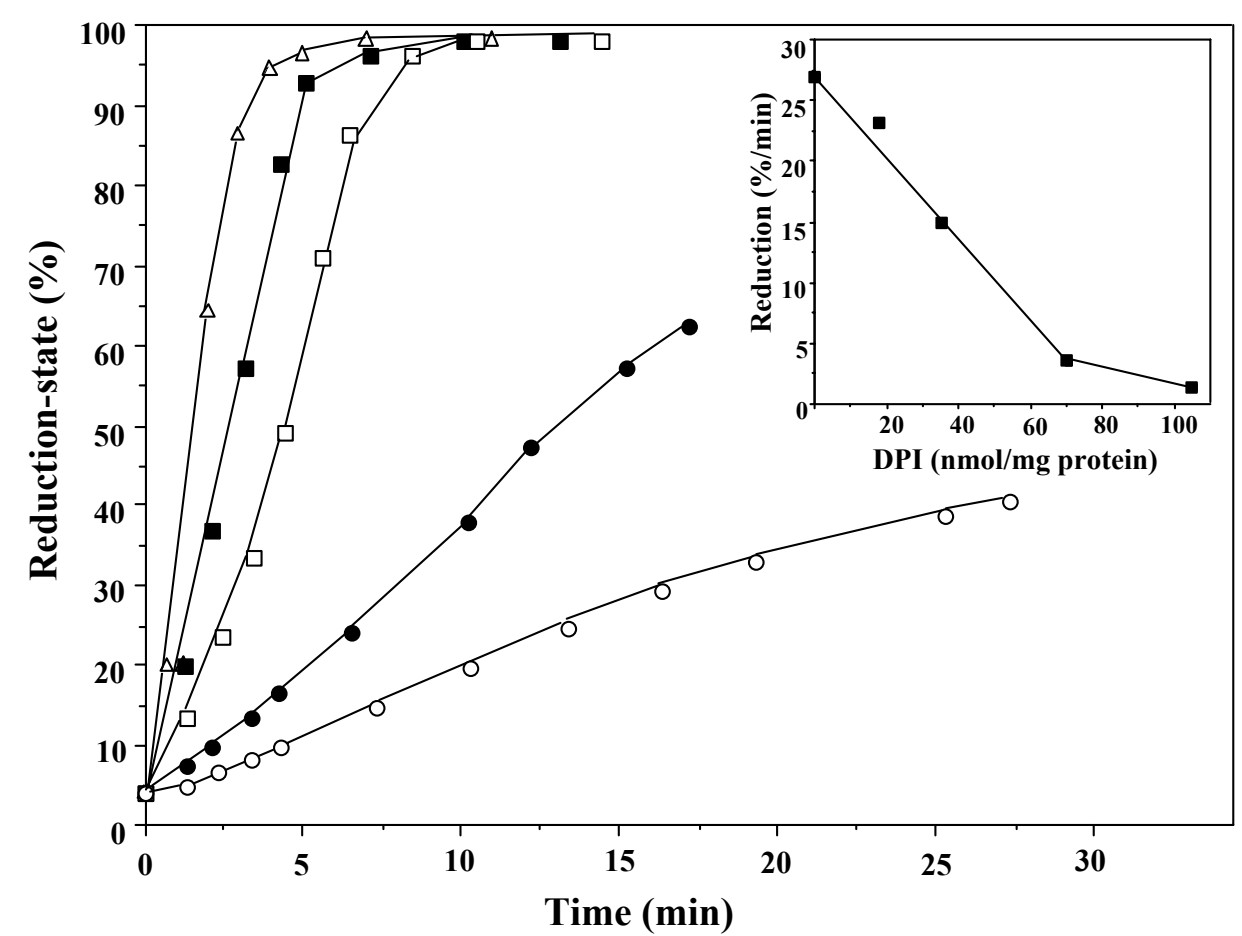

FIG. 2: Inhibition by DPI of $\mathrm{H}_{2}$-dependent cytochrome reduction in washed membranes of Ms. mazei Gö1. Anaerobic membranes ( $285 \mu \mathrm{g}$ protein) were diluted in $0.5 \mathrm{ml} 50$ $\mathrm{mM}$ Tris/ $\mathrm{HCl}, \mathrm{pH}$ 7, which was reduced as described in Materials and Methods under an atmosphere of molecular nitrogen. Aerobic $\mathrm{H}_{2} \mathrm{O}$ was added until $95 \%$ of the total heme groups were in the oxidized state. The membranes were incubated for $2 \mathrm{~min}$ in the presence of the following DPI concentrations: DPI omitted

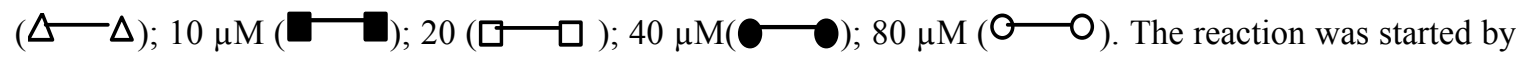
flushing the reaction cuvette with molecular hydrogen. A redox difference spectrum $(600-400 \mathrm{~nm})$ was 
taken at each time point. The proportion of cytochrome reduction was calculated from the height of the $\gamma$ Peak relative to the fully reduced sample and plotted as a function of time. Inset: Determination of the $\mathrm{IC}_{50}$ value

In addition, the effect of DPI on the kinetics of the oxidation of reduced cytochromes by CoB-S-S-CoM was analyzed. (Fig. 3). Membranes from Ms. mazei were titrated with $\mathrm{Na}_{2} \mathrm{~S}_{2} \mathrm{O}_{4}$ until $95 \%$ of the heme groups were reduced. The addition of the heterodisulfide to washed anaerobic membranes resulted in the decrease of reduced cytochromes from $100 \%$ to $20 \%$. The kinetics of the cytochrome oxidation was too rapid to be resolved with the method employed. This CoB-S-S-CoM-dependent oxidation of reduced cytochromes was also inhibited by DPI. In the presence of $80 \mu \mathrm{M}$ of the inhibitor only 20 $\%$ of the total heme groups were oxidized within a time-period of $2 \mathrm{~min}$.

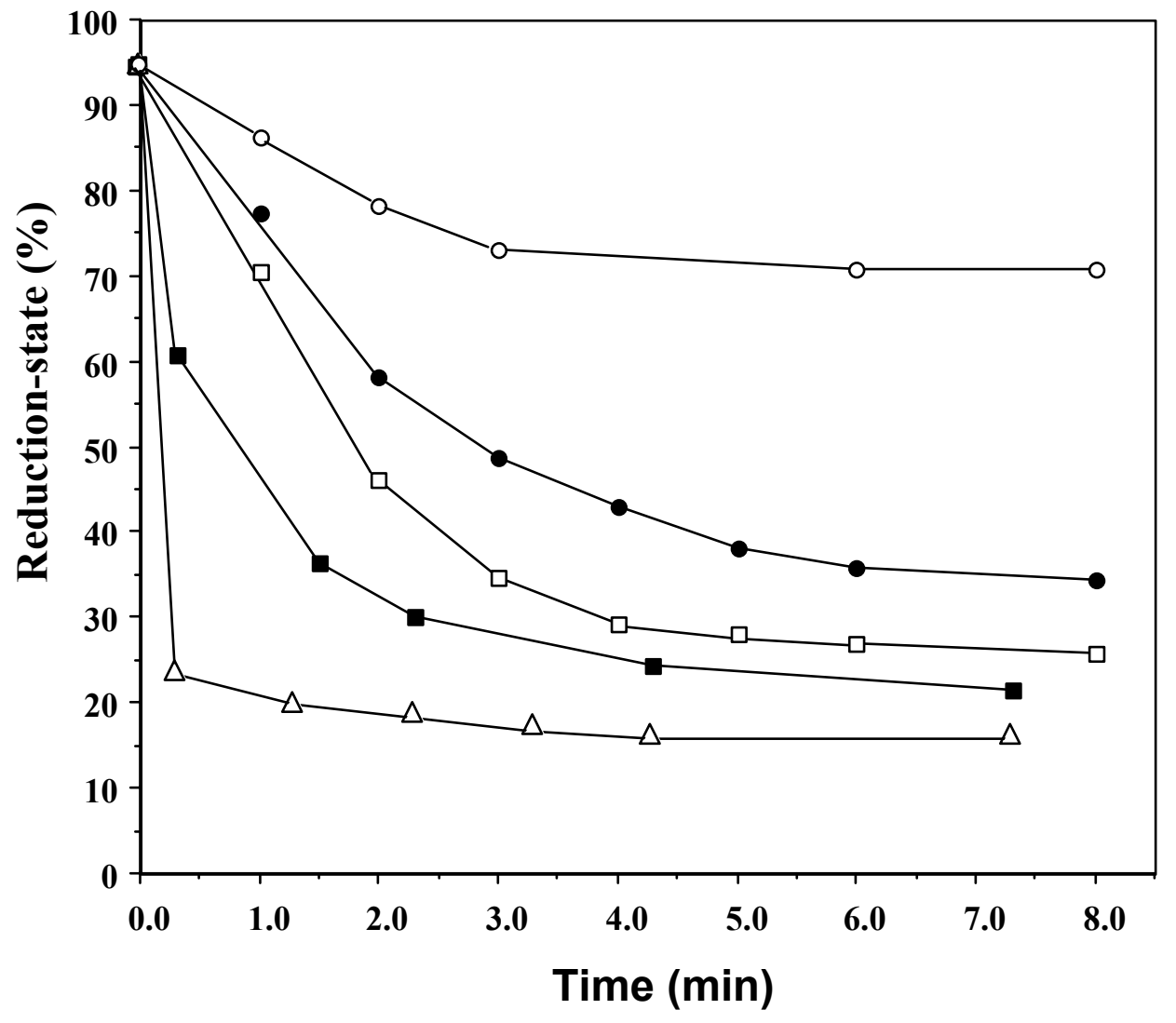

FIG. 3: Kinetics of the oxidation of reduced cytochromes by heterodisulfide and the

effect of DPI. Anaerobic membranes $(200 \mu \mathrm{g}$ protein) were diluted in $0.5 \mathrm{ml} 50 \mathrm{mMTris} / \mathrm{HCl}, \mathrm{pH} 7$, which was reduced as described in Materials and Methods under an atmosphere of molecular nitrogen. The assay mixture was titrated with $\mathrm{Na}_{2} \mathrm{~S}_{2} \mathrm{O}_{4}(50 \mathrm{mM}$ stock solution) until $95 \%$ of the total heme groups were 
reduced. The reaction mixture was incubated for 2 min with DPI as indicated. The reaction was started by the addition of $180 \mathrm{nmol}$ CoB-S-S-CoM. DPI omitted $(\triangle-\Delta) ; 10 \mu \mathrm{M}$ DPI ); $20 \mu \mathrm{M}$ DPI $(\square \square) ; 40 \mu \mathrm{M} \operatorname{DPI}(-) ; 80 \mu \mathrm{M}$ DPI (○-O). At each time point the redox state of the cytochromes was estimated from the $\gamma$-Peak as described in Fig. 2.

A)

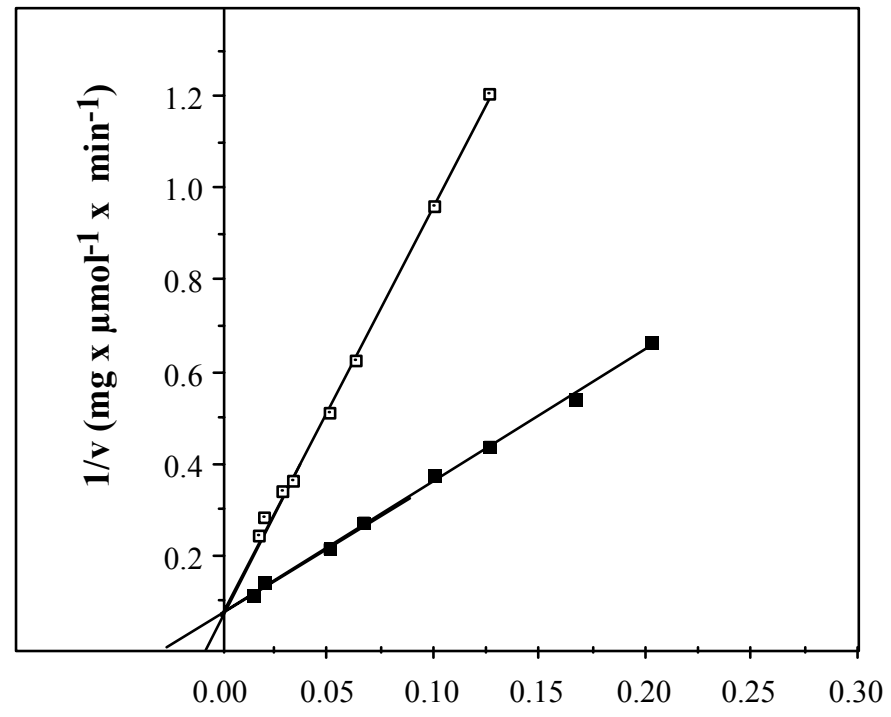

1/2-hydroxy-phenazine $(\mu \mathrm{M}-1)$

B)

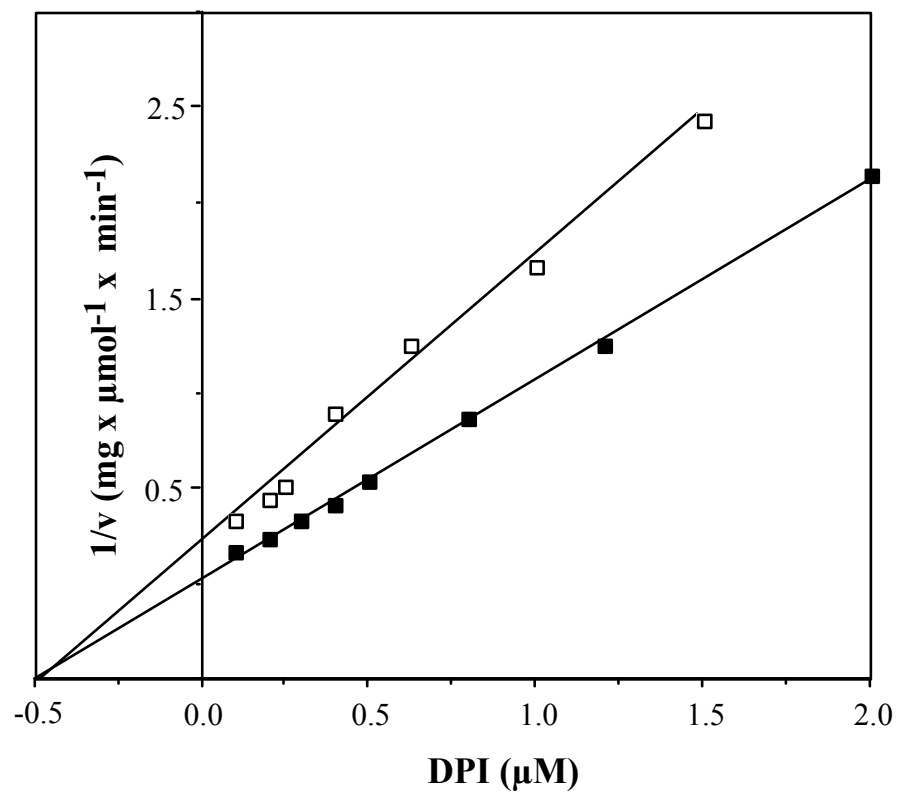

FIG. 4. Competitive inhibition of the purified $\mathrm{F}_{420} \mathrm{H}_{2}$ dehydrogenase by DPI. The activity of the purified enzyme $(0.13 \mu \mathrm{g}$ protein $)$ was measured in anaerobic cuvettes which contained $1 \mathrm{ml}$ $25 \mathrm{mM}$ Mops, $\mathrm{pH} 7,4 \mathrm{mM}$ dithioerythritol and $1 \mathrm{mg} / 1$ resazurine under an atmosphere of molecular 
nitrogen. The reaction was started by the addition of 2-hydroxyphenazine and the oxidation of $\mathrm{F}_{420} \mathrm{H}_{2}(30$ $\mu \mathrm{M}$ final concentration) was followed at $420 \mathrm{~nm}$.

A) Double-reciprocal plot of the 2-hydroxyphenazine-dependent $\mathrm{F}_{420} \mathrm{H}_{2}$ oxidation: ( $\square$ ) plus DPI (1 $\mu \mathrm{M}$ final concentration); (- DPI omitted.

B) Dixon plot of the 2-hydroxyphenazine-dependent $\mathrm{F}_{420} \mathrm{H}_{2}$ oxidation: ( $\left.\square-\square\right) \quad 30 \quad \mu \mathrm{M} \quad 2$ hydroxyphenazine; (-) $60 \mu \mathrm{M}$ 2-hydroxyphenazine.

The inhibitory effect of DPI on the $\mathrm{F}_{420} \mathrm{H}_{2}$ dehydrogenase purified from Ms. mazei Gö1 was analyzed in more detail. Recently, it was shown that $\mathrm{F}_{420} \mathrm{H}_{2}$-oxidation followed simple Michaelis-Menten kinetics with an apparent $\mathrm{Km}$ value of $35 \mu \mathrm{M}$ with respect to 2hydroxyphenazine (Abken et al. 1998).

The double-reciprocal plot for the 2-hydroxy-phenazine-dependent $\mathrm{F}_{420} \mathrm{H}_{2}$-oxidation revealed that DPI is a competitive inhibitor of the enzyme, indicated by an increased $\mathrm{K}_{\mathrm{m}}$ value of $100 \mu \mathrm{M}$ for 2-hydroxyphenazine in the presence of DPI (Fig. 4a). A $\mathrm{K}_{\mathrm{i}}$ value of $0.45 \mu \mathrm{M}$ was determined from the Lineweaver-Burk plot. The same value was obtained when the DPI concentration in the reaction assay was varied and the data were plotted according to Dixon (1964; Fig. 4b). Also the $\mathrm{F}_{420} \mathrm{H}_{2}$-dependent reduction of methylviologen + metronidazol as catalyzed by the purified enzyme and the membranebound enzyme was inhibited by DPI. However, a 10-fold higher amount of the inhibitor was necessary to observe this effect (Table 1 and Table 2) indicating that there are two DPI sensitive components in the $\mathrm{F}_{420} \mathrm{H}_{2}$ dehydrogenase which differ by their sensitivity to the inhibitor. 


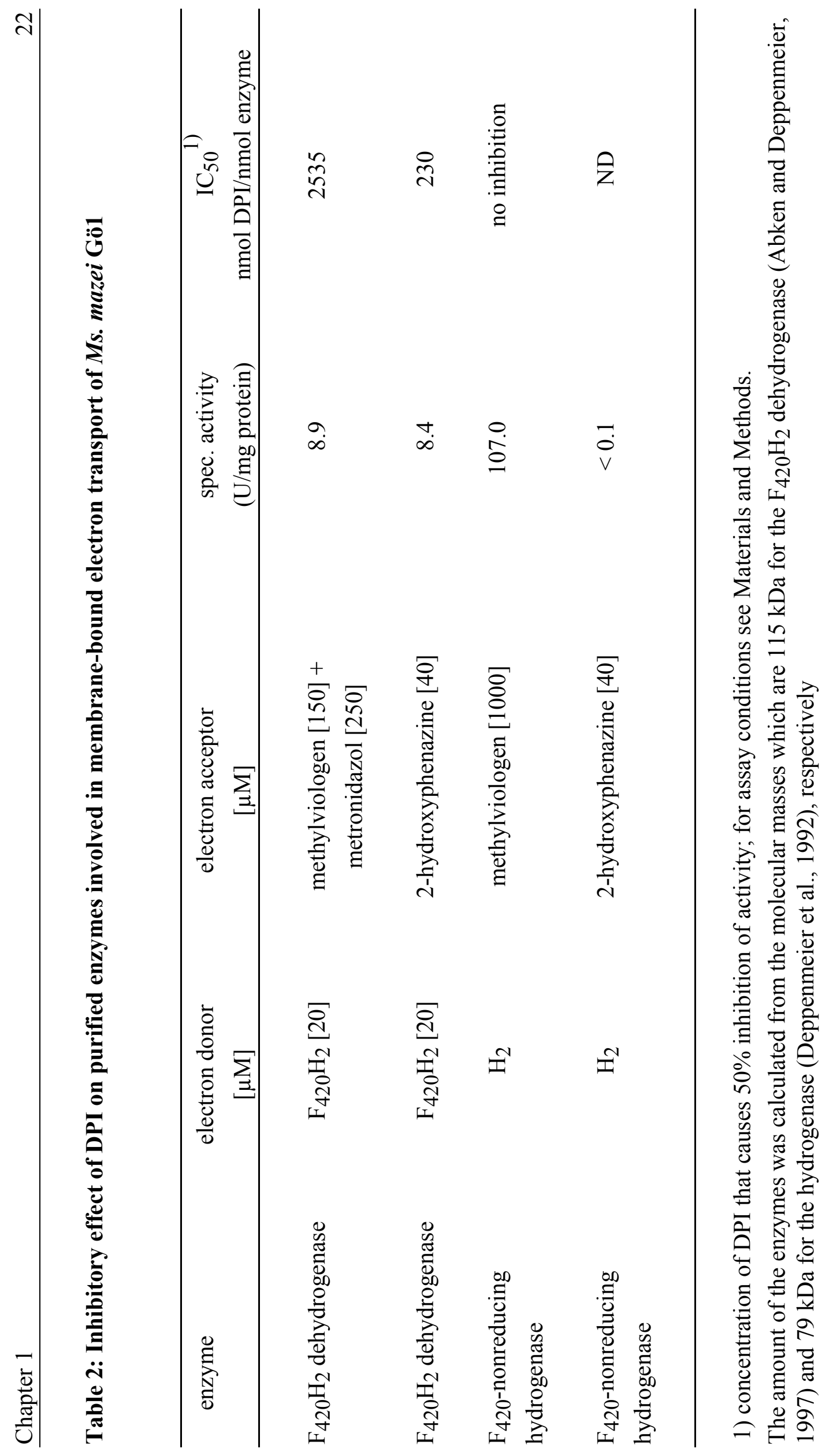




\section{Discussion}

The $\mathrm{F}_{420} \mathrm{H}_{2}$ :heterodisulfide oxidoreductase and the $\mathrm{H}_{2}$ :heterodisulfide oxidoreductase from Ms. mazei Gö1 represent typical energy-conserving electron transport chains. However, the components are unusual with respect to their composition and chemical structure (Thauer et al., 1993; Deppenmeier et al., 1996; Thauer, 1997). The $\mathrm{F}_{420} \mathrm{H}_{2}$ dehydrogenase has been purified from Archaeoglobus fulgidus (Kunow et al., 1994, Methanolobus tindarius (Haase et al., 1992) and Ms. mazei Gö1 (Abken and Deppenmeier, 1997). It was shown that the protein from the latter organisms consists of five non-identical subunits and contains FeS cluster and FAD (Fig. 5). In vitro the enzyme catalyzes the transfer of electron from $\mathrm{F}_{420} \mathrm{H}_{2}$ to 2-hydroxyphenazine. The physiological electron acceptor is probably methanophenazine which is a dibenzopyrazine derivative connected to a pentaisoprenoide side chain via an ether bridge at the $\mathrm{C} 2$ atom of the ring structure Gö1 (Abken et al., 1998). Furthermore, it was shown that reduced 2-hydroxyphenazine acts as electron donor for the heterodisulfide reductase (Bäumer et al., 1998). This enzyme has been purifed from the methylotrophic methanogens Ms. barkeri (Künkel et al., 1997 ) and Ms. thermophila (Simianu et al., 1998) and consists of two subunits (HdrD, HdrE; Fig. 5). HdrD contains FeS clusters and harbours the active site for disulfide reduction. HdrE represents a b-type cytochrome (Cytb 2 ; Fig. 5).

Various inhibitors of the NADH dehydrogenase (complex I) and quinone:cyt c oxidoreductase (complex III) such as antimycin, myxothiazol, HQNQ and rotenone were tested for their ability to inhibit the $\mathrm{F}_{420} \mathrm{H}_{2}$ :heterodisulfide oxidoreductase (Kamlage and Blaut, 1992). It was found that these compounds did not affect the $\mathrm{F}_{420} \mathrm{H}_{2}$-dependent CoB-S-S-CoM reduction at all. Iodonium compounds inhibit the activity of a variety of flavoproteins such as eubacterial and mitochondrial NADH dehydrogenases (Ragan and Bloxham, 1977; Majander et al., 1994) as well as NADPH oxidases (Doussiére and Vignais, 1992; Deme et al., 1994), NO synthase (Stuehr et al., 1991), NADPHcytochrome P450 reductase and xanthine oxidase (Doussiére and Vignais, 1992). For the 
NADPH oxidase complex of bovine neutrophils it was shown that there are two reaction sites of DPI

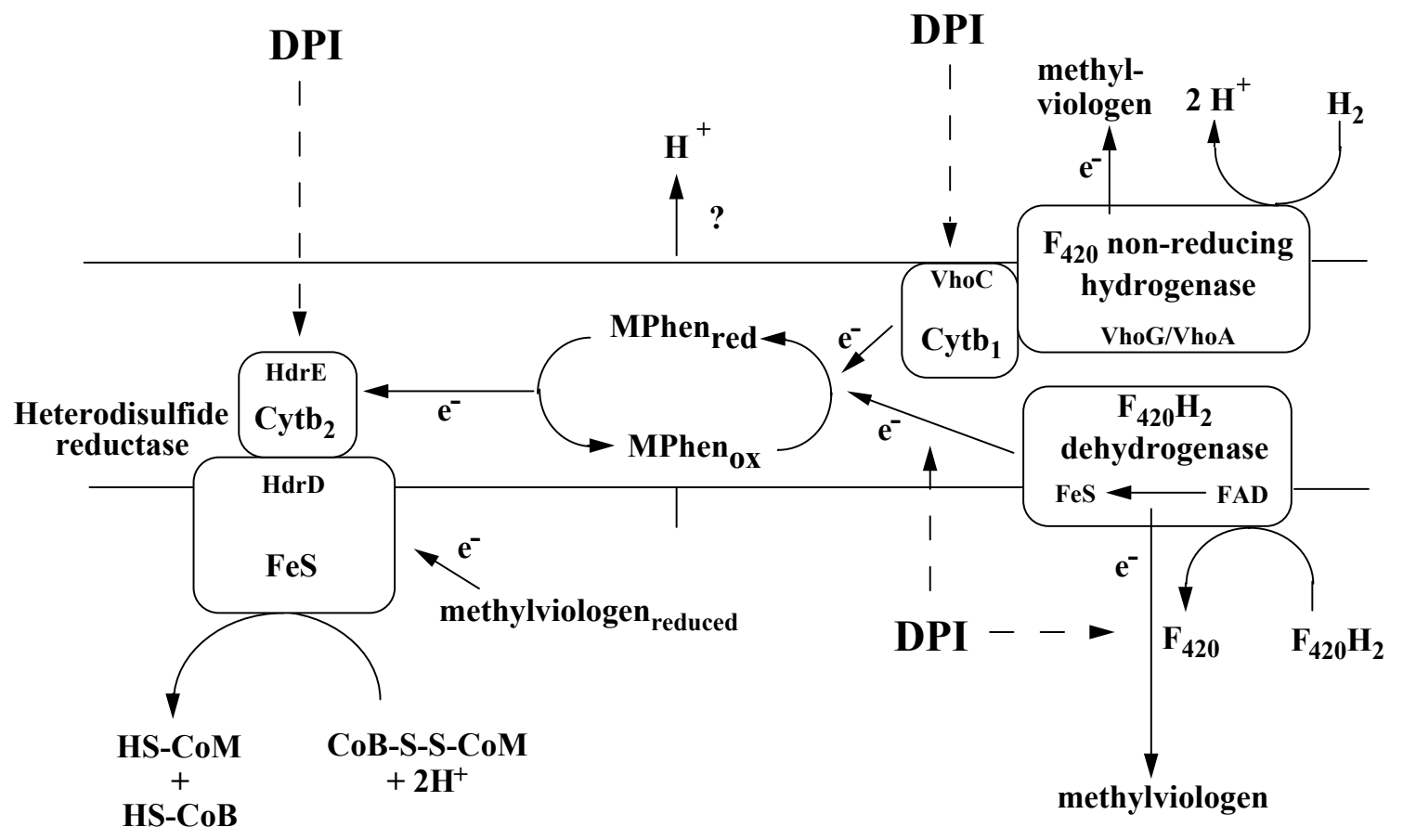

FIG. 5. Tentative model of the membrane-bound electron transport chains from $M$ s. mazei Gö1 and inhibition by DPI.

(Doussiére and Vignais, 1992). At high concentrations (100 nmol/mg membrane protein) the inhibitor interacts with the NADPH dehydrogenase component of the oxidase complex probably by binding to the flavine (O'Donnell et al., 1993). At low concentrations ( $<10 \mathrm{nmol} / \mathrm{mg}$ protein) DPI inhibits the low-potential cytochrome $\mathrm{b}_{558}$. All the above mentioned enzymes contain either flavines or b-type cytochromes with low mid-point potentials. Since both membrane-bound electron transport systems of $M s$. mazei Gö1 also contain such components, the reason of inhibition by DPI is obvious.

From the results presented in this publication several sites of interaction of DPI with components of the $\mathrm{F}_{420} \mathrm{H}_{2}$ :heterodisulfide oxidoreductase are possible (Fig. 5). The $\mathrm{F}_{420} \mathrm{H}_{2}$ dehydrogenase is competitively inhibited by DPI, indicating that the inhibitor and 2-hydroxy- phenazine compete at the site of phenazine reduction $\left(\mathrm{K}_{\mathrm{i}}=0.45 \mu \mathrm{M}\right)$. This 
observation is comparable to the inhibition of NADH oxidation in mitochondria of rats by DPI (apparent $\mathrm{K}_{\mathrm{i}}=4 \mu \mathrm{M}$ ), which is overcome by catalytic amounts of menadione (Holland et al. 1972, Gatley and Sherratt, 1976). At higher DPI concentrations methylviologen-dependent $\mathrm{F}_{420} \mathrm{H}_{2}$ oxidation as catalyzed by the purified $\mathrm{F}_{420} \mathrm{H}_{2}$ dehydrogenase from Ms. mazei Gö1 is also inhibited. From the above-mentioned effects of DPI on flavoproteins (O'Donnell et al., 1993) it is possible that the inhibitor interacts with $\mathrm{FAD}$ as one of the prosthetic groups of the $\mathrm{F}_{420} \mathrm{H}_{2}$ dehydrogenase when added in high concentrations. In this case electron transport to FAD or to FeS clusters would be abolished and reduction of methylviologen is no more possible. The reduction of CoB-SS-CoM as catalyzed by the heterodisulfide reductase is inhibited by DPI when reduced 2hydroxyphenazine is added. The inhibitor does not interfere with reduced methylviologen as electron donor. Since the oxidation of reduced cytochromes in washed membranes in the presence of $\mathrm{CoB}-\mathrm{S}-\mathrm{S}-\mathrm{CoM}$ is inhibited by DPI, electron transport from reduced phenazine to cytochrome $b_{2}$ as part of the heterodisulfide reductase is probably blocked (Fig. 5). This polypeptide contains a low potential b-type heme-group (-180 mV; Simianu et al., 1998). Therefore, inhibition by DPI is reasonable.

Washed membranes are able to reduce 2-hydroxyphenazine in the presence of molecular hydrogen. The reaction is catalyzed by a membrane-bound $\mathrm{F}_{420} \mathrm{H}_{2}$-nonreducing hydrogenase. From sequencing data it is known that the protein is composed of three subunits (VhoGAC). The core enzyme consisting of the subunits VhoGA contains several FeS centers and the Ni-Fe center (Deppenmeier et al., 1995; Deppenmeier, 1996) which is thought to be responsible for $\mathrm{H}_{2}$-oxidation (Albracht, 1994; Sorgenfrei et al., 1997). The heme-b containing subunit VhoC (cyt $b_{1}$ ) is lost in the course of the purification procedure (Deppenmeier et al., 1992). The purified enzyme (VhoGA) is able to reduce methylviologen but it does not interact with 2-hydroxyphenazine. Taking together these results we conclude that the $\mathrm{F}_{420}$-nonreducing hydrogenase catalyzes the oxidation of molecular hydrogen in washed membranes of Ms. mazei Gö1 and channels the electrons to the tightly linked cytochrome $b_{1}$ (Fig. 5). In a following redox reaction methanophenazine is reduced and transfers electrons to cytochrome $b_{2}$, which acts as 
electron donor for heterodisulfide reductase. As already mentioned $\mathrm{H}_{2}$-dependent 2hydroxyphenazine reduction as catalyzed by washed membranes is inhibited by DPI in contrast to the reduction of methylviologen. Therefore, we assume that DPI acts as an inhibitor of electron transport from cytochrome $b_{1}$ to 2-hydroxyphenazine (Fig. 5). This is also indicated by the fact that DPI inhibits cytochrome reduction when membranes are incubated in the presence of molecular hydrogen. The structural similarity between DPI and phenazines with respect to their planar configuration (Fig. 1) makes the possibility attractive that the inhibitor is able to bind to positions where interactions between 2hydroxyphenazines and compounds of the electron transport systems take place. We assume that in vivo these interactions are between methanophenazine and $\mathrm{F}_{420} \mathrm{H}_{2}$ dehydrogenase and between cytochrome $b_{1}$ and hydrogenase, respectively, as well as between cytochrome $b_{2}$ of the heterodisulfide reductase and reduced methanophenazine (see Fig. 5).

\section{References}

Abken, H. J. \& Deppenmeier, U. (1997) Purification and properties of an $\mathrm{F}_{420} \mathrm{H}_{2}$ dehydrogenase from Methanosarcina mazei Gö1, FEMS Lett. 154, 231-237.

Abken, H. J., Tietze, M., Brodersen, J., Bäumer, S., Beifuss, U. \& Deppenmeier, U. (1998) Isolation and characterization of methanophenazine and function of phenazines in membrane-bound electron transport of Methanosarcina mazei Gö1, J. Bacteriol. 180, 2027-2032.

Albracht, S. P. J. (1994) Nickel hydrogenases: in search of the active site, Biochem. Biophys. Acta 1188, 167-204.

Bäumer, S., Murakami, E., Brodersen, J. Gottschalk, G., Ragsdale, S. W. \& Deppenmeier, U. (1998) The $\mathrm{F}_{420} \mathrm{H}_{2}$ :heterodisulfide oxidoreductase system from Methanosarcina species, FEBS Lett. 428, 295-298. 
Deme, J., Doussiere, J., De Sandro, V., Dupuy, C., Pommier, J. \& Virion, A. (1994) The $\mathrm{Ca}^{2+} / \mathrm{NADPH}$-dependent $\mathrm{H}_{2} \mathrm{O}_{2}$ generator in thyroid plasma membrane: inhibition by diphenyleneiodonium, Biochem. J. 301, 75-81.

Deppenmeier, U., Blaut, M., Mahlmann, A. \& Gottschalk, G. (1990) Reduced coenzyme $\mathrm{F}_{420} \mathrm{H}_{2}$-dependent heterodisulfide oxidoreductase: a proton translocating redox system in methanogenic bacteria, Proc. Nat.l Aca.d Sci.USA 87, 9449-9453.

Deppenmeier, U., Blaut, M., Gottschalk, G. (1991) $\mathrm{H}_{2}$ : heterodisulfide oxidoreductase, a second energy-conserving system in the methanogenic strain Gö1, Arch. Microbiol. 155: 272-277.

Deppenmeier, U., Blaut, M., Schmidt, B. \& Gottschalk, G. (1992) Purification and properties of a $\mathrm{F}_{420}$-nonreactive membrane-bound hydrogenase from Methanosarcina strain Gö1. Arch Microbiol 157, 505-511.

Deppenmeier, U., Blaut, M., Lentes, S., Herzberg, C., Gottschalk, G. (1995) Analysis of the vhoGAC and vhtGAC operons from Methanosarcina mazei strain Gö1, both encoding a membrane-bound hydrogenase and a cytochrome b, Eur. J. Biochem. 227, 261-269.

Deppenmeier, U. (1996), Different structure and expression of the operons encoding the membrane-bound hydrogenases from Methanosarcina mazei Gö1, Arch. Microbiol. $164,370-376$.

Deppenmeier, U., Müller, V. \& Gottschalk, G. (1996) Pathways of energy conservation in methanogenic archaea, Arch. Microbiol. 165, 149-163.

Dixon, M. \& Webb, E. C. (1964) Enzymes (2.ed), Long Mans, London

Doussière, J. \& Vignais, P.V. (1992) Diphenylene iodonium as an inhibitor of the NADH oxidase complex of bovine neutrophils, Eur. J. Biochem. 208, 61-71.

Dross, F., Geisler, V., Lengler, R., Theis, F., Krafft, T., Fahrenholz, F., Kojro, E., Duchene, A., Tripier, D., Juvenal, K. \& Kröger, A. (1992) The quinone-reactive Ni/Fe-hydrogenase of Wolinella succinogenes, Eur. J. Biochem. 206, 93-102.

Ermler, U., Grabarse, W., Shima, S., Goubeaud, M. \& Thauer, R. K. (1997) Crystal structure of methyl-coenzyme M reductase: The key enzyme of biological methane formation, Science 278, 1457-1462. 
Gatley, S. J. \& Sherratt, H. S. A. (1976) The effects of diphenyleneiodonium on mitochondrial reactions, Biochem. J. 158, 307-315.

Haase, P., Deppenmeier, U., Blaut, M. \& Gottschalk, G. (1992) Purification and characterization of $\mathrm{F}_{420} \mathrm{H}_{2}$-dehydrogenase from Methanolobus tindarius, Eur. J. Biochem. 203, 527-531.

Heiden, S., Hedderich, R., Setzke, E. \& Thauer, R. K. (1994) Purification of a two subunit cytochrome $b$ containing heterodisulfide reductase from methanol grown Methanosarcina barkeri, Eur. J. Biochem. 221, 855-861.

Hedderich, R. and Thauer. R. K. (1988) Methanobacterium thermoautothrophicum contains a soluble enzyme system that specifically catalyzes the reduction of the heterodisulfide of coenzyme $\mathrm{M}$ and 7-mercaptoethanoylthreononephosphate with $\mathrm{H}_{2}$. FEBS Lett. 234, 223-234

Holland, P. C. \& Sherratt, H. S. A. (1972) Biochemical effects of the hypoglycaemic compound diphenyleneiodonium, Biochem. J. 129, 39-54.

Hughes, P. E. \& Tove, S. B. (1982) Occurrence of $\alpha$-Tocopherolquinone and $\alpha$ Tocopherolquinol in microorganisms, J. Bacteriol. 151, 1397-1402.

Kamlage, B. \& Blaut, M. (1992) Characterization of cytochromes from Methanosarcina Strain Gö1 and their involvement in electron transport during growth on methanol, $J$. Bacteriol. 174, 3921-3927.

Kemner, J. M. \& Zeikus, J. G. (1994) Purification and characterization of membranebound hydrogenase from Methanosarcina barkeri MS, Arch. Microbiol. 161, 47-54.

Künkel, A., Vaupel, M., Heim, S. Thauer, R. K. \& Hedderich, R. (1997) Heterodisulfide reductase from methanol-grown cells of Methanosarcina barkeri is not a flavoprotein, Eur. J. Biochem., 244, 226-234.

Kunow, K., Linder, D., Stetter, K.O., Thauer, R.K. (1994) $\mathrm{F}_{420} \mathrm{H}_{2}$ :quinone oxidoreductase from Archaeoglobus fulgidus, Eur. J. Biochem. 223, 503-511.

Majander, A., Finel, M. \& Wikström, M. (1994) Diphenyleneiodonium inhibits reduction of iron-sulfur clusters in the mtiochondrial NADH-ubiquinone oxidoreductase, $J$. Biol. Chem. 269, 21037-21042. 
Noll, K. M, Donnelly, M. I. \& Wolfe, R. S. (1986) Synthesis of 7mercaptoheptanoylthreonine phosphat and its activity in the methylcoenzyme $\mathrm{M}$ methylreductase system, J. Biol. Chem. 262, 513-515.

O’Donnell, P.B., Tew, D.G., Jones, O.T.G. \& England, P.J. (1993) Studies on the inhibitory mechanism of iodonium compounds with special reference to neutrophil NADPH oxidase, Biochem. J. 290, 41-49.

Ragan, C. I. (1976) NADH-ubiquinone oxidoreductase, Biochim. Biophys. Acta 456, 249290.

Ragan, C. I. \& Bloxham, D. P. (1977) Specific labelling of a constituent polypeptide of bovine heart mitochondrial reduced nicotinamide-adenine dinucleotide-ubiquinone reductase by the inhibitor diphenyleneiodonium, Biochem. J. 163, 605-615

Ruppert, C., Wimmers, S, Lemker, T. \& Müller, V. (1998) The $A_{1} A_{O}$ ATPase from Methanosarcina mazei:: Cloning of the 5' end of the aha operon encoding the membrane domain and expression of the proteolipid in a membrane-bound form in Escherichia coli, J. Bacteriol. 180, 3448-3452.

Simianu, M., Murakami, E., Brewer, J. M. \& Ragsdale, S. W. (1998) Purification and properties of the heme and iron-sulfur containing heterodisulfide reductase from Methanosarcina thermophila, J. Bacteriol. in press.

Sorgenfrei, O., Müller, S., Pfeiffer, M., Sniezko, I. \& Klein, A. (1997) The [NiFe] hydrogenases of Methanococcus voltae: genes, enzymes and regulation, Arch. Microbiol. 167, 189-195.

Stuehr, D. J., Fasehun, O. A., Kwon, N. S., Gross, S. S., Gonzalez, J. A., Levi, R. \& Nathan, C. F. (1991) Inhibition of macrophage and endothelial cell nitric oxide synthase by diphenyleneiodonium and its analogs, FASEB J. 5, 98-103.

Thauer, R.K., Hedderich, R., Fischer, R. (1993) Reactions and enzymes involved in methanogenesis from $\mathrm{CO}_{2}$ and $\mathrm{H}_{2}$. In: Ferry JG (ed) Methanogenesis. Chapman \& Hall, New York, London, pp 209-252.

Thauer, R. K. (1997) Biodiversity and unity in biochemistry, Antonie van Leeuwenhook $71,21-32$ 


\title{
Chapter 2
}

\section{Energy conservation by the $\mathrm{H}_{\mathbf{2}}$ :heterodisulfide oxidoreductase from Methanosarcina mazei Gö1: identification of two proton-translocating segments}

\begin{abstract}
The membrane-bound $\mathrm{H}_{2}$ :heterodisulfide oxidoreductase system of the methanogenic archaeon Methanosarcina mazei Gö1 catalyzed the $\mathrm{H}_{2}$-dependent reduction of 2hydroxyphenazine and the dihydro-2-hydroxyphenazine-dependent reduction of the heterodisulfide of HS-CoM and HS-CoB (CoM-S-S-CoB). Washed inverted vesicles of this organism were found to couple both processes with the transfer of protons across the cytoplasmic membrane. The maximal $\mathrm{H}^{+} / 2 \mathrm{e}^{-}$ratio was 0.9 for each reaction. The electrochemical proton gradient $\left(\Delta \mu_{\mathrm{H}^{+}}\right)$thereby generated was shown to drive ATP synthesis from ADP $+\mathrm{P}_{i}$, exhibiting stoichiometries of 0.25 ATP synthesized per two electrons transported for both partial reactions. ATP synthesis and the generation of $\Delta \mu_{\mathrm{H}^{+}}$were abolished by the uncoupler 3,5-di-tert-butyl-4-hydroxy-benzylidene-malononitrile (SF 6847). The ATP synthase inhibitor $N, N^{\prime}$-dicyclohexylcarbodiimide did not affect $\mathrm{H}^{+}$-translocation, but led to an almost complete inhibition of ATP synthesis and decreased the electron transport rates. The latter effect was relieved by the addition of SF 6847 . Thus, the energy conserving systems showed a stringent coupling which resembles the phenomenon of respiratory control. The results indicate that two different proton-translocating segments are present in the $\mathrm{H}_{2}$ :heterodisulfide oxidoreductase system. The first one involves the 2hydroxy-phenazine-dependent hydrogenase and the second one the heterodisulfide reductase.
\end{abstract}




\section{Introduction}

Methanosarcina (Ms.) mazei Gö1 belongs to the methylotrophic methanogens of the order Methanosarcinales and can grow on $\mathrm{H}_{2}+\mathrm{CO}_{2}$, methanol, methylamines and acetate. The pathways of methanogenesis from these substrates have been analyzed in detail in recent years $(8,11,29)$. All substrates are converted to methyl-S-CoM (2methylthioethanesulfonate), either by reduction of $\mathrm{CO}_{2}$ or by demethylation of methanol and acetate, respectively. Methane is formed from methyl-S-CoM by the catalytic activity of the methyl-S-CoM reductase which uses HS-CoB (7-mercaptoheptanoylthreonine phosphate) as electron donor. The reaction leads to the production of a heterodisulfide (CoM-S-S-CoB) from HS-CoM and HS-CoB which is the terminal electron acceptor of the membrane-bound electron transport systems of Ms. mazei Gö1. The source of reducing equivalents necessary for the reduction of CoM-S-S-CoB depends on the growth substrate. If molecular hydrogen is present, a membrane-bound $\mathrm{F}_{420}$-nonreducing hydrogenase channels electrons via b-type cytochromes to the heterodisulfide reductase which reduces the terminal electron donor $(6$, 13). This electron transport system was referred to as $\mathrm{H}_{2}$ :heterodisulfide oxidoreductase and is coupled to proton-translocation across the cytoplasmic membrane (8). When cells are grown on methanol part of the methyl groups are oxidized to $\mathrm{CO}_{2}$ and reducing equivalents are transferred to coenzyme $\mathrm{F}_{420}$. In Methanosarcina-strains $\mathrm{F}_{420} \mathrm{H}_{2}$ is reoxidized by the membrane-bound $\mathrm{F}_{420} \mathrm{H}_{2}$ dehydrogenase which is part of the $\mathrm{F}_{420} \mathrm{H}_{2}$ :heterodisulfide oxidoreductase (7). Parallel to the $\mathrm{H}_{2}$-dependent system electrons are channeled to the heterodisulfide reductase resulting in the reduction of CoM-S-S-CoB and in the formation of an electrochemical proton gradient. It was shown that the resulting $\Delta \mu_{\mathrm{H}}{ }^{+}$is the driving force for ATP synthesis from ADP $+P_{i}$ as catalyzed by an $A_{1} A_{0}$-type ATP synthase (25). Since other components of the systems were unknown at that time only the overall electron transport reaction could be analyzed. Very recently, a new redox-active component was isolated from the cytoplasmic membran of strain Göl and was referred to as 
methanophenazine (1). Furthermore, it was shown that key enzymes of the membrane-bound electron transfer systems were able to interact with 2-hydroxyphenazine (2-OH-phenazine) which is a water-soluble analogue of methanophenazine (2). Using 2-OH-phenazine the process of electron transfer from molecular hydrogen to the heterodisulfide can be divided into two partial reactions (6):

1. $\mathrm{H}_{2}+2-\mathrm{OH}$-phenazine $\rightarrow$ dihydro-2-OH-phenazine $\left(\Delta \mathrm{G}^{0 \prime}=-31.8 \mathrm{~kJ} / \mathrm{mol}\right) \quad$ [eq. 1]

2. dihydro-2-OH-phenazine $+\mathrm{CoM}-\mathrm{S}-\mathrm{S}-\mathrm{CoB} \rightarrow$ 2-OH-phenazine + HS-CoM + HS-CoB $\left(\Delta \mathrm{G}^{0 \prime}=-10.6 \mathrm{~kJ} / \mathrm{mol}\right)$

In this publication it is shown that both reactions are coupled to proton-translocation and that the resulting electrochemical proton gradient is used for ATP synthesis.

\section{Materials and Methods}

Growth of cells and preparation of washed vesicles. Ms. mazei Gö1 (DSM 3647) was grown in 1-1 glass bottles or, for mass culturing, in 20-1 carboys on $150 \mathrm{mM}$ methanol in a medium described previously (7). Washed vesicles of strain Gö1 (21) were prepared according to Deppenmeier et al. (7) with the exception that the final protein concentration was $10-15 \mathrm{mg} / \mathrm{ml}$.

Assay conditions. Proton translocation was monitored by a pH electrode (model 8103 Ross, Orion research, Küsnacht, Switzerland) which was inserted into a glass vessel (11 ml) from the top through a rubber stopper. The electrode was connected with a Orion model EA 920 $\mathrm{pH}$ meter and a chart recorder. After gassing with $\mathrm{H}_{2}$ or $\mathrm{N}_{2}$, the vessel was filled with $3 \mathrm{ml}$ $40 \mathrm{mM} \mathrm{KSCN}$ solution containing $0.5 \mathrm{M}$ sucrose, $1 \mathrm{mg} / \mathrm{ml}$ resazurine and $10 \mathrm{mM}$ dithioerythritol, followed by the addition of $50-80 \mu \mathrm{l}$ washed vesicles $(1-1.4 \mathrm{mg}$ 
protein/assay). The medium was continuously stirred and the $\mathrm{pH}$ was adjusted to 6.8-6.9. Additions were made with a microliter syringe from the side arm. Proton uptake coupled to reaction 1 was followed by the addition of $4.5-20 \mathrm{nmol}$ 2-OH-phenazine (4.5 $\mathrm{mM}$ or $20 \mathrm{mM}$ stock solution in ethanol) under an atmosphere of molecular hydrogen. To determine the $\mathrm{H}^{+}$transfer in the course of reaction 2 the vessel was gassed with $\mathrm{N}_{2}$ and $240 \mathrm{nmol} \mathrm{CoM-S-S-}$ $\mathrm{CoB}$ were added. The reaction was started by the addition of $4.5-20$ nmol dihydro-2-OHphenazine. After finishing the experiments the $\mathrm{pH}$ changes were calibrated with standard solutions of $\mathrm{HCl}$ or $\mathrm{NaOH}$. CoB-S-S-CoM was synthesized by the method of Noll et al. (23) and Kamlage and Blaut (15). 2-OH -phenazine was prepared according to Abken et al. (1) and was reduced as described by Bäumer et. al. (2).

Electron transfer reactions and ATP synthesis were investigated in $1.5 \mathrm{ml}$ glass cuvettes filled with $0.6 \mathrm{ml} 40 \mathrm{mM}$ potassium phosphate, $\mathrm{pH} \mathrm{7,} \mathrm{containing} 20 \mathrm{mM} \mathrm{MgSO}_{4}, 0.5 \mathrm{M}$ sucrose, $10 \mathrm{mM}$ dithioerythritol and $1 \mathrm{mg} / \mathrm{ml}$ resazurin (buffer A) under anaerobic conditions. Furthermore, $10 \mu \mathrm{ADP}(10 \mathrm{mM}$ stock solution) and $10 \mu \mathrm{l}$ AMP (100 mM stock solution) were added. AMP inhibits the membrane-bound adenylate kinase of Ms. mazei Gö1 (8). This enzyme activity leads to an ADP-disproportionation which would otherwise interfere with the electron transfer-driven ATP-synthesis. Additions were made as indicated. 2-OH-phenazine, dihydro-2-OH-phenazine, $\mathrm{N}, \mathrm{N}^{\prime}$-dicyclohexylcarbodiimide (DCCD) and 3,5-di-tert-butyl-4-hydroxy-benzylidenemalononitrile (SF 6847) were added as ethanolic solutions. The controls received ethanol only. To determine the ATP concentration 1-2 $\mu 1$ aliquots were withdrawn with a syringe and analyzed using the luciferin/luciferase assay (16) in combination with a biocounter M1500 (Lumac, Landgraaf, Netherlands). Redox reactions with 2-OH-phenazine and dihydro-2-OH-phenazine were followed photometrically at 475 $\mathrm{nm}\left(\varepsilon=2.5 \mathrm{mM}^{-1} \mathrm{x} \mathrm{cm}^{-1}\right)$, under an atmosphere of $\mathrm{H}_{2}$ and $\mathrm{N}_{2}$, respectively. 


\section{RESULTS}

Proton translocation due to $\mathbf{H}_{2}$-dependent heterodisulfide reduction. Washed inverted vesicles from Ms. mazei Gö1 were tested for their ability to couple electron transfer with the translocation of protons across the cytoplasmic membrane.

A)
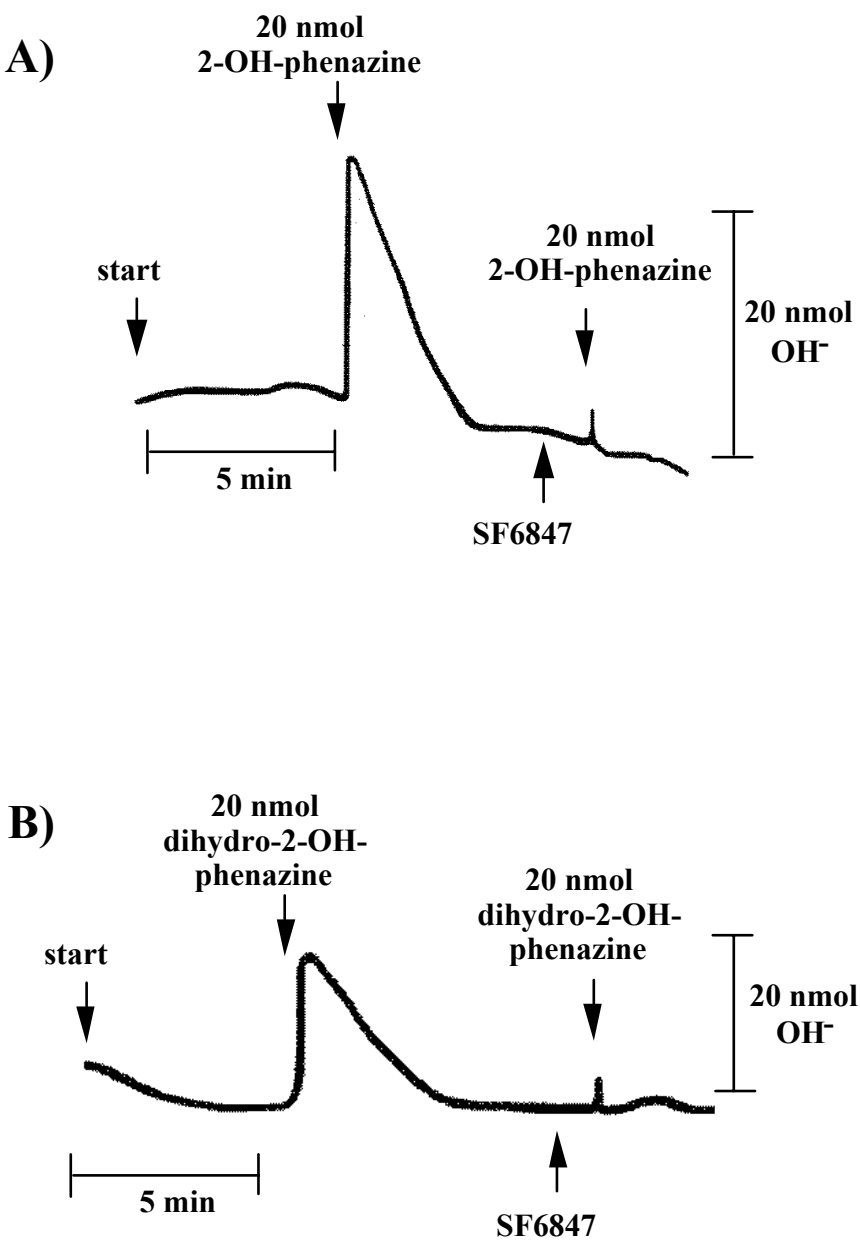

FIG. 1. Proton uptake by washed inverted vesicles from Ms. mazei Gö1. The experiments were performed as described in materials and methods. The amount of translocated protons was calculated from the difference between maximal alkalinization and the final baseline after reacidification. The reaction was started by pulses of 2-OH-phenazine or dihydro-2-OH-phenazine as indicated. SF 6847 was added as an ethanolic solution to a final concentration of $15 \mathrm{nmol} / \mathrm{mg}$ protein. A) $\mathrm{H}_{2}$-dependent reduction of 2-OH- 
phenazine under an atmosphere of molecular hydrogen. B) dihydro-2-OH-phenazine-dependent reduction of CoM-S-S-CoB under an atmosphere of molecular nitrogen.

Therefore, concentrated vesicles were diluted with a sucrose/thiocyanide solution under an atmosphere of molecular hydrogen and were pulsed with 2-OH-phenazine as shown in Fig. 1a. When the electron acceptor was added, a short period of alkalinization of the medium was monitored which is due to a rapid proton movement into the lumen of the inverted vesicles. In the second phase a reacidification was observed until a stable $\mathrm{pH}$-value was reached again.

TABLE 1. Proton translocation by washed inverted vesicles of Methanosarcina mazei Gö1

\begin{tabular}{lcc}
\hline \multicolumn{1}{c}{ Substrates } & Additions & $\mathrm{H}^{+} / 2 \mathrm{e}^{-}$-ratio \\
\hline $\mathrm{H}_{2}+$ CoB-S-S-CoM & None & 2.0 \\
$\mathrm{H}_{2}+$ 2-OH-phenazine & None & 0.9 \\
$\mathrm{H}_{2}+$ 2-OH-phenazine & DCCD & 0.9 \\
$\mathrm{H}_{2}$ & Ethanol & $<0.1$ \\
Dihydro-2-OH-phenazine + & None & 0.9 \\
$\quad$ & & \\
CoM-S-S-CoB & DCCD & 0.9 \\
Dihydro-2-OH-phenazine + & & $<0.1$ \\
$\quad$ CoM-S-S-CoB & 2-OH-phenazine & $<0.1$ \\
CoM-S-S-CoB & Ethanol & \\
CoM-S-S-CoB &
\end{tabular}

Each value exhibits an average of at least 10 determinations 
It is thought that the consumption of 2-OH-phenazine is responsible for this effect. The energy conserving electron transport comes to an end leading to a decay of the generated $\Delta \mu_{\mathrm{H}}{ }^{+}$by passive diffusion of protons from the lumen of the inverted vesicles to the medium. After calibration of the system the extent of reversible alkalinization was calculated resulting in an average ratio of 0.9 protons translocated per 2-OH-phenazine reduced (Tab. 1). No alkalinization was observed when 2-OH-phenazine was replaced by ethanol (Tab. 1) or when the reaction was performed under an atmosphere of molecular nitrogen (not shown) indicating that proton transfer was specifically coupled to the $\mathrm{H}_{2}$-dependent 2-OH-phenazine reduction. The addition of the protonophore 3,5-di-tert-butyl-4-hydroxybenzylidenemalononitrile (SF 6847) led to a complete inhibition of measurable proton movement (Fig. 1a). In the presence of this proton conducting agent the membrane becomes specifically permeable to protons and can no longer sustain a proton potential. $\mathrm{H}^{+}-$ translocation was not affected by $\mathrm{N}, \mathrm{N}^{\prime}$-dicyclocarbodiimide (DCCD) up to a concentration of $250 \mathrm{nmol} / \mathrm{mg}$ protein (Tab. 1) which was sufficient to inhibit ATP synthesis (see Fig. 2). Since DCCD inhibits the catalytic activity of the $\mathrm{A}_{1} \mathrm{~A}_{0}$-Type ATP synthase of Ms. mazei Gö1 (3), this enzyme was not responsible for proton translocation via ATP hydrolysis. Interestingly, the second reaction of the $\mathrm{H}_{2}$ :heterodisulfide oxidoreductase system (eq. 2) was also able to generate a proton gradient. As evident from Fig. $1 \mathrm{~b}$ the addition of dihydro2-OH-phenazine resulted in the transfer of protons into the lumen of the inverted vesicles when incubated in the presence of CoM-S-S-CoB under an atmosphere of nitrogen. A maximal stoichiometry of $0.9 \mathrm{H}^{+} / 2 \mathrm{e}^{-}$was determined (Tab. 1). The addition of oxidized 2$\mathrm{OH}-$ phenazine or ethanol instead of dihydro-2-OH-phenazine prevented proton translocation (Tab. 1) indicating that the latter process is strictly coupled with the electron transport from reduced phenazine to CoM-S-S-CoB in washed inverted vesicles of Ms. mazei Gö1. Again, the electron transfer-dependent formation of a proton gradient was abolished when the uncoupler SF 6847 was present in the reaction mixture (Fig. 1b). As evident the $\mathrm{H}^{+} / 2 \mathrm{e}^{-}$ 
stoichiometries of the partial reactions added up to 1.8 which is in the same range as the coupling efficiency of the electron transport from $\mathrm{H}_{2}$ to heterodisulfide (Tab. $1 ;(8)$ ).

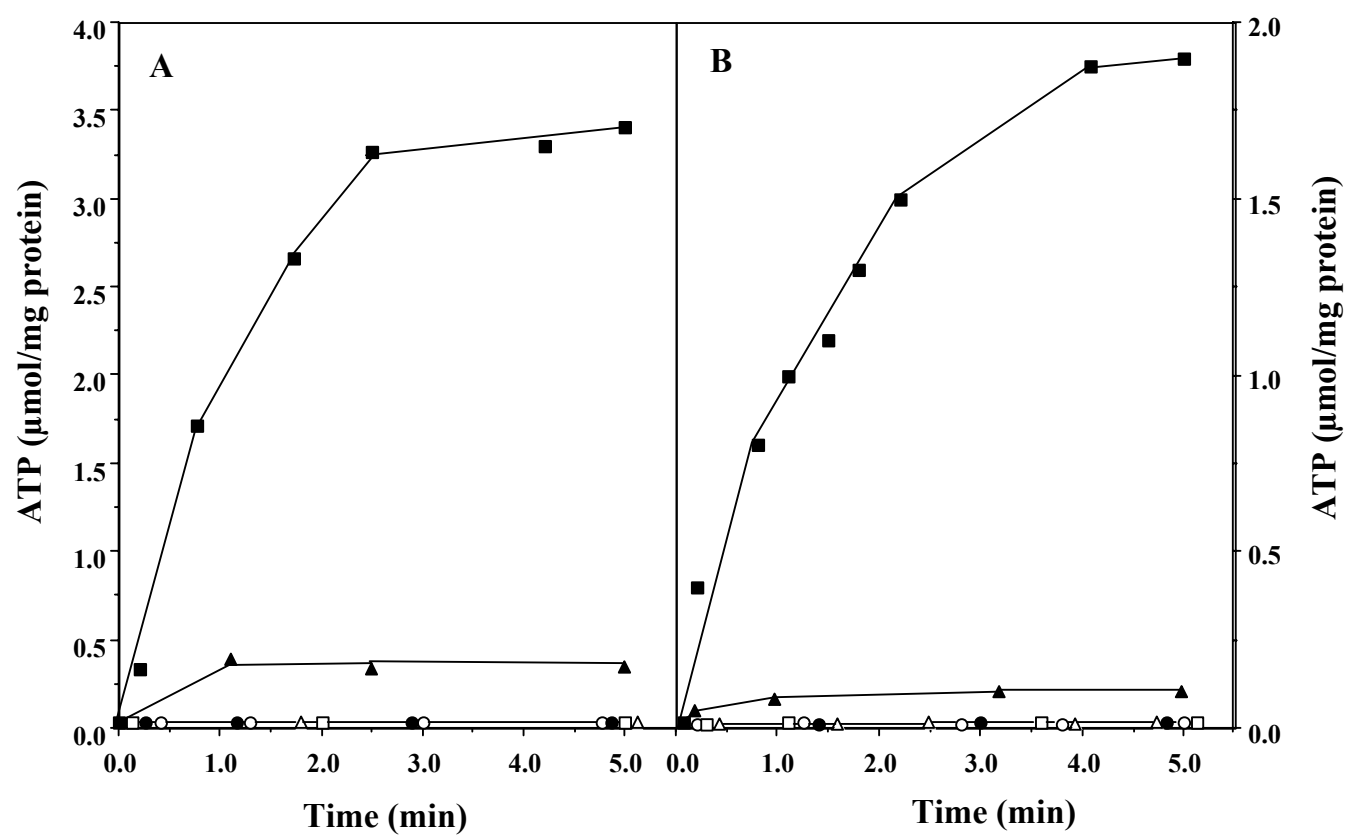

FIG. 2. Redox-driven ATP synthesis as catalyzed by washed inverted vesicles from Ms.

mazei Gö1. The experiments were performed as described in materials and methods. The concentrations of ADP, SF 6847 and DCCD were $0.16 \mathrm{mM}, 25 \mu \mathrm{M}$ and $250 \mathrm{nmol} / \mathrm{mg}$ protein, respectively. A) ATP synthesis in the course of $\mathrm{H}_{2}$-dependent-2-OH-phenazine reduction. The glass cuvette was gassed with $\mathrm{H}_{2}$ and contained $600 \mu 1$ buffer A, $1.6 \mathrm{mM}$ AMP and $125 \mu \mathrm{M}$ 2-OH-phenazine. The reaction was started by the addition of washed vesicles (14 $\mu \mathrm{g}$ protein). The following additions were made: $(\boldsymbol{\square})+\mathrm{ADP},(\Delta)+\mathrm{ADP}+\mathrm{SF} 6847,($

)$+\mathrm{ADP}+\mathrm{DCCD},(\bullet)+\mathrm{ADP}+\mathrm{SF}+\mathrm{DCCD},(\square)$ ADP omitted, $(\mathrm{O})+\mathrm{ADP}$ under $\mathrm{N}_{2}$. B) ATP synthesis coupled to dihydro-2-OH-phenazine dependent heterodisulfide reduction. The experiment was performed as described under A) with the exception that the reaction mixture contained dihydro-2-OH-phenazine (instead of 2-OH-phenazine) and $240 \mathrm{nmol}$ CoM-S-S-CoB. The atmosphere was $\mathrm{N}_{2}$. The following additions were made: 
$(\boldsymbol{\square})+\mathrm{ADP},(\Delta)+\mathrm{ADP}+\mathrm{SF} 6847,(\boldsymbol{\Delta})+\mathrm{ADP}+\mathrm{DCCD},(\bullet)+\mathrm{ADP}+\mathrm{SF}+\mathrm{DCCD},(\square)$ ADP omitted,
$(\mathrm{O})+\mathrm{ADP}$, CoM-S-S-CoB omitted.

These results indicate that strain Gö1 possesses two different proton-translocating segments in the $\mathrm{H}_{2}$ :heterodisulfide oxidoreductase system.

Coupling of electron transport and ATP-synthesis. It was shown that the $\mathrm{H}_{2}$-dependent heterodisulfide reduction was coupled to ATP synthesis (8). The question arose whether ATP formation could also be observed in the course of the phenazine-dependent reactions both of which were coupled to the generation of an electrochemical proton gradient (Fig. 1). Under an atmosphere of molecular hydrogen washed vesicles catalyzed the 2-OH-phenazine reduction with an initial rate of $6.0 \mu \mathrm{mol} \mathrm{x} \mathrm{min}^{-1} \mathrm{x} \mathrm{mg}$ protein ${ }^{-1}$ (Tab. 2).

Table 2: Effects of ADP, DCCD and SF6847 on electron transport rates

Addition(s)

\begin{tabular}{c} 
Electron transfer $\left(\mu \mathrm{mol} \mathrm{min}^{-1} \mathrm{mg}^{\text {protein }}{ }^{-1}\right)$ from: \\
\hline $\mathrm{H}_{2}$ to $2-\mathrm{OH}$ phenazine \\
Dihydro $-2-\mathrm{OH}-$ phenazine to \\
CoM-S-S-CoB
\end{tabular}

\begin{tabular}{lll}
\hline ADP & 6.0 & 2.4 \\
None & 3.0 & 1.2 \\
SF & 5.8 & 2.8 \\
SF + ADP & 6.1 & 2.9 \\
DCCD + ADP & 4.8 & 1.1 \\
DCCD + SF + ADP & 5.7 & 2.7 \\
\hline
\end{tabular}

After $1 \mathrm{~min}$, the rate slowly decreased due to the depletion of 2-OH-phenazine. The reaction was coupled to the phosphorylation of ADP as indicated by a rapid increase of the ATP 
concentration upon start of the reaction (Fig. 2a). The estimated value for the first minute was $1.5 \mu \mathrm{mol}$ ATP $\mathrm{x} \min ^{-1} \mathrm{x}$ mg protein ${ }^{-1}$ resulting in a ratio of $0.25 \mathrm{~mol}$ ATP formed per mol OH-phenazine reduced. In the presence of the ATP synthase inhibitor DCCD the phosphorylation of ADP was strongly inhibited (Fig. 2a) and 2-OH-phenazine reduction slowed down to $4.8 \mathrm{U} / \mathrm{mg}$ protein (Tab. 2). The latter effect was also observed when ADP was omitted. Addition of the uncoupler SF 6847 to $\mathrm{H}_{2}$-metabolizing vesicles led to an increase of the phenazine reduction rate either in the presence of DCCD or in the absence of ADP up to $95 \%$ and $97 \%$ of the control assay (Tab. 1), respectively. Furthermore, SF 6847 abolished ATP synthesis (Fig. 2a) due to the decay of $\Delta \mu_{\mathrm{H}}^{+}$. Absolutely no ATP was formed when ADP was omitted (Fig. 2a) indicating that the latter nucleotide was not present in washed inverted vesicles.

When the electron transfer from dihydro-2-OH-phenazine to CoM-S-S-CoB was analyzed the initial kinetics of ADP phosphorylation was $0.6 \mu \mathrm{mol} \mathrm{x} \mathrm{min}^{-1} \mathrm{x} \mathrm{mg}$ protein $^{-1}$ (Fig. 2b) while the initial rate of substrate conversion was $2.4 \mu \mathrm{mol} \mathrm{x} \min ^{-1} \mathrm{x} \mathrm{mg} \operatorname{protein}^{-1}$ (Tab. 2) indicating a ATP $/ 2 \mathrm{e}^{-}$stoichiometry of 0.25 within the first minute of the reaction. ATP synthesis was abolished when either the uncoupler SF 6847 was added or when one of the substrates (dihydro-2-OH-phenazine or CoM-S-S-CoB) was omitted. In parallel to the $\mathrm{H}_{2}$ dependent 2-OH-phenazine reduction the addition of DCCD led to a decrease of electron transport from dihydro-2-OH-phenazine to CoM-S-S-CoB (Tab. 2) and to inhibition of ATP synthesis (Fig. 2b). Furthermore, in the absence of ADP the heterodisulfide reductase activity decreased to $50 \%$ compared to the control rate (ADP added; Tab. 2) and ATP synthesis was abolished (Fig. 2b). Inhibition of electron transfer under these conditions was relieved by the addition of SF 6847 , indicated by the stimulation of electron transport activities 2.4-fold (addition of DCCD; Tab. 2) and 2.3-fold (ADP omitted; Tab. 2) in comparison to the assays not incubated with the uncoupler. Thus, the effect of SF 6847 and DCCD on both partial electron transport reactions resemble the phenomenon of respiratory control observed in mitochondria. 


\section{DISCUSSION}

Several membrane-bound proteins and enzyme systems from Methanosarcina strains have been identified to be involved in the generation of transmembrane electrochemical ion gradients.

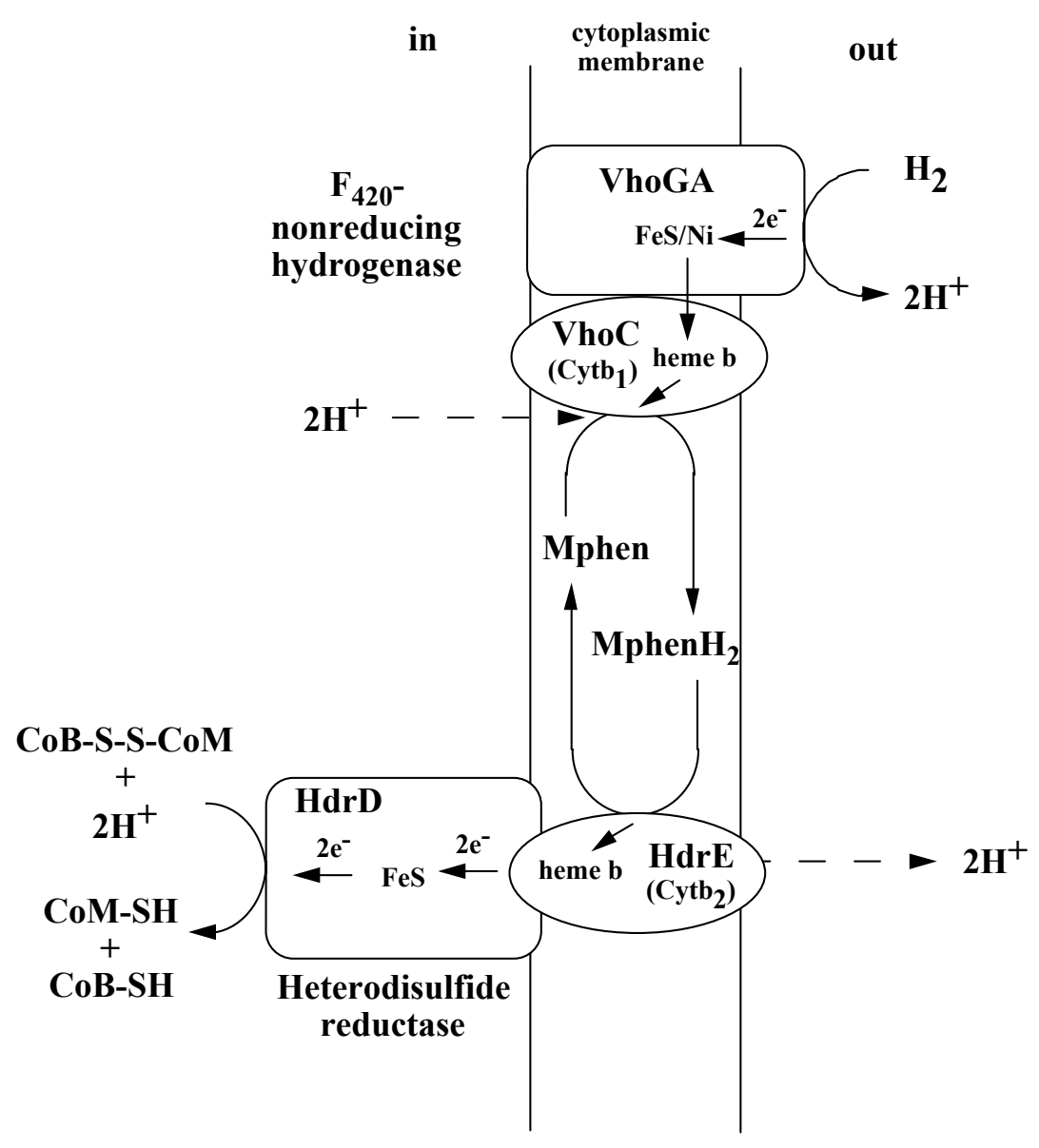

FIG. 3. Tentative scheme of membrane-bound electron transfer coupled to proton translocation in Methanosarcina mazei Gö1. Mphen, methanophenazine; $\mathrm{MphenH}_{2}$, dihydromethanophenazine; VhoG, $40 \mathrm{kDa}$ subunit of the $\mathrm{F}_{420}$-nonreducing hydrogenase; VhoA, $60 \mathrm{kDa}$ subunit of the $\mathrm{F}_{420}$-nonreducing hydrogenase; VhoC, cytochrome $\mathrm{b}_{1}$ encoded by the third gene $(v h o C)$ of the hydrogenase operon; HdrDE subunits of the heterodisulfide reductase; FeS, iron-sulfur clusters; Ni, nickel-ironcenter of the $\mathrm{F}_{420}$-nonreducing hydrogenase. 
The $\mathrm{H}_{2}$ :heterodisulfide oxidoreductase, the $\mathrm{F}_{420} \mathrm{H}_{2}$ :heterodisulfide oxidoreductase and the CO:heterodisulfide oxidoreductase generate a proton motive force by redox-potential driven $\mathrm{H}^{+}$-translocation $(24,8)$. In contrast, the methyl- $\mathrm{H}_{4} \mathrm{MPT}$ :HS-CoM methyltransferase (20) and probably the formyl-MF dehydrogenase (14) are reversible sodium ion pumps. It is remarkable that protons as well as sodium ions are employed by Ms. mazei Gö1 as coupling ions in energy conservation.

In this publication we focus on the catalytic activity of the $\mathrm{H}_{2}$ :heterodisulfide oxidoreductase system which is composed of a membrane-bound, $\mathrm{F}_{420}$-nonreducing hydrogenase and the heterodisulfide reductase (29). Until recently the detailed analysis of the system was hindered by the fact that no information about the nature of electron carriers mediating electron transfer between the enzymes were available. With the identification of methanophenazine and the elucidation of the reactivity of its water-soluble analogue 2-OH-phenazine the overall mechanism of electron transfer became evident (Fig. 3). It was found that the $\mathrm{F}_{420^{-}}$ nonreducing hydrogenase (VhoGA) catalyzes the oxidation of molecular hydrogen and transfers electrons via a b-type cytochrome (VhoC) to 2-OH-phenazine (eq. 1). The resulting dihydro-2-OH-phenazine is oxidized by the heterodisulfide reductase and the electrons are transferred to CoM-S-S-CoB (eq. 2; (6)). Here it is shown that both partial reactions of the $\mathrm{H}_{2}$ :heterodisulfide oxidoreductase are coupled to proton-translocation exhibiting stoichiometries of $0.9 \mathrm{H}^{+} / 2 \mathrm{e}^{-}$. Thus, the ratios added up to $1.8 \mathrm{H}^{+} / 2 \mathrm{e}^{-}$which corresponds to the efficiency of the overall electron transport from $\mathrm{H}_{2}$ to CoM-S-S-CoB. Keeping in mind that about $50 \%$ of the membrane structures present in the vesicle preparations catalyzed electron transport but were unable to establish a proton gradient (8), the $\mathrm{H}^{+} / 2 \mathrm{e}^{-}$-values of the partial reactions and of the overall reaction increase to 1.8 and 3.6, respectively. Accordingly, the sum of the ATP $/ 2 \mathrm{e}^{-}$ratios of both reactions would rise from 0.5 to about 1.0. In agreement with this hypothesis is the fact that $3-4 \mathrm{H}^{+} / 2 \mathrm{e}^{-}$were transferred by whole cell preparations of Ms. barkeri when methane formation from methanol $+\mathrm{H}_{2}$ was analyzed 
(5). Under standard conditions the sum of the changes of free energy associated with reaction 1 and 2 is about $-40 \mathrm{~kJ} / \mathrm{mol}$, which is sufficient to drive the phosphorylation of 1 mol ATP $\left(\Delta \mathrm{G}^{0 \prime}=+31.8 \mathrm{~kJ} / \mathrm{mol}(28)\right)$. However, under the conditions of the cell the $\Delta \mathrm{G}$ value is probably more negative. It is to note that the methyl-CoM reductase, which is present in abundance in the cell, catalyzes the irreversible formation of the heterodisulfide from methyl$\mathrm{CoM}$ and $\mathrm{HS}-\mathrm{CoB}\left(\Delta \mathrm{G}^{0 \prime}=-45 \mathrm{~kJ} / \mathrm{mol}\right)$. Therefore, it is likely that the intercellular ratio of $[\mathrm{CoM}-\mathrm{S}-\mathrm{S}-\mathrm{CoB}] /[\mathrm{HS}-\mathrm{CoM}][\mathrm{HS}-\mathrm{CoB}]$ is very high. As a consequence the span of available free energy would be greater than calculated from standard conditions, indicating that the energy-conserving reduction of CoM-S-S-CoB is ,pushed“ by the preceding methaneforming reaction (29).

A tentative scheme of the mechanism of proton translocation is shown in Fig. 3, which is based on the structure and location of the key enzymes of the system. The operon encoding the $\mathrm{F}_{420}$-nonreducing hydrogenase from Ms. mazei Gö1 contains three genes (8). The deduced amino acid sequences revealed that the small (VhoG) and the large subunit (VhoA) of the protein are homologous to the corresponding polypeptides of membrane-bound $\mathrm{NiFe}$ hydrogenases from several bacteria $(9,18,22)$. The organisms contain a b-type cytochrome which is connected to the core enzyme. In Ms. mazei this function is fulfilled by VhoC (cytochrome b1) which is encoded by the third gene of the hydrogenase operon. Electron microscopic immunogold labeling experiments revealed that at least part of the large subunit of the enzyme from Ralstonia eutropha is exposed towards the periplasm (10). Therefore, it is most possible that the active center of the enzyme is located at the periplasmic face of the membrane. During $\mathrm{H}_{2}$-oxidation by $R$. eutropha, a electrochemical proton gradient is generated by linking movement of electrons from the periplasmic side of the cytoplasmic side of the membrane with the release of protons in the periplasm and uptake of protons from the cytoplasm in the course of ubiquinone reduction $(4,17)$. The same mechanism was suggested for $\Delta \mathrm{p}$ generation by fumarate respiration with $\mathrm{H}_{2}$ in Wolinella succinogenes (12). 
Since the membrane-bound hydrogenases from $R$. eutropha and $W$. succinogenes are homologous to the corresponding enzyme from Ms. mazei Gö1 the same kind of energy conservation might be involved in the latter organism. The oxidation of molecular hydrogen at the periplasmic site of the cytoplasmic membrane of strain Gö1 would lead to the production of two skalar protons. The electrons derived from the reaction are transferred to cytochrome b1, which would accept two protons from the cytoplasm for the reduction of methanophenazine (Fig. 3).

The mechanism of energy conservation in the course of partial reaction 2 might also be based on scalar proton transfer. The purified heterodisulfide reductase from Methanosarcina species which catalyzes the dihydro-2-OH-phenazine dependent CoM-S-S-CoB reduction, is composed of two subunits $(19,26)$. HdrD harbours the active center and contains two $\mathrm{Fe}_{4} \mathrm{~S}_{4}$ clusters which are involved in the reaction mechanism (26). The subunit is predicted to be membrane-associated since transmembrane-spanning helices are absent (27). HdrE is a btype cytochrome and contains two distinct heme-groups. Hydropathy plots revealed that the protein possesses five transmembrane-spanning helices (19). Redox-driven $\mathrm{H}^{+}$-translocation was detected using washed vesicles from strain Gö1. However, the purified heterodisulfide reductase also catalyzed the reduction of CoM-S-S-CoB with dihydro-2-OH-phenazine as electron donor with high rates indicating that the enzyme is directly involved in proton translocation. A tentative mechanism of this process is shown in Fig. 3. We assume that in vivo electrons from dihydromethanophenazine are transferred to the heme group of HdrE and scalar protons are released at the outer phase of the cytoplasmic membrane. In a second step the electrons are channeled to FeS-clusters of $\mathrm{HdrD}$ and in the reactive center CoM-S-S-CoB is reduced to HS-CoM and HS-CoB. We propose that protons necessary for this reaction are derived from the cytoplasm and are transferred to the active site by a proton-conducting channel built around a selected number of polar amino acid side-chains as well as bound water molecules. 


\section{REFERENCES}

1. Abken, H.-J., M. Tietze, J. Brodersen, S. Bäumer, U. Beifuss and U. Deppenmeier. 1998. Isolation and characterization of methanophenazine and the function of phenazines in membrane-bound electron transport of Methanosarcina mazei Gö1. J. Bacteriol. 180:2027-2032.

2. Bäumer, S., E. Murakami, J. Brodersen, G. Gottschalk, S. W. Ragsdale and U. Deppenmeier. 1998. The $\mathrm{F}_{420} \mathrm{H}_{2}$ :heterodisulfide oxidoreductase system from Methanosarcina species. FEBS Lett. 428:295-298.

3. Becher, B. and V. Müller. 1994. $\Delta \mu, \stackrel{\sim}{\mathrm{Na}^{+}}$drives the synthesis of ATP via a $\mathrm{Na}^{+}-$ translocating $\mathrm{F}_{1} \mathrm{~F}_{\mathrm{O}}$-ATP synthase in membrane vesicles of the archaeon Methanosarcina mazei strain Gö1. J. Bacteriol. 176:2543 - 2550.

4. Bernhard, M., E. Schwartz, J. Rietdorf and B. Friedrich. 1997. The Alcaligenes eutrophus membrane-bound hydrogenase gene locus encodes functions involved in maturation and electron transport coupling. J. Bacteriol. 178:4522-4529.

5. Blaut, M., V. Müller and G. Gottschalk. 1987. Proton translocation coupled to methanogenesis from methanol+ hydrogen in Methanosarcina barkeri. FEBS Lett 215:53-57.

6. Brodersen, J., S. Bäumer, H. J. Abken, G. Gottschalk and U. Deppenmeier. 1999. Inhibition of membrane-bound electron transport of the methanogenic archaeon Methanosarcina mazei Gö1 by diphenyleneiodonium. Eur. J. Biochem. in press

7. Deppenmeier, U., M. Blaut, A. Mahlmann, and G. Gottschalk. G. 1990. Reduced coenzyme $\mathrm{F}_{420} \mathrm{H}_{2}$-dependent heterodisulfide oxidoreductase: a proton translocating redox system in methanogenic bacteria. Proc. Natl. Acad. Sci. USA 87: 9449-9453. 
8. Deppenmeier, U., V. Müller, and G. Gottschalk. 1996. Pathways of energy conservation in methanogenic archaea. Arch. Microbiol. 165:149-163.

9. Dross, F., V. Geisler, R. Lengler, F. Theis, T. Krafft, F. Fahrenholz, E. Kojro, A. Duchene, D. Tripier, K. Juvenal and A. Kröger. 1992. The quinone-reactive Ni/Fehydrogenase of Wolinella succinogenes. Eur. J. Biochem. 206:93-102.

10. Eismann, K., K. Mlejnek, D. Zipprich, M. Hoppert, H. Gerberding, and F. Mayer. (1995). Antigenic Determinants of the membrane-bound hydrogenase in Alcaligenes eutrophus are exposed toward the periplasm. J. Bacteriol. 177:6309-6312.

11. Ferry, J. G. 1997. Enzymology of the fermentation of acetate to methane by Methanosarcina thermophila. BioFactors 6: 25-35.

12. Gross, R., J. Simon, F. Theis, and A. Kröger. 1998. Two membrane anchors of Wolinella succinogenes hydrogenase and their function in fumarate and polysulfide respiration. Arch. Microbiol. 170:50-58.

13. Heiden, S., R. Hedderich, E. Setzke, and R. K.Thauer. 1993. Purification of a cytochrome b containing $\mathrm{H}_{2}$ :heterodisulfide oxidoreductase complex from membranes of Methanosarcina barkeri. Eur. J. Biochem. 213:529-535.

14. Kaesler, B., and P. Schönheit. 1989. The role of sodium ions in methanogenesis. Formaldehyde oxidation to $\mathrm{CO}_{2}$ and $2 \mathrm{H}_{2}$ in methanogenic bacteria is coupled with primary electrogenic $\mathrm{Na}^{+}$translocation at a stoichiometry of 2-3 $\mathrm{Na}^{+} / \mathrm{CO}_{2}$. Eur. J. Biochem. 184:223-232.

15. Kamlage, B. and M. Blaut. 1992. Characterization of cytochromes from Methanosarcina Strain Gö1 and their involvement in electron transport during growth on methanol. J. Bacteriol. 174:3921-3927. 
16. Kimmich, G.A., Randles, J., Brand, J.S.: Assay of picomole amounts of ATP, ADP and AMP using the luciferase enzyme system. Anal. Biochem. $\underline{69}, 187-206$ (1975).

17. Kömen, R., D. Zannoni, and K. Schmidt. 1991. The electron transport system of Alcaligenes eutrophus. Arch. Microbiol. 155: 436-443.

18. Kortlüke, C., K. Horstmann, E. Schwartz, M. Rohde, R. Binsack, and B. Friedrich. 1992. A gene complex coding for the membrane-bound hydrogenase of Alcaligenes eutrophus H16. J. Bacteriol. 174:6277-6289.

19. Künkel, A., M. Vaupel, S. Heim, R. K. Thauer, and R. Hedderich. 1997. Heterodisulfide reductase from methanol-grown cells of Methanosarcina barkeri is not a flavoprotein. Eur. J. Biochem. 244:226-234.

20. Lienard, T., B. Becher, M. Marschall, S. Bowien, and G. Gottschalk. 1996. Sodium ion translocation by $\mathrm{N}_{5}$-methyltetrahydromethanopterin:coenzyme $\mathrm{M}$ methyltransferase from Methanosarcina mazei Gö1 reconstituted in ether liposomes. Eur J. Biochem. 239:857-864.

21. Mayer F, A. Jussofie, M. Salzmann, M. Lübben, M. Rohde and G. Gottschalk. 1987. Immunoelectron microscopic demonstration of ATPase on the cytoplasmic membrane of the methanogenic bacterium strain Gö1. J. Bacteriol. 169:2307-2309.

22. Menon, N. K., J. Robbins, H. D. Peck, Jr., C. Y. Chatelus, E. S. Choi, and A. E. Przybyla. 1990. Cloning and sequencing of a putative Escherichia coli [NiFe] hydrogenase-1 operon containing six open reading frames. J. Bacteriol. 172:1969-1977.

23. Noll, K. M, M. I. Donnelly, and R. S. Wolfe. 1986. Synthesis of 7mercaptoheptanoylthreonine phosphat and its activity in the methylcoenzyme $\mathrm{M}$ methylreductase system. J. Biol. Chem. 262:513-515. 
24. Peer CW, M. H. Painter, M. E. Rasche and J. G. Ferry. 1994. Characterization of a CO:heterodisulfide oxidoreductase system from acetate-grown Methanosarcina thermophila. J. Bacteriol. 176:6974-6979.

25. Ruppert, C., S. Wimmers, T. Lemker, and V. Müller. 1998. The $A_{1} A_{O}$ ATPase from Methanosarcina mazei:: Cloning of the $5^{\prime}$ end of the aha operon encoding the membrane domain and expression of the proteolipid in a membrane-bound form in Escherichia coli. J. Bacteriol. 180:3448-3452.

26. Simianu, M., E. Murakami, J. M. Brewer, and S. W. Ragsdale. 1998. Purification and properties of the heme and iron-sulfur containing heterodisulfide reductase from Methanosarcina thermophila. Biochemistry 37:10027-10039.

27. Sonnhammer, E. L. L., G. von Heijne, and A. Krogh. 1998. A hidden Markov model for predicting transmembrane helices in protein sequences. Proc. of Sixth Int. Conf. on Intelligent Systems for Molecular Biology. Menlo Park, CA: AAAI Press.

28. Thauer, R. K., K. Jungermann, and K. Decker. 1977. Energy conservation in chemotrophic anaerobic bacteria. Bact. Review 41:100-180.

29. R. K. Thauer. 1998. Biochemistry of methanogenesis: a tribute to Marjory Stephenson. Microbiology. 144: 2377-2406. 


\title{
Chapter 3
}

\section{The $\mathrm{F}_{420} \mathrm{H}_{2}$ Dehydrogenase from Methanosarcina mazei is a Redox-driven Proton Pump Closely Related to NADH Dehydrogenases}

\begin{abstract}
The $\mathrm{F}_{420} \mathrm{H}_{2}$ dehydrogenase is part of the energy conserving electron transport system of the methanogenic archaeon Methanosarcina mazei Gö1. Here it is shown that cofactor $\mathrm{F}_{420} \mathrm{H}_{2}$ dependent reduction of 2-hydroxyphenazine as catalyzed by the membrane-bound enzyme is coupled to proton translocation across the cytoplasmic membrane exhibiting a stoichiometry of $0.9 \mathrm{H}^{+}$translocated per two electrons transferred. The electrochemical proton gradient thereby generated was shown to drive ATP synthesis from ADP $+\mathrm{Pi}$. The gene cluster encoding the $\mathrm{F}_{420} \mathrm{H}_{2}$ dehydrogenase of Ms. mazei Gö1 comprises 12 genes which are referred to as fpo A B C D H IJKLMNO. Analysis of the deduced amino acid sequences revealed that the enzyme is closely related to proton translocating NADH dehydrogenases of respiratory chains from bacteria (NDH-1) and eukarya (complex I). Like the NADHdependent enzymes the $\mathrm{F}_{420} \mathrm{H}_{2}$ dehydrogenase is composed of three subcomplexes. The gene products FpoAHJKLMN are highly hydrophobic and are homologous to subunits that form the membrane integral module of NDH-1. Fpo BCDI have their counterparts in the amphipatic membrane-associated module of NDH-1. Homologues to the hydrophilic NADH-oxidizing input module are not present in Ms. mazei Gö1. Instead, the gene product FpoF may be responsible for $\mathrm{F}_{420} \mathrm{H}_{2}$ oxidation and may function as the electron input part. Thus, the $\mathrm{F}_{420} \mathrm{H}_{2}$ dehydrogenase from Methanosarcina mazei Gö1 resembles eukaryotic and bacterial proton translocating $\mathrm{NADH}$ dehydrogenases in many ways. The enzyme from the
\end{abstract}


methanogenic archaeon functions as a NDH-1/complex I homologue and is equipped with an alternative electron input unit for the oxidation of reduced cofactor $\mathrm{F}_{420}$ and a modified output module adopted to the reduction of methanophenazine.

\section{Introduction}

Ms. $m a z e i^{1}$ strain Gö1 is a strictly anaerobic methanogenic archaeon which converts a limited number of simple substrates $\left(\mathrm{H}_{2}+\mathrm{CO}_{2}\right.$, methanol, methylamines, acetate) to methane. Methyl-S-CoM is the central intermediate in all methanogenic pathways and is reductively demethylated to methane catalyzed by the methyl-S-CoM reductase. The two electrons required for the reduction are derived from $\mathrm{HS}-\mathrm{CoB}$ resulting in the formation of a heterodisulfide (CoB-S-S-CoM) of HS-CoM and HS-CoB (1). An energy-conserving step in the metabolism of methanogens is the reduction of CoB-S-S-CoM with either molecular hydrogen or reduced coenzyme $\mathrm{F}_{420}$. In recent years, the membrane-bound electron transfer of Ms. mazei Gö1 has been analyzed in detail, resulting in the discovery of two proton translocating systems referred to as $\mathrm{H}_{2}$ :heterodisulfide oxidoreductase and $\mathrm{F}_{420} \mathrm{H}_{2}$ :heterodisulfide oxidoreductase, respectively (2).

During growth on methylated substrates, part of the methyl groups of the substrates is oxidized to $\mathrm{CO}_{2}$, and reducing equivalents are transferred to $\mathrm{F}_{420}$. The reduced cofactor $\left(\mathrm{F}_{420} \mathrm{H}_{2}\right)$ is reoxidized by the above-mentioned membrane-bound electron transport system consisting of an $\mathrm{F}_{420} \mathrm{H}_{2}$ dehydrogenase and a heterodisulfide reductase. The transfer of electrons between the enzymes is most likely mediated by methanophenazine, a hydrophobic cofactor which has been isolated from the cytoplasmic membrane of Ms. mazei Gö1. The overall process has been shown to be competent in driving proton translocation across the cytoplasmic membrane (3). The resulting electrochemical proton gradient is the driving force for ATP synthesis from ADP $+\mathrm{P}_{\mathrm{i}}$ catalyzed by an $\mathrm{A}_{1} \mathrm{~A}_{0}$-type ATP synthase $(2,4)$. 
The $\mathrm{F}_{420} \mathrm{H}_{2}$ dehydrogenase with a molecular mass of $115 \mathrm{kDa}$ has been purified from $M s$. mazei Gö1 and contains iron-sulfur clusters and FAD (5). The isolated enzyme is very similar to the corresponding protein from Methanolobus tindarius (6) and is composed of five different subunits with molecular masses of 40, 37, 22, 20 and $17 \mathrm{kDa}$. A $\mathrm{F}_{420} \mathrm{H}_{2}$ dehydrogenase has also been purified form the sulfate-reducing archaeon Archaeoglobus fulgidus (7).

In this report the gene locus encoding the $\mathrm{F}_{420} \mathrm{H}_{2}$ dehydrogenase on the Ms. mazei genome is described. Furthermore, it is shown that the corresponding enzyme is a novel proton pump contributing to the generation of the electrochemical proton gradient in the methanogenic organism.

\section{Materials and Methods}

Assay conditions -Washed inverted vesicles of Ms. mazei Gö1 (DSM 3647) were prepared according to Ide et al. (8). Proton translocation, electron transport and ATP synthesis was monitored as described previously (8). The isolation and reduction of $\mathrm{F}_{420}$ as well as the synthesis of 2-OH-phenazine was performed according to Abken et al. (9).

Determination of $\mathrm{N}$-terminal amino acid sequences - The $\mathrm{F}_{420} \mathrm{H}_{2}$ dehydrogenase was purified as described previously (5). The subunits were separated on SDS/PAGE and electroblotted onto polyvinylidene difluoride membranes (Pall GmbH, Dreieich, Germany). N-terminal sequences were determined by Dr. B. Schmidt (Zentrum Biochemie, University of Göttingen) on an Applied Biosystems Procise Sequencer. 
Cloning and sequencing of the fpo gene cluster ${ }^{2}$ - The complete genomic sequence of Ms. mazei Gö1 is determined by a whole-genome-shotgun approach. More than 18.000 clones carrying inserts of approximately $2.5 \mathrm{~kb}$ length, from small insert libraries representative of the whole genome, were sequenced from both ends usind LICOR IL 4200 and ABI PRISM 377 DNA sequencers. The generated sequence readings were assembled into contigs with the Prap software implemented in the STADEN software package.

Computer analysis - Protein sequence analysis was performed with the following internet servers: 1. PredictProtein server 2. SignalP V1.1 World Wide Web Prediction Server, Center for Biological Sequence Analysis. 3. PSORT Prediction server.

\section{Results}

Proton translocation activity of the $\mathrm{F}_{420} \mathrm{H}_{2}$ dehydrogenase - It was shown that electron transport from $\mathrm{F}_{420} \mathrm{H}_{2}$ to $\mathrm{CoM}-\mathrm{S}-\mathrm{CoB}$ as catalyzed by washed inverted vesicles from $M s$. mazei Gö1 is coupled to proton translocation across the cytoplasmic membrane (3). With the identification of methanophenazine as an electron carrier in the membrane the redox-driven proton translocation could be analyzed in more detail. It became evident that the key enzymes of the membrane-bound electron transfer systems were able to interact with 2-OHphenazine which is a water-soluble homologue of methanophenazine (9). Reducing equivalents from $\mathrm{F}_{420} \mathrm{H}_{2}$ were transferred to 2-OH-phenazine by the membrane-bound $\mathrm{F}_{420} \mathrm{H}_{2}$ dehydrogenase. Furthermore, the heterodisulfide reductase present in the cytoplasmic membrane was able to use reduced 2-OH-phenazine as electron donor for the reduction of CoB-S-S-CoM (10). 
Taking advantage of 2-OH-phenazine as electron acceptor, it became evident that the $\mathrm{F}_{420} \mathrm{H}_{2}$ dehydrogenase is directly involved in the generation of an electrochemical proton gradient (Fig. 1). Concentrated vesicles were diluted with a sucrose/thiocyanate solution containing $200 \mathrm{nmol} \mathrm{F}_{420} \mathrm{H}_{2}$

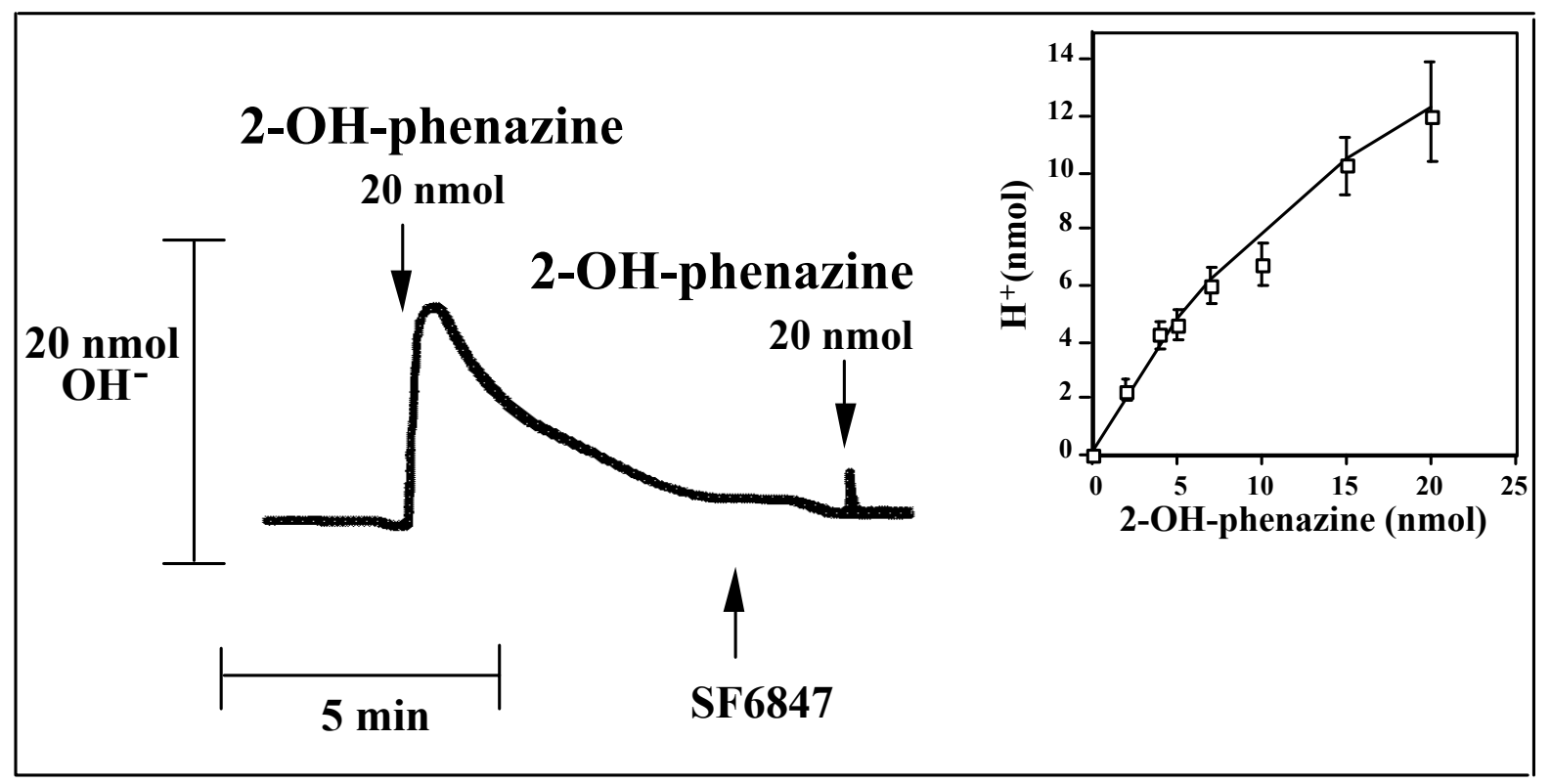

Fig. 1: Redox-driven proton uptake by washed inverted vesicles from Ms. mazei Gö1.

Proton translocation was monitored in a glass vessel connected to a sensitve $\mathrm{pH}$ electrode as described previously (8). After gassing with $\mathrm{N}_{2}$, the vessel was filled with $3 \mathrm{ml} 40 \mathrm{mM} \mathrm{KSCN}$ solution containing $0.5 \mathrm{M}$ sucrose, $1 \mathrm{mg} / \mathrm{ml}$ resazurine, $10 \mathrm{mM}$ dithioerythritol and $200 \mathrm{nmol} \mathrm{F}_{42} \mathrm{H}_{2}$, followed by the addition of 50-80 $\mu \mathrm{l}$ washed vesicles ( $1-1.4 \mathrm{mg}$ protein/assay). The assay was continuously stirred and the $\mathrm{pH}$ was adjusted to 6.8-6.9. The reaction was started by the addition of $20 \mathrm{nmol} 2-\mathrm{OH}$-phenazine ( $20 \mathrm{mM}$ stock solution in ethanol) After finishing the experiments the $\mathrm{pH}$ changes were calibrated with a $\mathrm{NaOH}$ standard solution. SF 6847 was added to a final concentration of $15 \mathrm{nmol} / \mathrm{mg}$ protein where indicated. Inset: Dependency of electron transport and $\mathrm{H}^{+}$transfer. 
and were pulsed with 2-OH-phenazine under an atmosphere of molecular nitrogen. In the course of electron transport from $\mathrm{F}_{420} \mathrm{H}_{2}$ to 2-OH-phenazine a rapid alkalinization of the medium occurred which due to proton movement into the lumen of the inverted vesicles. Thiocyanate was used as a permanent charge-compensating cation required to exchange for the ejected protons, thus maintaining the electroneutrality across the membrane. After consumption of $\mathrm{F}_{420} \mathrm{H}_{2}$ the energy conserving electron transport stopped leading to a decay of the generated $\Delta \mu_{\mathrm{H}}{ }^{+}$by passive diffusion of protons from the lumen of the inverted vesicles to the medium. This is indicated in the second reaction phase where a reacidification took place until the base line was reached again. After calibration of the instrument response with $\mathrm{NaOH}$ as an internal standard the extent of reversible alkalinization was used to calculate the $\mathrm{H}^{+} / 2 \mathrm{e}^{-}$ratio. As evident from Fig. 1 (inset) the extent of $\mathrm{H}^{+}$ejection was dependent on the amount of 2-OH-phenazine added. From the linear part of the reaction curve (0 to $7 \mathrm{nmol} 2-$ OH-phenazine/assay) a stoichiometry of $0.9 \pm 0.2 \mathrm{H}^{+} / 2 \mathrm{e}^{-}$was determined. Proton translocation was not observed when 2-OH-phenazine was replaced by ethanol or when $\mathrm{F}_{420}$, instead of $\mathrm{F}_{420} \mathrm{H}_{2}$, was added indicating that proton transfer was specifically coupled to the $\mathrm{F}_{420} \mathrm{H}_{2}$-dependent 2-OH-phenazine reduction. In the presence of the protonophore SF 6847 the generation of a $\mathrm{pH}$ gradient was abolished and a reversibel alkalinization was prevented (Fig. 1).

Coupling of electron transport and ATP synthesis - When the electron transfer from $\mathrm{F}_{420} \mathrm{H}_{2}$ to 2-OH-phenazine was analyzed the initial velocity of substrate conversion was $0.42 \pm 0.03$ $\mu \mathrm{mol} \times \min ^{-1} \times \mathrm{mg}$ protein ${ }^{-1}$ (Table I). After $1 \mathrm{~min}$, the rate slowly decreased due to the depletion of reduced $\mathrm{F}_{420}$. The reaction was coupled to the phosphorylation of ADP as indicated by a rapid increase of the ATP content upon start of the reaction (Fig. 2). The initial rate of ATP synthesis was $0.11 \pm 0.03 \mu \mathrm{mol} \mathrm{x} \mathrm{min}^{-1} \mathrm{x} \mathrm{mg}$ protein ${ }^{-1}$ resulting in an ATP/2 $\mathrm{e}^{-}$ stoichiometry of about 0.26 within the first minute of the reaction. In the absence of ADP, 2$\mathrm{OH}-$ phenazine reduction slowed down to $0.3 \pm 0.02 \mathrm{U} / \mathrm{mg}$ protein (Table I) and ATP synthesis was not possible (Fig. 2). The ATP synthase inhibitor DCCD led to a strong 
inhibition of phosphorylation of ADP and resulted in a slight decrease of the electron transport rate $(0.32 \pm 0.04 \mathrm{U} / \mathrm{mg}$ protein). SF 6847 abolished ATP synthesis (Fig. 2) due to the decay of $\Delta \mu_{\mathrm{H}}{ }^{+}$. Inhibition of electron transfer in the presence of DCCD or in the absence of ADP was relieved by the addition of SF 6847 (Table I). The results of the experiments outlined are clearly in accordance with the chemiosmotic coupling mechanism of ATP synthesis. Furthermore, the effect of SF 6847 , DCCD and ADP on the rate of electron transport resembles the phenomenon of respiratory control. The low control ratio is explained by the fact that about $50 \%$ of the vesicles were uncoupled and catalyzed electron transfer without generating an electrochemical proton gradient (2).

Table 1: Effect of ADP, DCCD and SF 6847 on electron transfer rates from $\mathrm{F}_{420} \mathrm{H}_{2}$ to 2-OH-phenazine

Additions

ADP

None

SF

$\mathrm{SF}+\mathrm{ADP}$

$\mathrm{DCCD}+\mathrm{ADP}$

$\mathrm{DCCD}+\mathrm{SF}+\mathrm{ADP}$
Electron transport rate

$\left(\mu \mathrm{mol} \times \min ^{-1} \times \mathrm{mg} \operatorname{protein}^{-1}\right)^{\mathrm{a}}$

\footnotetext{
${ }^{\mathrm{a}} 1 \mu \mathrm{mol} \mathrm{F}_{420} \mathrm{H}_{2}$ oxidized or $1 \mu \mathrm{mol} 2-\mathrm{OH}-$ phenazine reduced per min and mg protein

The conditons were same as in Fig. 2. Each value represents an average of at least 10 determinations
} 
Structure of the fpo operon coding for the $\mathrm{F}_{420} \mathrm{H}_{2}$ dehydrogenase from Ms. mazei Gö1 - The entire genome of Ms. mazei Gö1 is currently sequenced in the Genomic Laboratory Göttingen. In the course of the sequencing process the data were checked for the presence of regions coding for the

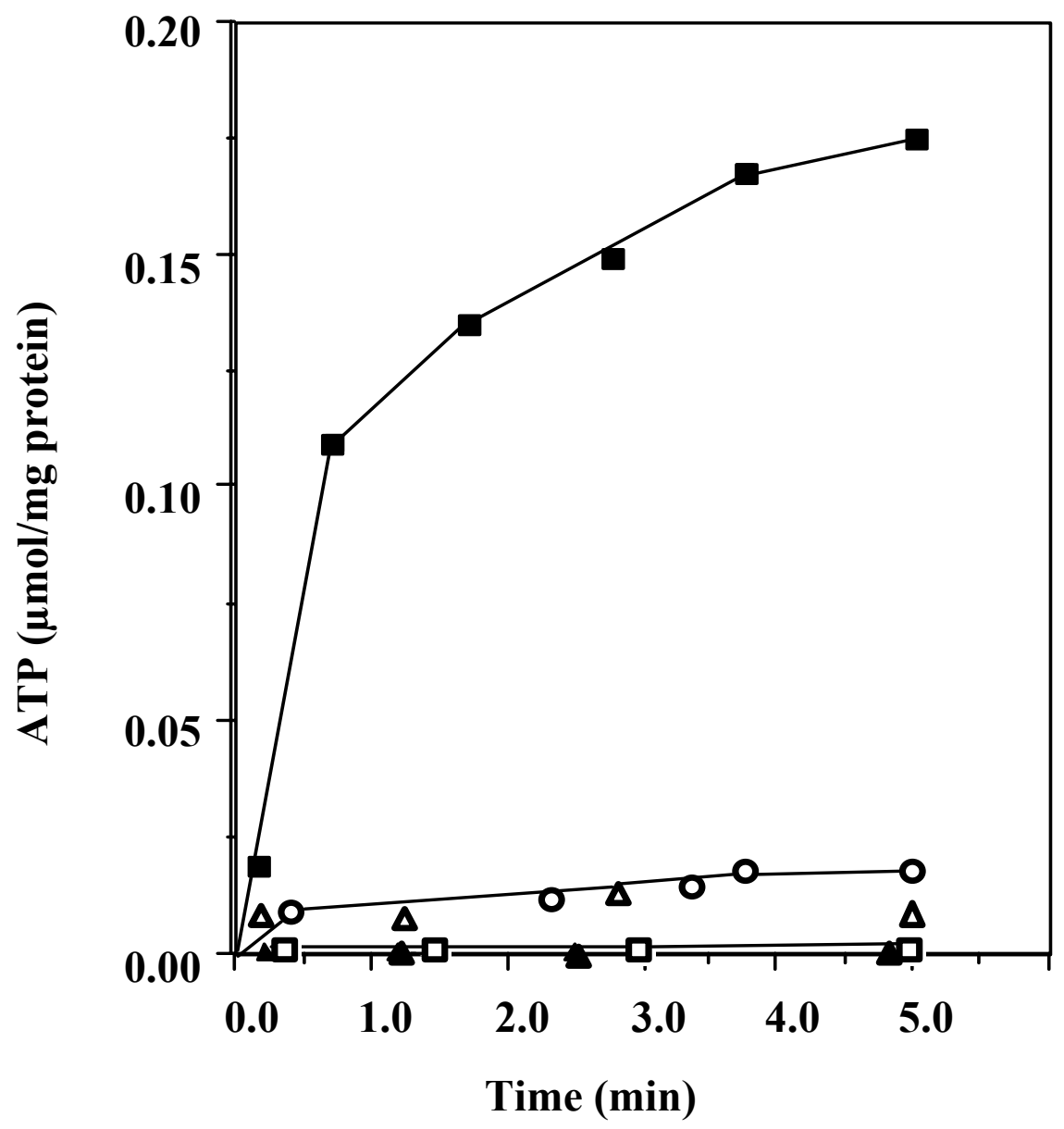

Fig. 2: ATP synthesis in the course of $\mathrm{F}_{420} \mathrm{H}_{2}$ dependent 2-OH-phenazine reduction. ATP synthesis was analyzed in $1.5 \mathrm{ml}$ glass cuvettes filled with $0.8 \mathrm{ml} 40 \mathrm{mM}$ potassium phosphate, pH 7 , containing $20 \mathrm{mM} \mathrm{MgSO} 4,0.5 \mathrm{M}$ sucrose, $10 \mathrm{mM}$ dithioerythritol and $1 \mathrm{mg} / \mathrm{ml}$ resazurin under an atmosphere of molecular nitrogen. After addition of $\mathrm{F}_{420} \mathrm{H}_{2}(64 \mu \mathrm{M})$ and 2-OH-phenazine $(125 \mu \mathrm{M})$ the reaction was 
started by the injection of washed vesicles (19 $\mu \mathrm{g}$ protein). The concentrations of ADP, SF 6847 and DCCD were $0.16 \mathrm{mM}, 25 \mu \mathrm{M}$ and $250 \mathrm{nmol} / \mathrm{mg}$ protein, respectively. $(\boldsymbol{\square})+\mathrm{ADP},(\boldsymbol{\Delta}) \mathrm{F}_{420} \mathrm{H}_{2}$ omitted, $(\boldsymbol{\Delta})+\mathrm{ADP}$ + SF 6847, ( $\square$ ) ADP omitted, (O ) + ADP + DCCD. 2-OH-phenazine, DCCD and SF 6847 were added as ethanolic solutions. The controls received ethanol only. To determine the ATP concentration 1-2 $\mu 1$ aliquots were withdrawn with a syringe and analyzed using the luciferin/luciferase assay as described previously (3).

known N-terminal amino acid sequences obtained from five subunits of the purified enzyme. Finally, one DNA fragment was identified which codes for the 40, 22, 20 und $16 \mathrm{kDa}$ subunits of the purified $\mathrm{F}_{420} \mathrm{H}_{2}$ dehydrogenase (Fig. 3). The proposed name for the gene locus is fpo for $\underline{\mathrm{F}}_{420} \mathrm{H}_{2}$ :phenazine oxidoreductase. The fragment comprises 12 genes which were designated fpo $A, B, C, D, H, I, J, K, L, M, N, O$. Each gene is preceded by at least one putative ribosome binding site starting with the initiation codon ATG or GTG $(f p o L)$ and is terminated by the stop codons TAA or TGA. Other putative open reading frames could not be identified in the direct neighbourhood of the flanking genes $f p o A$ and $f p o O$, respectively. Upstream of $f p o A$ is an AT-rich region, which contains potential archaeal consensus promoter sequences (Fig. 4a). At the opposite boundary a stem loop was found downstream of $f p o O$ (Fig. 4b), followed by a T-rich region. The RNA duplex stability is $-51 \mathrm{~kJ} / \mathrm{mol}(11)$. Furthermore, two different repeats of a $9 \mathrm{bp}$ and a $10 \mathrm{bp}$ sequence (TAAAGTGGCT and CTTTATTTT) were identified in this region (Fig. 4b). These structures are similar to transcriptional termination sites of polypeptide-encoding genes from other archaea (12). All 12 structural genes are organized so compactly in the cluster that there is almost no intergenic space for promoter or terminator-like sequences. Therefore, the genes fpoA-O may represent one operon. Evidence for this assumption came from northern blot analysis. A 11 kb signal was obtained when RNA from methanol-grown cells was hybridized with a specific probe (not shown). The size of the transcript is in full accordance with the length of the predicted fpo genes. 


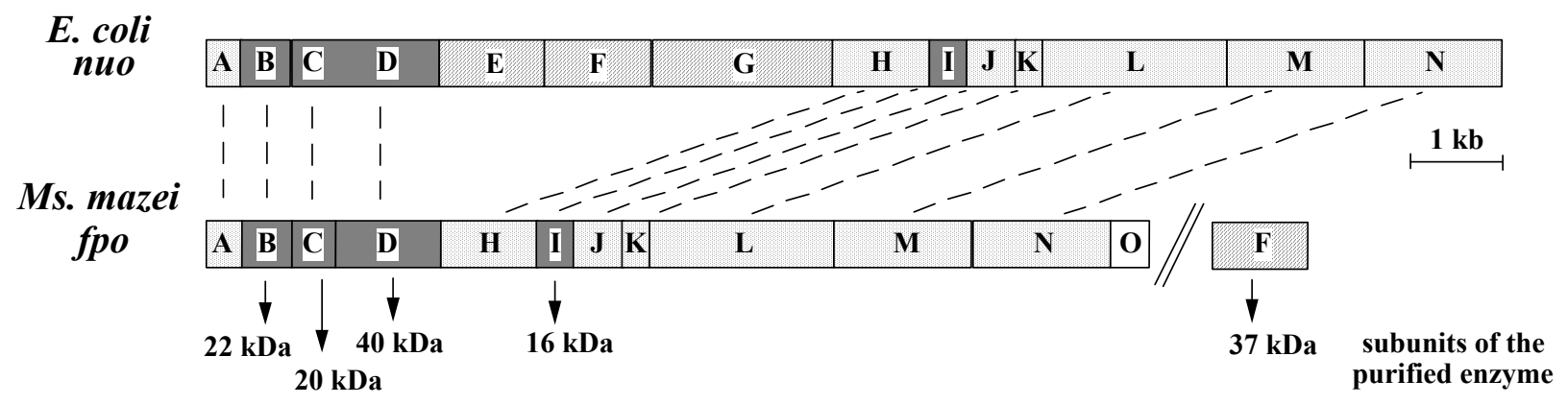

Fig. 3: Organization of the fpo gene cluster from Ms. mazei Gö1 compared to the nuo operon from $\boldsymbol{E}$. coli. The size of the boxes is proprotional to the length of the genes. Homologous genes are marked by broken lines. Subunits of the purified core enzyme of the $\mathrm{F}_{420} \mathrm{H}_{2}$ dehydrogenase are indicated by black arrows. The genes are shaded according to the function of the encoded polypeptides (see text):

membrane-associated module

membrane-integrale module

input module

unkown function

The deduced N-terminal amino acid sequences from fpo $B, C, D$ and $I$ were identical to the $\mathrm{N}$-termini of four subunits of the purified $\mathrm{F}_{420} \mathrm{H}_{2}$ dehydrogenase. The fifth subunit is encoded by the $f p o F$ gene which will be described below. Since the gene products of the remaining fpo genes were not found in the homogeneous protein preparation it is most likely that only a subcomplex of the $\mathrm{F}_{420} \mathrm{H}_{2}$ dehydrogenase was purified and the other subunits were lost during purification. However, the core enzyme composed of FpoBCDFI showed catalytic activity with $\mathrm{F}_{420} \mathrm{H}_{2}$ as electron donor and serveral artificial dyes as electron acceptors (10). 

A)
region upstream of $f p o A$
promoter consenus sequence: AAANNTTTATATA

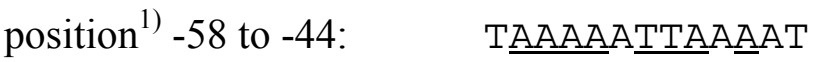
position $^{1)}-412$ to $-397: \quad$ TAATATTATATA

\section{B)}

region downstream of $f p o O$

Stop codon $\quad>>>>>>>>>>>>\quad<<<<<<<<<<<<<<$

TAAATATTGAGTAAAGCTACTTTTIAAAGTGGCTTTATTTTTTATT

CTTTATTTTGGTCTTTCGgTAGATtGCTTtTtTtCATtATAATAAA

CGTAAATTTTAAAATGTAAAGTGGCTGTAATCTTTAAAAAAAGTTT

1) The numbers indicate the distance to the start codon of $f p o A$

Fig. 4: Putative promoter (A) and terminator sequences (B) upstream and downstream of the fpo gene cluster. (A) Conserved base pairs are underlined. (B) The stop codon of $f p o O$ is marked in bold. Stem loop structures are marked by open arrows indicating the length and the orientation of the stems. Tandem repeats are underlined.

The deduced primary sequences of all predicted $\mathrm{F}_{420} \mathrm{H}_{2}$ dehydrogenase subunits from $M s$. mazei Gö1 were compared with those of other organisms. Eleven polypeptides showed significant homologies to NADH:plastoquinone oxidoreductases from cyanobacteria or chloroplasts and to NADH:UQ oxidoreductases from mitochondria and bacteria (complex I, $\mathrm{NDH}-1)$. Alignments of the fpo gene products A-N indicated similarities of $42-71 \%$ and identities of $37-60 \%$ to the corresponding subunits of the above-mentioned enzyme 
complexes (Table II). With the exception of nqo6 from Thermus thermophilus (13) and of nuoI from Pyrococcus abyssi (14) highest scores were obtained for gene products of higher plants and algae. On the other hand the fpo genes are arranged in the same order as bacterial NDH-1 genes. This fact prompted us to number the gene according to the nomenclature of the nuo operon from E. coli (Fig. 3).

Table 2. Homologies of deduced amino acid sequences of fpo genes from Ms. mazei Gö1 to corresponding gene products of NADH dehydrogenases from other organisms

\begin{tabular}{|c|c|c|c|c|}
\hline $\begin{array}{l}\text { deduced amino } \\
\text { acid sequence from } \\
\text { Ms. mazei Gö1 }\end{array}$ & $(\mathrm{kDa})$ & $\begin{array}{l}\text { highest homology } \\
\text { to deduced amino acid } \\
\text { sequence from }\end{array}$ & $\begin{array}{c}\text { identity } \\
(\%)\end{array}$ & $\begin{array}{c}\text { similarity } \\
(\%)\end{array}$ \\
\hline fpoA & 14.1 & ndhC (Synechocystis PCC 6803) & 43 & 56 \\
\hline$f p o B$ & 20.7 & nqo6 (Thermus thermophilus) & 53 & 64 \\
\hline fpoC & 18.3 & ndhJ (Nicotiana tabacum) & 38 & 42 \\
\hline fpoD & 42.5 & ndhH $($ Secale cereale $)$ & 48 & 63 \\
\hline fpoH & 38.0 & ndh1 (Plectonema boryanum) & 43 & 55 \\
\hline fpoI & 15.2 & nuol (Pyrococcus abyssi) & 40 & 53 \\
\hline fpoJ & 18.5 & ndh6 (Plectonema boryanum) & 39 & 51 \\
\hline fpoK & 11.3 & ndhE (Synechocystis PCC 6803) & 52 & 67 \\
\hline fpoL & 72.3 & ndh7 (Pisum sativum) & 60 & 71 \\
\hline fpoM & 53.9 & ndh4 (Artemia salina) & 40 & 47 \\
\hline fpoN & 52.7 & ndhB (Synechocystis PCC 6803) & 37 & 50 \\
\hline fpoO & 15.0 & - & - & - \\
\hline fpoF & 38.4 & frhB (Methanococcus jannaschii) ${ }^{1)}$ & 38 & 48 \\
\hline
\end{tabular}

1) part of the $\mathrm{F}_{420}$-reducing hydrogenase

Hydropathy plots revealed that the deduced polypeptides from fpo $A, H, J, K, L, M$ and $N$ are membrane-integral components. The largest subunits are predicted to contain 14 (FpoM,N) to 16 (FpoL) transmembrane helices and the smaller peptides FpoJ and FpoH 2 and 8 membrane-spanning helices. Computer programs (PSORT Prediction/ SignalP-Server) revealed that FpoA and FpoK may contain N-terminal signal peptides with cleavage sites at 
amino acid position 38 and 23, respectively. If this prediction is correct each of the processed polypeptides would comprise two transmembrane helices. In summary, the membrane integral part of the $\mathrm{F}_{420} \mathrm{H}_{2}$ dehydrogenase complex showed high similarities to the corresponding module of bacterial NDH-1 with respect to composition and homology of the amino acid sequences. In the bacterial nuo/nqo operons known so far the genes encoding hydrophobic subunits are clustered at the 3 'end of the operon with the exception of nuoA/nqo7 which is located at the very beginning of the operon. The same organisation is given in the fpo gene cluster from Ms. mazei Gö1. It is important to note that the hydrophobic subunits of bacterial NDH-1 and of the $\mathrm{F}_{420} \mathrm{H}_{2}$ dehydrogenase have their counterparts in mitochondrially encoded complex I subunits from Eukarya (15).

Secondary structure prediction classifies the gene products FpoB, C, D and FpoI as nonmembrane proteins. This is in agreement to the cellular localization of the homologous polypeptides from bacterial NDH-1 of Nuo BCDI from E. coli (16) and eukaryotic complex I of PSST, 30k, 49k, TYKY from bovine heart (17). These subunits comprise a module that connects the membrane-integral subcomplex to the NADH-oxidizing device (Fig. 3). It is most likely that FpoBCDI have a similar function in the $\mathrm{F}_{420} \mathrm{H}_{2}$ dehydrogenase. In subunit FpoB and FpoI binding motifs for up to three tetranuclear iron-sulfur centers are present which are invariably conserved in the bacterial and eukaryotic equivalents (Table III). It has been suggested that these prosthetic groups mediate electron transport between the subcomplexes and play an important role in energy conversion of NDH-1 and complex I (18).

The amino acid sequence derived from the open reading frame designated fpoO contains motifs for the binding of one [Fe2-S2] cluster (Table III). The correponding polypeptide has no counterpart in NDH-1 or complex I and shows no homologies to any known protein. This hydrophilic polypeptide was not copurified with the core enzyme and its function is unknown. 
Table 3: Binding motifs in the deduced amino acid sequences of the fpo genes

Subunit

position of conserved cysteine residues

putative type

and binding sites

FpoB

$\mathrm{C}^{60} \mathrm{C}^{61} \mathrm{xxE}(\mathrm{x}){ }_{60} \mathrm{C}^{125}(\mathrm{x}){ }_{29} \mathrm{C}^{155} \mathrm{P}$

[Fe4-S4]

FpoI

$\mathrm{C}^{43} \mathrm{xxC}^{46} \mathrm{xxC}^{49} \mathrm{xxxC}^{53} \mathrm{P}$

[Fe4-S4]

$\mathrm{C}^{83} \mathrm{xxC}^{86} \mathrm{xxC}^{89} \mathrm{xxxC}^{93} \mathrm{P}$

[Fe4-S4]

FpoO

$\operatorname{SCRxGxCSxCxxxK(x)}{ }_{25} \mathrm{C}$

[Fe2-S2]

FpoF

$\mathrm{C}^{33} \mathrm{xxC}^{36} \mathrm{xxC}^{39} \mathrm{xxxC}^{43} \mathrm{P}$

[Fe4-S4]

$\mathrm{C}^{64} \mathrm{xxC}^{67} \mathrm{xxC}^{70} \mathrm{xxxC}^{74} \mathrm{P}$

[Fe4-S4]

$\mathrm{F}_{420} \mathrm{H}_{2}$ and $\mathrm{FAD}$ binding site

NADH is oxidized by the hydrophilic NADH dehydrogenase fragment of NDH-1 or complex I which is composed of NuoFGH [E. coli] or subunits $24 \mathrm{k}, 51 \mathrm{k}$ and $75 \mathrm{k}$ [bovine heart] (16, 17). Gene encoding these subunits are not present in the fpo gene cluster or anywhere else on the Ms. mazei chromosome indicating that the input module is different and adjusted to the oxidation of $\mathrm{F}_{420} \mathrm{H}_{2}$ as electon donor of the $\mathrm{F}_{420} \mathrm{H}_{2}$ dehydrogenase. A suitable candidate for this function is the $37 \mathrm{kDa}$ subunit of the purified core enzyme. The N-terminal sequence of this polypeptide was not found in the deduced amino acid sequences of the fpo gene cluster. However, a gene coding for the fifth subunit $(37 \mathrm{kDa})$ of the purified enzyme was identified at a different location on the chromosome and was referred to as $f p o F$ ( $\mathrm{F}$ for $\mathrm{F}_{420}$ ). The deduced amino acid sequences shows motifs for two [Fe4-S4] clusters. It is homologous to the $\beta$ subunit of $\mathrm{F}_{420}$-reducing hydrogenases and to subunits of the $\mathrm{F}_{420} \mathrm{H}_{2}$ dehydrogenase from Methanolobus tindarius (FfdB; (19)) and Archaeoglobus fulgidus (AF1833; (20)). In the latter organism the $f p o F$-homologue gene AF1833 is part of the operon encoding the 
$\mathrm{F}_{420} \mathrm{H}_{2}$ dehydrogenase. Recently, the gene was overexpressed in E. coli and the corresponding polypeptide was purified to homogeneity. The subunit contained non-heme iron, acid-labile sulfur and FAD and was able to oxidize $\mathrm{F}_{420} \mathrm{H}_{2}$ when the artificial electron acceptor methylviologen was added (unpublished results). Since AF1833 and FpoF are structurally equivalent and FpoF it is part of the purified $\mathrm{F}_{420} \mathrm{H}_{2}$ dehydrogenase from $M s$. mazei Gö1 it may function as electron input device of the enzyme.

\section{Discussion}

Energetics of the $\mathrm{F}_{420} \mathrm{H}_{2}$ dehydrogenase - $\mathrm{F}_{420}$ is the central cytoplasmic electron carrier in the methanogen Ms. mazei Gö1. The cofactor is involved in the process of methanogenesis from $\mathrm{H}_{2}+\mathrm{CO}_{2}$ and from methylated compounds such as methanol and methylamines. In the methylotrophic pathway of methane formation (21) three out of four methyl-groups are reduced to methane. The remaining methyl-moiety is oxidized to $\mathrm{CO}_{2}$ and the resulting reducing equivalents are transferred to $\mathrm{F}_{420}$. The membrane-bound $\mathrm{F}_{420} \mathrm{H}_{2}$ dehydrogenase catalyzes the reoxidation of $\mathrm{F}_{420} \mathrm{H}_{2}$ and most likely transfers the electrons to the novel membrane-integral cofactor methanophenazine which is a linear sesterterpenic ether of 2$\mathrm{OH}$-phenazine (2). Previous studies indicate that the protein is part of the membrane-bound $\mathrm{F}_{420} \mathrm{H}_{2}$ :heterodisulfide oxidoreductase which is one of the major energy conserving systems of Ms. mazei Gö1 (3). It was found that the electron transport from $\mathrm{F}_{420} \mathrm{H}_{2}$ to the heterodisulfide (CoM-S-S-CoB) is coupled to the transfer of 3-4 protons across the cytoplasmic membrane. Using 2-OH-phenazine as a water-soluble precursor of methanophenazine it became evident that the overall electron transfer can be divided into two partial reactions [eq. 1,2 ] catalyzed by the $\mathrm{F}_{420} \mathrm{H}_{2}$ dehydrogenase and the heterodsulfide reductase, respectively.

$\mathrm{F}_{420} \mathrm{H}_{2}+2-\mathrm{OH}$-phenazine $\rightarrow \mathrm{F}_{420}+$ dihydro-2-OH-phenazine $\left(\Delta \mathrm{G}^{0 \prime}=-31.8 \mathrm{~kJ} / \mathrm{mol}\right)$ [eq. 1] dihydro-2-OH-phenazine + CoM-S-S-CoB $\rightarrow$ 2-OH-phenazine + HS-CoM + HS-CoB $\left(\Delta \mathrm{G}^{0 \prime}=-10.6 \mathrm{~kJ} / \mathrm{mol}\right) \quad$ [eq. 2] 
Very recently, it was shown that the dihydrophenazine-dependent heterodisulfide reduction (eq. 2) is coupled to proton translocation exhibiting a stoichiometry of $2 \mathrm{H}^{+} / 2 \mathrm{e}^{-}$(8). The experiments in this publication show that in the first partial reaction catalyzed by the $\mathrm{F}_{420} \mathrm{H}_{2}$ dehydrogenase a maximum of $0.9 \pm 0.2$ protons per two electron were translocated. Taking into account that about $50 \%$ of the vesicles are uncoupled (2) a $\mathrm{H}^{+} / 2 \mathrm{e}^{-}$ratio of about 2.0 could be considered. Then, the $\mathrm{H}^{+} / 2 \mathrm{e}^{-}$stoichiometries of the partial reactions would add up to 4 and support the value of $3-4 \mathrm{H}^{+} / 2 \mathrm{e}^{-}$translocated in the overall electron transport from $\mathrm{F}_{420} \mathrm{H}_{2}$ to heterodisulfide (3). In summary, the data clearly indicate that the $\mathrm{F}_{420} \mathrm{H}_{2}$ dehydrogenase is a redox-driven proton pump showing a maximal energetic efficiency of about $2 \mathrm{H}^{+}$translocated per $2 \mathrm{e}^{-}$transported.

Comparison of $\mathrm{F}_{420} \mathrm{H}_{2}$ dehydrogenase and proton translocating $\mathrm{NADH}$ dehydrogenases The $\mathrm{F}_{420} \mathrm{H}_{2}$ dehydrogenase from Ms. mazei Gö1 resembles eukaryotic complex I and bacterial NDH-1 in many ways: 1. The membrane-bound, flavin and iron-sulfur containing enzymes are characterized by a complex subunit composition. 2. The electron donors $\mathrm{F}_{420} \mathrm{H}_{2}$ and NADH are both reversible hydride donors with comparable mid-point potentials. 3. Both enzymes take advantage of small hydrophobic non-proteinous electron acceptors namely quinones in case of the NADH dehydrogenase and methanophenazine in case of $\mathrm{F}_{420} \mathrm{H}_{2}$ dehydrogenase. The electron acceptors are highly hydrophobic and can diffuse within the cytoplasmic membrane. Several experimental data indicate that semiquinone radicals are produced in the course of the NADH dehydrogenase reaction (22). The same could be true for methanophenazine since the direct precursor 2-OH-phenazine is also reduced in two $1 \mathrm{e}^{-}$ transfer reactions forming a semiphenazine radical as an intermediate in solution (23). 4. It was shown that mitochondrial and bacterial NADH:ubiquinone oxidoreductases as well as the $\mathrm{F}_{420} \mathrm{H}_{2}$ dehydrogenase are inhibited by diphenyleneiodonium chloride $(24,25)$. 5 . The redox-reaction catalyzed by the proteins is coupled to proton translocation. 
It is shown in this publication that the physiological characteristics of the $\mathrm{F}_{420} \mathrm{H}_{2}$ dehydrogenase are supported by genetic data. The deduced primary sequences of the $M s$. mazei
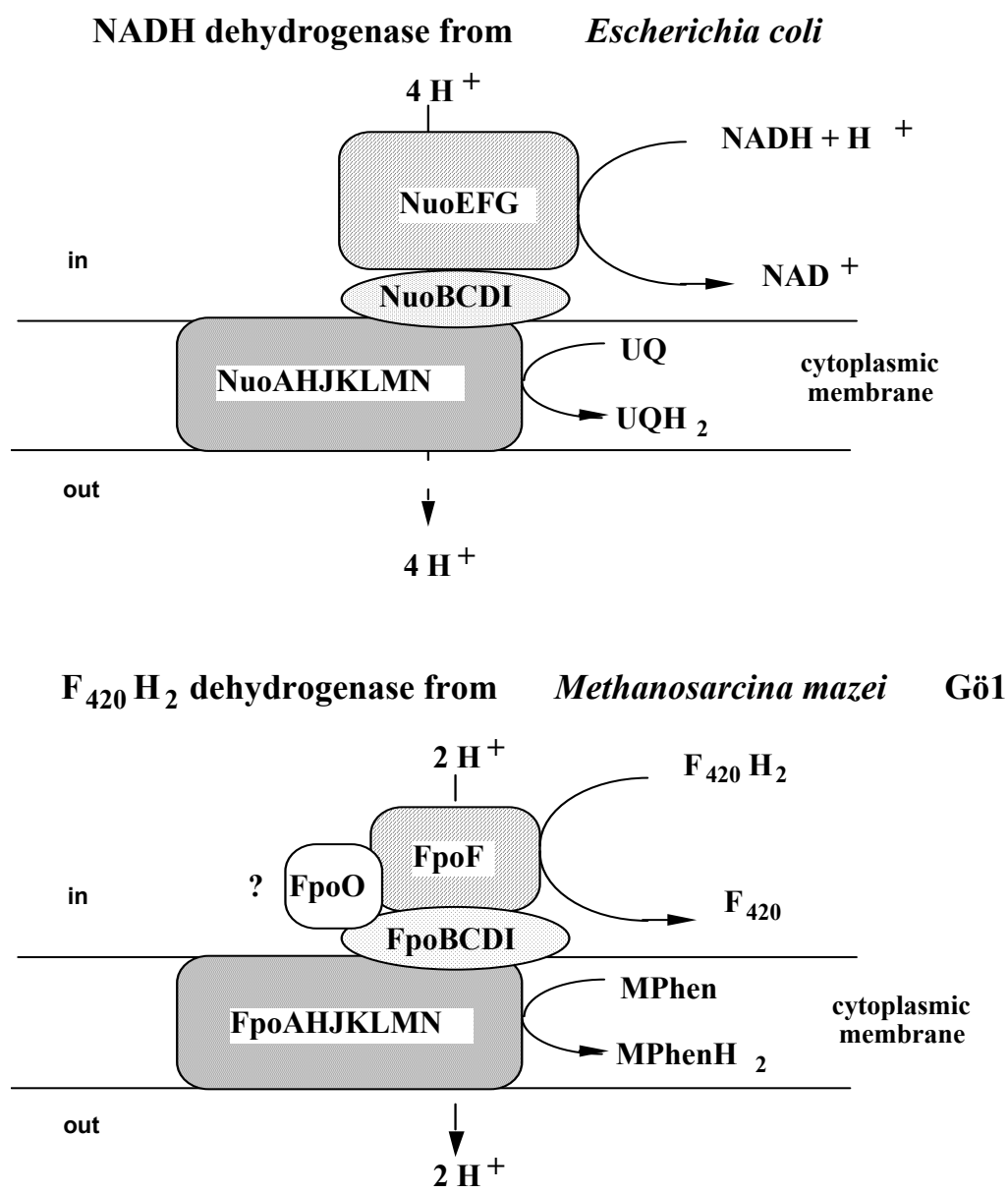

Fig. 5: Tentative models of the $\mathrm{F}_{420} \mathrm{H}_{2}$ dehydrogenase and the NADH dehydrogenase 1

from $\boldsymbol{E}$. coli. Proton translocating activity is indicated by broken arrows. UQ, ubiquinone 10; MPhen, methanophenazine. Functionally homologous subcomplexes are indicated by equal shading.

$\because \because$ membrane-associated module $\quad \square$ membrane-integrale module input module $\square$ unkown function 
Gö1 $\mathrm{F}_{420} \mathrm{H}_{2}$ dehydrogenase subunits were compared with those of other organisms and with those of some phylogenetically related enzymes. For eleven proteins encoded by fpoA to fpoN related counterparts exist in bacterial NDH-1 and mitochondrial complex I. The organization of the genes resembles operons encoding the proton-translocating NADH:ubiquinone oxidoreductases $(\mathrm{Ndh} / \mathrm{Nqo})$ from several bacteria such as $E$. coli, Thermus thermophilus and Rhodobacter capsulatus $(26,13,27)$. The bacterial enzyme is composed of 13 to 14 different subunits (28) which form the following modules (nomenclature according to $E$. coli) 1. The hydrophilic NADH dehydrogenase fragment composed of NuoEFG catalyzes the oxidation of NADH. 2. NuoAHJKLMN form the membrane-integral module and are involved in quinone reduction and proton-translocation, 3. NuoBCDI connect the above-mentioned subunits and catalyze electron transfer from module 1 to 3 (29).

The detailed reaction mechanism of the enzyme is unknown. Several intrinsic redox components were detected which are involved in NADH-dependent quinone recduction (18). The NuoEFG module contains most of the redox-active prosthetic groups (16). One noncovalently bound FMN and at least five EPR detectable iron-sulfur clusters form a long electron transfer chain guiding electron transfer from NADH to the [Fe4-S4] cluster N2 which is part of the amphipathic connecting fragment NuoBCDI. It is still a matter of debate whether this cluster is bound to NuoB or NuoI. However, it is well established that reduced N2 successively injects single electrons into the membraneous subcomplex, thereby activating a serial array of quinones which are directly involved in $\mathrm{H}^{+}$translocation (30).

The native structure of the $\mathrm{F}_{420} \mathrm{H}_{2}$ dehydrogenase is still unknown. However, the primary sequence informations, operon structure and the homology to bacterial NDH-1 allow to draw a tentative model (Fig. 5). The gene product FpoF forms the input module which oxidizes $\mathrm{F}_{420} \mathrm{H}_{2}$ by hydride transfer. FAD present in this subunit catalyzes a two electron/one electron switch to reduce the [Fe4-S4] clusters. It is still an open question whether the gene product of 
$f p o O$ is also part of the input module. This polypeptide is predicted to be hydrophilic and probably contains [Fe2-S2]-clusters. On the other hand this polypeptide was not copurified with the core enzyme indicating that it is not essential for catalytic activity. From the $\mathrm{F}_{420} \mathrm{H}_{2}$-oxidizing device the electrons are then channeled to the amphipathic connecting fragment composed of FpoBCDI which is highly homologous to the corresponding module of NDH-1. Since all iron-sulfur signatures are conserved in FpoB and FpoI it is reasonable to assume that a FeS-cluster comparable to N2 is present in one of these subunits. In analogy to NDH-1 and complex I cluster N2 should transfer electrons to the membrane integral module composed of FpoAHJKLMN. Inspite of the fact that the composition of the membraneous part of the $\mathrm{F}_{420} \mathrm{H}_{2}$ dehydrogenase and $\mathrm{NDH}-1$ is identical the further electron transport pathway of the $\mathrm{F}_{420} \mathrm{H}_{2}$-dependent enzyme is difficult to predict since methanogenic archaea do not contain quinones. Therefore, the reaction mechanism of the $\mathrm{F}_{420} \mathrm{H}_{2}$ dehydrogenase must be different at this point and must involve the electron carrier methanophenazine. The mid-point potential of 2-OH -phenazine which is a potential precursor of methanophenazine, was determined to $-255 \mathrm{mV}$ (23). With the assumption that the redox potential of methanophenazine is similar, the change of free energy $\left(\Delta G^{0}\right)$ coupled to the $\mathrm{F}_{420} \mathrm{H}_{2}$ dependent methanophenazine reduction is only $-20.2 \mathrm{~kJ} / \mathrm{mol}$ compared to a $\Delta \mathrm{G}^{\mathrm{o}}$ of -80.9 $\mathrm{kJ} / \mathrm{mol}$ for the NADH dependent reduction of ubiquinone. These thermodynamic facts are reflected by the coupling efficiencies of the enzymes since the maximal $\mathrm{H}^{+} / 2 \mathrm{e}^{-}$ratio of the $\mathrm{F}_{420} \mathrm{H}_{2}$ dehydrogenase is 2.0 , in contrast to $\mathrm{NDH}-1 /$ complex I which translocates four or even more protons across the membrane per reaction cycle (30).

Despite the aforementioned differences the $\mathrm{F}_{420} \mathrm{H}_{2}$ dehydrogenase represents a NDH-1 homologue in the methanogenic archaeon Ms. mazei Gö1 which is equipped with an alternative input device and a modified proton translocating machinery. Further analysis of the enzyme may contribute to the understanding also of the reaction mechanism of NADH dehydrogenases. 
Interestingly, fpo-like gene clusters were not detected in the methanogenic archaea Methanococcus jannaschii (31) and Methanobacterium thermoautotrophicum (32) indicating that a $\mathrm{F}_{420} \mathrm{H}_{2}$ dehydrogenase is absent in these organisms. This fact is in accordance to the finding that the electron transport chains from obligate hydrogenotrophic methanogens of the orders Methanobacteriales and Methanococcoles are different from those of methylotrophic methanogens belonging to the order Methanosarcinales (2).

\section{References}

1. Thauer, R. (1998) Microbiology 144, 2377-2406

2. Deppenmeier, U., Lienard, T., and Gottschalk, G. (1999) FEBS Lett. 457, 291-297

3. Deppenmeier, U., Blaut, M., Mahlmann, A., and Gottschalk, G. (1990) Proc. Natl. Acad. Sci. USA 87, 9449-9453

4. Müller, V., Ruppert, C., and Lemker, T. (1999) J. Bioenerg. Biomem. 31, 15-27

5. Abken, H. J., and Deppenmeier, U. (1997) FEMS Lett. 154, 231-237

6. Haase, P., Deppenmeier, U., Blaut, M., and Gottschalk, G. (1992) Eur. J. Biochem. 203, $527-531$

7. Kunow, K., Linder, D., Stetter, K. O., and Thauer, R. K. (1994) Eur. J. Biochem. 223, 503511

8. Ide, T., Bäumer, S., and Deppenmeier, U. (1999) J. Bacteriol. 181, 4076-4080

9. Abken, H. J., Tietze, M., Brodersen, J., Bäumer, S., Beifuss, U., and Deppenmeier, U. (1998) J. Bacteriol. 180, 2027-2032

10. Bäumer, S., Murakami, E., Brodersen, J., Gottschalk, G., Ragsdale, S. W., and Deppenmeier, U. (1998) FEBS Lett. 428, 295-298

11. Freier, S. M., Kierzek, R., Jaeger, J. A., Sugimoto, N., Caruthers, M. H., Neilson, T., and Turner, D. H. (1986) Proc. Natl. Acad. Sci. USA 83, 9373-9377

12. Brown, J. W., Daniels, C. J., and Reeve, J. N. (1989) CRC Crit. Rev. Microbiol. 16, 287-338 
13. Yano, T., Chu, S. S., Sled, V. D., Ohnishi, T., and Yagi, T. (1997) J. Biol. Chem. 272, $4201-4211$

14. Heilig, R.: Pyrococcus abyssi genome sequence: Genoscope - Centre National de Sequencage BP 19191006 EVRY cedex - FRANCE, Web : www.genoscope.cns.fr

15. Finel, M. (1998) Biochim. Biophys. Acta 1364, 112-121

16. Friedrich, T. (1998) Biochim. Biophys. Acta 1364, 134-146

17. Walker, J. E., Skehel, J. M., and Buchanan, S. K. (1995) Methods Enzymol. 260, 14-34

18. Ohnishi, T. (1998) Biochim. Biophys. Acta 1364, 186-206

19. Westenberg, D. J., Braune, A., Ruppert, C., Müller, V., Herzberg, C., Gottschalk, G., and Blaut, M. (1999) FEMS Microbiol. Lett. 170, 389-98

20. Klenk, H. P., Clayton, R. A., Tomb, J. F., White, O., Nelson, K. A., Dodson, R. J., Gwinn, M., Hickey, E. K., Peterson, J. D., Richardson, D. L., Kerlavage, A. R., Graham, D. E., Kyrpides, N. C., Fleischmann, R. D., Quackenbusch, J., Lee, N. H., Sutton, G. G., Gill, S., Kirkness, E. F., Dougherty, B. A., McKenny, K., Adams, M. D., Loftus, B., and Venter, J. C. (1997) Nature 390, 364-370

21. Deppenmeier, U., Müller, V., and Gottschalk, G. (1996) Arch. Microbiol. 165, 149-163

22. Ohnishi, T., Sled, V. D., Yano, T., Yagi, T., Burbaev, D. S., and Viogradov, A. D. (1998) Biochim. Biophys. Acta 1365, 301-308

23. Mann, S. (1970) Arch. Mikrobiol. 71, 304-318.

24. Brodersen, J., Bäumer, S., Abken, H. J., Gottschalk, G., and Deppenmeier, U. (1999) Eur. J. Biochem. 259, 218-224

25. Majander, A., Finel, M., and Wikström, M. J. (1994) J. Biol. Chem. 269, 21037-21042

26. Weidener U., Geier, S., Ptock, A., Friedrich, T., Leif, H., and Weiss, H. (1993) J. Mol. Biol. 233, 109-122

27. Dupuis, A. Chevallet, M., Darrouzet, E., Duborjal, H., Lunardi, J., and Issartel, J. P. (1998) Biochim. Biophys. Acta $1364,147-165$ 
28. Yagi, T., Yano, T., Di Bernardo, S., and Matsuno-Yagi, A. (1998) Biochim. Biophys. Acta 1364, 125-133

29. Friedrich, T., and Weiss, H. J. (1997) theor. Biol. 187, 529-540.

30. Dutton, P. L, Moser, C. C., Sled, V., Daldal, F., and Ohnishi, T. (1999) Biochim. Biophys. Acta $1364,245-257$

31. Bult, C., White, J., O., Olsen, G. J., Zhou, L., Fleischmann, R. D., Sutton, G. G. J., Blake, A., FitzGerald, L. M., Clayton, R. A., Gocayne, J. D., Kerlavage, A. R., Dougerty, B. A., Tomb, J.-F., Adams, M. D., Reich, C. I., Overbeek, R., Kirkness, E. F., Weinstock, K. G., Merrick, J. M., Glodek, A., Scott, J. L., Geoghagen, N. S. M., Weidman, J. F., Fuhrmann, J. L., Nguyen, D., Utterback, T. R., Kelley, J. M., Peterson, J. D., Sadow, P. W., Hanna, M. C., Cotton, M. D., Roberts, K. M., Hurst, M. A., Kaine, B. P., Borodovsky, M., Klenk, H.-P., Fraser, C. M., Smith, H. O., Woese C. R., and Venter, J. C. (1996) Science 273, 1058-1073

32. Smith, D. R., Doucette-Stamm, L. A., Deloughery, C., Lee, H., Dubois, J., Aldrege, T., Bashirzahdeh, R., Blakely, D., Cook, R., Gilbert, K., Harrison, D., Hoang, L., Keagle, P., Lumm, W., Pothier, B., Qiu, D., Spadafora, R., Vicaire, R., Wang, Y., Wierzbowski, J., Gibson, R., Jiwani, N., Caruso, A., Bush, D., Safer, H., Patwell, D., Prabhakar, S., McDougall, S., Shimer, G., Goyal, A., Pietrokovski, S., Church, G. M., Daniels, C. J., Mao, J., Rice, P., Nölling, J., Reeve, J. N. (1997) J. Bacteriol. 179, $7135-7155$ 


\section{Chapter 4}

\section{Methanophenazine: structure, total synthesis and function of a new cofactor from methanogenic archaea}

\section{Introduction}

Methanogenic organisms belong to the kingdom of archaea, which differ from eukarya and bacteria in a significant way.[1] Methanogenic archaea are widespread in anoxic environments such as the sediments of lakes and rivers as well as the intestinal tract of ruminants. They form the end of the anaerobic food chain and transform simple substrates like hydrogen/carbon dioxide, formic acid, methanol, methylamines and acetic acid into methane. The latter subsequently is oxidized under aerobic conditions and is thus able to reenter the carbon cycle. Due to the influences of civilization the amount of methane, one of the greenhouse gases, in the atmosphere has continuously increased during the last century.[2] A variety of unique enzymes and unusual cofactors contribute to its formation by methanogenic archaea. The central intermediate of all metabolic pathways of methanogens is methyl-S-CoM, which is reductively demethylated to methane under the catalytic influence of methyl-CoM-reductase.[3] The two electrons required in this process are derived from $\mathrm{CoB}-\mathrm{SH}$ and lead to the formation of a heterodisulfide (CoB-S-S-CoM) from CoB-SH and CoM-SH.[4] The reduction of CoB-S-S-CoM is an energy-conserving step in the metabolism of methylotrophic methanogens. [5] Two recently detected proton-translocating enzymic systems, the $\mathrm{H}_{2}$ :heterodisulfide oxidoreductase and the $\mathrm{F}_{420} \mathrm{H}_{2}$ :heterodisulfide oxidoreductase, are involved in the membrane-bound electron transfer of Methanosarcina mazei Gö1.[6] The electron transport of $\mathrm{F}_{420} \mathrm{H}_{2}$ to $\mathrm{CoB}-\mathrm{S}-\mathrm{S}-\mathrm{CoM}$ is mediated by an $\mathrm{F}_{420} \mathrm{H}_{2}$ dehydrogenase transferring the electrons to the heterodisulfide oxidase via electron carriers. In the presence of molecular hydrogen a membrane-bound hydrogenase serves as an electron-feeding component to the heterodisulfide reductase (Scheme 1). 


\section{Synthesis report}

To begin with, the structure of the electron carrier was not known. Recently, we have been able to isolate a phenazine ether from membranes of Methanosarcina mazei Gö1.[7] Detailed NMR analysis of the sensitive natural product, which could only be obtained in small amounts, indicated that its lipophilic side chain, which we assume to be responsible for the anchorage in the membrane, consists of five isoprenoid units linked to each other in a headto-tail manner. Unlike the saturated $\mathrm{C}_{5}$ unit, which is directly linked to the 2-phenazinyl residue, the remaining

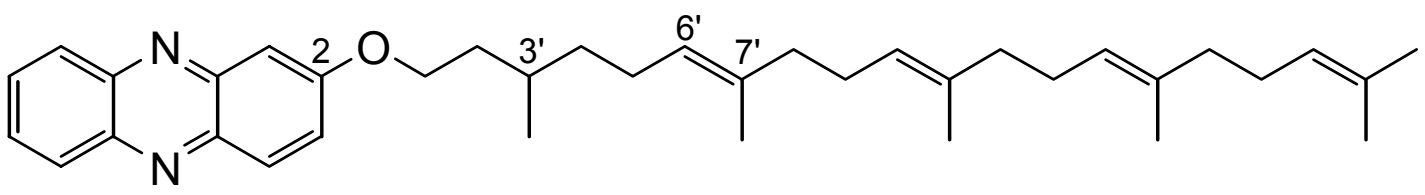

Figure 1: Structure of Methanophenazine

four units are unsaturated. Three of them exhibit $(\underline{E})$-configurated double bonds. The redox active natural product referred to as methanophenazine (MP) $\underline{\underline{\mathbf{1}}}$ is the first phenazine whatsoever isolated from archaea.

Since methanogens lack the usual quinones it was assumed that $\underline{\underline{\mathbf{1}}}$ functions as an electron carrier in the cytoplasmic membrane and unlike other natural phenazines takes part in the energy-conserving electron transport. Larger amounts of the natural product are necessary to determine the biological function of $\underline{\underline{1}}$ and to elucidate the absolute configuration at C-3'. As its isolation from Gö1 is quite time-consuming the only way possible was to synthesize the natural product. To this purpose $\underline{\underline{\mathbf{1}}}$ was to be convergently built from the three building blocks $\underline{\underline{4}}, \underline{\underline{8}}$ and $\underline{\underline{12}}$ (Scheme 2). Diastereoselective linking of $\underline{\underline{4}}$ and $\underline{\underline{8}}$ to give $\underline{\underline{9}}$ and the subsequent etherification of $\underline{\underline{\mathbf{1 1}}}$ and $\underline{\underline{\mathbf{1 2}}}$ were regarded key steps. While the latter process seemed to be completely unproblematical it was unclear whether the reactivity of the alkyl metal derivative would be sufficient for the transition metal-catalyzed linking to the vinyl iodide. 


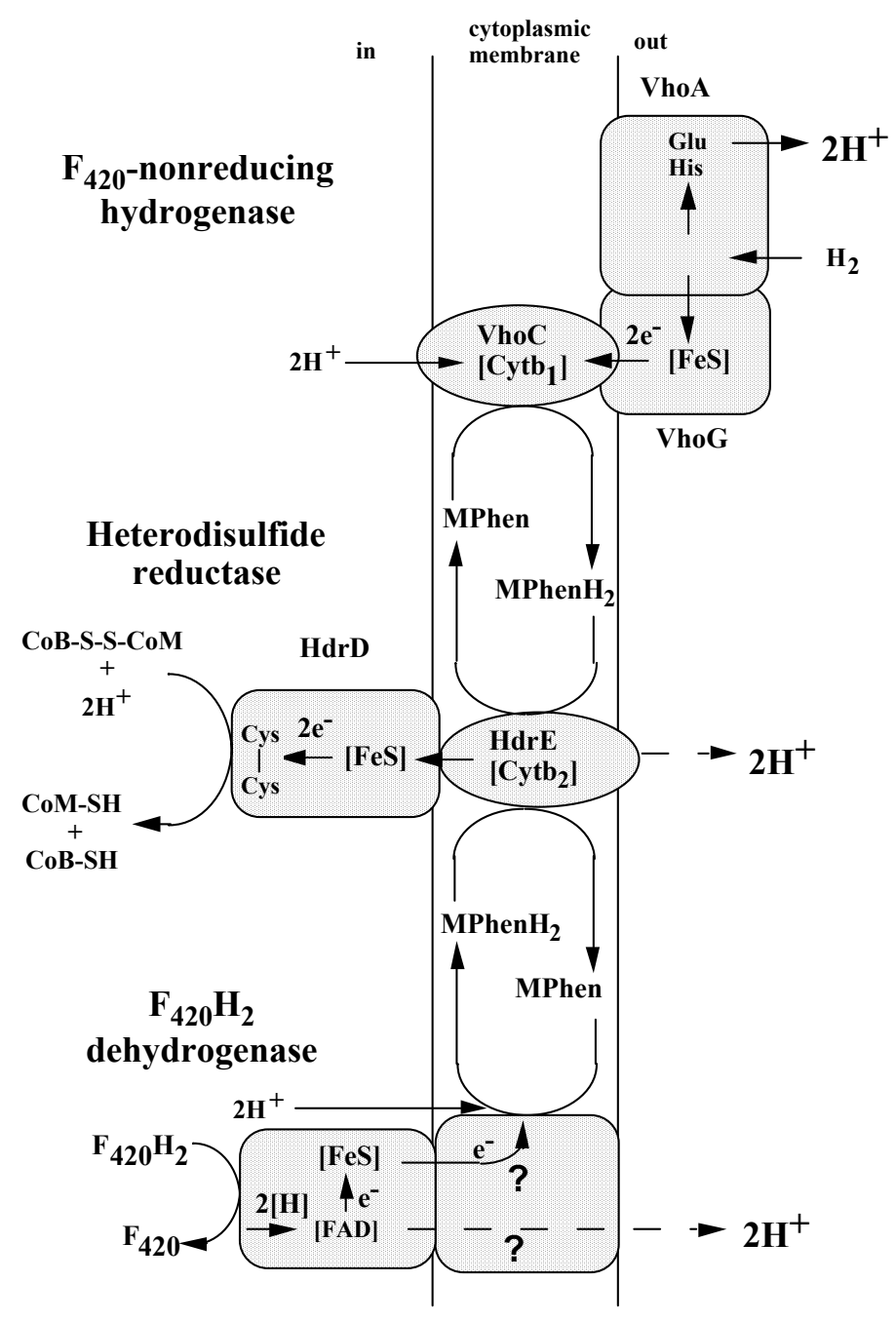

Figure 2. Model of the membrane-bound electron transfer of Methanosarcina mazei

Gö1. CoM-SH = coenzyme M; CoB-SH = coenzyme B; $\mathrm{F}_{420}=$ coenzyme $\mathrm{F}_{420} ; \mathrm{F}_{420} \mathrm{H}_{2}=$ reduced form of the coenzyme $\mathrm{F}_{420} ; \mathrm{MP}=$ methanophenazine; dihydro-MP = reduced form of methanophenazine.

In order to prepare $\underline{\underline{4}}(\underline{E}, \underline{E})$-farnesyl acetone $\underline{\underline{\mathbf{2}}}$ was first transformed into the terminal alkyne $\underline{\underline{\mathbf{3}}},[8]$ subsequently providing the $(\underline{E})$-vinyl iodide $\underline{\underline{4}}$ in diastereomerically pure form and $74 \%$ yield via Zr-catalyzed carboalumination with trimethylaluminum and quenching with iodine [9] (Scheme 2). The $\mathrm{C}_{5}$ building block $\underline{r a c}-\underline{\underline{8}}$ required for the linking with $\underline{\underline{4}}$ could be made available by selective monofunctionalization [10] of 3-methyl-pentane-1,5-diol $\underline{\underline{\mathbf{5}}}$ in a few steps. The advantage of this prochiral compound is the chance to form the enantiomerically 
pure compounds $\underline{\underline{\mathbf{8}}}$ and $\underline{\text { ent }} \underline{\underline{\mathbf{8}}}$ that are necessary to determine the absolute configuration of methanophenazine $\underline{\underline{\mathbf{1}}}$ by differentiating the enantiotopic $-\left(\mathrm{CH}_{2}\right)_{2}-\mathrm{OH}$ groups.

At the beginning, the coupling between the alkyl metal compounds released in situ from rac-

\section{$\underline{\mathbf{8}}$}

and the vinyl metal derivatives resulting from $\underline{\underline{4}}$ caused considerable difficulties thus indicating that the reactivity of the $\mathrm{sp}^{3}$ component was too low. The $(\underline{E})$-selective construction of the C-6', C-7' double bond [11] of the sesterterpene building block $\underline{\underline{9}}$ could only be achieved in $65 \%$ yield when the $\operatorname{Pd}(0)$-catalyzed coupling of the organozinc

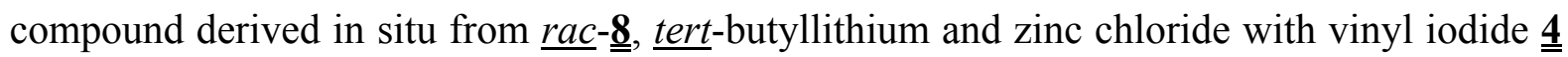
was performed. Cleavage of tert-butyldimethylsilyl ester and activation of the resulting alcohol $\underline{\underline{\mathbf{1 0}}}$ with methanesulphonic acid chloride provided mesylate $\underline{\underline{\mathbf{1 1}}}$, which was etherified with 2-hydroxy phenazine $\underline{\underline{\mathbf{1 2}}}$ [12] to give $\underline{\mathrm{rac}}-\underline{\underline{\mathbf{1}}}$. [13] When the synthesis was performed without isolation and purification of various intermediates, $\underline{r a c} \mathbf{\underline { \mathbf { 1 } }}$ could be produced from farnesyl acetone $\underline{\underline{\mathbf{2}}}$ with a total yield of more than $30 \%$. Spectroscopic data of the synthetic methanophenazine $\underline{\mathrm{rac}}-\underline{\underline{\mathbf{1}}}$ corresponded to those of the natural product in every respect.[14] Starting from the enantiomerically pure $C_{5}$ building blocks $\underline{\underline{1}}$ and $\underline{\underline{e n t}}-\underline{\underline{1}}$ will be accessible as well. And in this way it will be possible to determine the absolute configuration of the natural product.

First experiments on the biological function were performed using the model compound 2hydroxyphenazine $\underline{\underline{\mathbf{1 2}}}$ and its reduced form (dihydro- $\underline{\underline{\mathbf{1 2}}}$ ). It was demonstrated that all key enzymes react with the artificial electron carrier. ${ }^{[7]}$ After completion of the total synthesis similar tests could also be performed with methanophenazine $\underline{\operatorname{rac}}-\underline{\underline{1}}$ (MP) (Table 1). Here, washed cytoplasmic membranes of Methanosarcina mazei Gö1 were combined with rac-1 and the activities of the respective enzymes determined. The results clearly indicated that methanophenazine (MP) serves as an electron acceptor to both the membrane-bound hydrogenase and the $\mathrm{F}_{420} \mathrm{H}_{2}$ dehydrogenase if $\mathrm{H}_{2}$ and $\mathrm{F}_{420}$ were added, respectively. In addition, the heterodisulfide reductase uses the reduced form of methanophenazine (dihydro MP) as an electron donor for the heterodisulfide reduction. Therefore MP is able to mediate the electron transport between the membrane-bound enzymes so that the conversion by the proton-translocating electron transport systems [6] can be subdivided in two partial reactions each 
Table 1. Specific activities of the enzymes of the $\mathrm{F}_{420} \mathrm{H}_{2}$ :heterodisulfide oxidoreductase and $\mathrm{H}_{2}$ :heterodisulfide oxidoreductase systems.

\begin{tabular}{|c|c|c|c|}
\hline$\overline{\text { Enzyme }}$ & Electron donor & Electron acceptor & $\begin{array}{l}\text { Spec. activity } \\
{\left[\mathrm{U} \text { mg protein }{ }^{-1}\right]^{[\mathrm{a}]}}\end{array}$ \\
\hline $\begin{array}{l}\mathrm{F}_{420} \mathrm{H}_{2^{-}} \\
\text {dehydrogenase }\end{array}$ & $\mathrm{F}_{420} \mathrm{H}_{2}$ & $\underline{\underline{12}}$ & 0.20 \\
\hline $\begin{array}{l}\mathrm{F}_{420} \mathrm{H}_{2^{-}} \\
\text {dehydrogenase }\end{array}$ & $\mathrm{F}_{420} \mathrm{H}_{2}$ & MP & 0.15 \\
\hline $\begin{array}{l}\text { Membrane-bound } \\
\text { hydrogenase }\end{array}$ & $\mathrm{H}_{2}$ & $\underline{\underline{12}}$ & 2.2 \\
\hline $\begin{array}{l}\text { Membrane-bound } \\
\text { hydrogenase }\end{array}$ & $\mathrm{H}_{2}$ & MP & 3.2 \\
\hline $\begin{array}{l}\text { Heterodisulfide } \\
\text { reductase }\end{array}$ & dihydro-12 & CoB-S-S-CoM & 2.3 \\
\hline $\begin{array}{l}\text { Heterodisulfide } \\
\text { reductase }\end{array}$ & dihydro-MP & CoB-S-S-CoM & 2.6 \\
\hline
\end{tabular}

[a] $1 \mathrm{U}=1 \mu \mathrm{mol}$ substrate converted per minute.

(Scheme 1). In this way methanophenazine $\underline{\underline{\mathbf{1}}}$ was characterized as the first phenazine derivative involved in the electron transport of biological systems. The experiments reported here suggest that its role in the energy metabolism of methanogens is similar to that of ubiquinone in mitochondria and bacteria. 

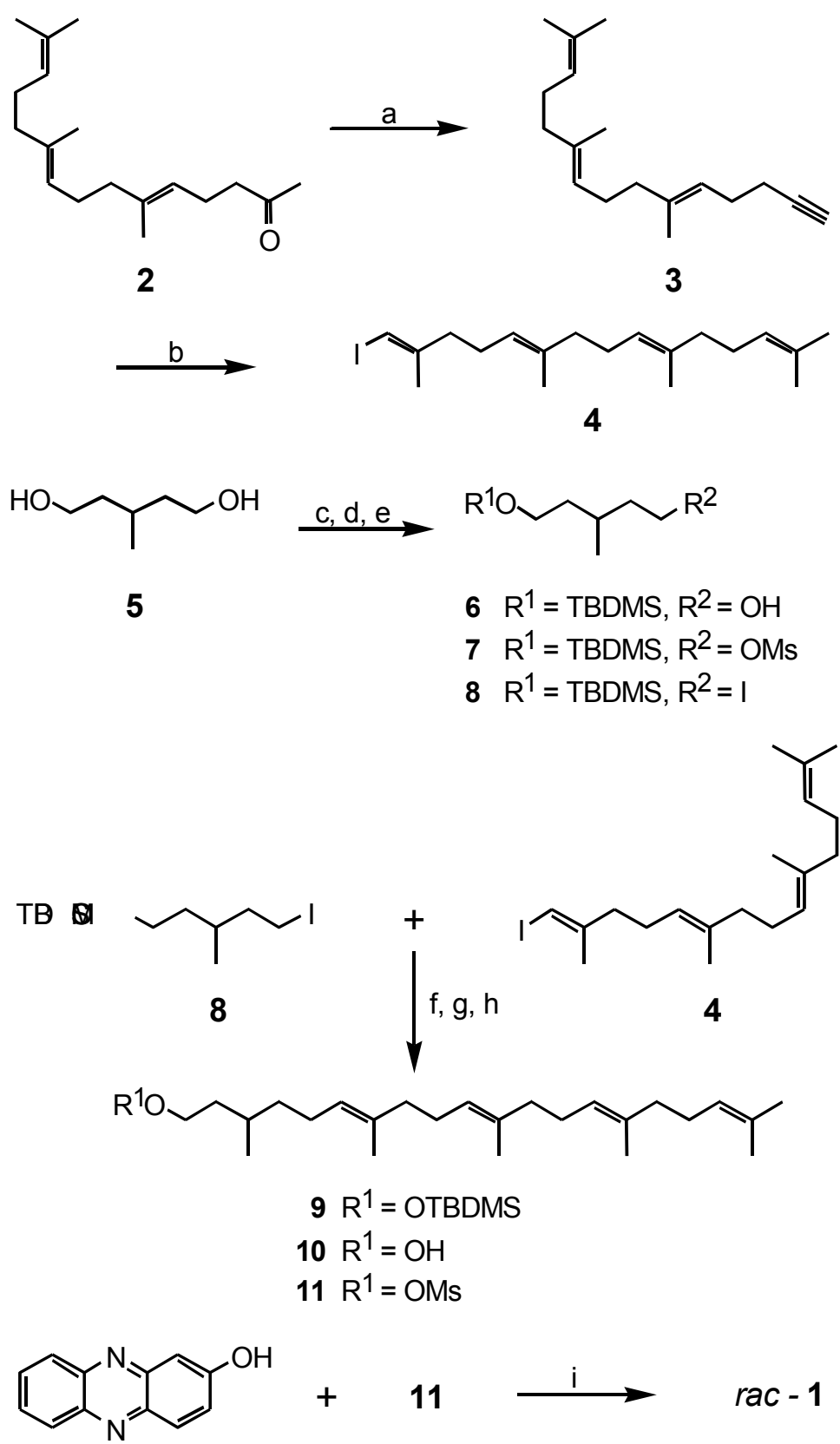

12

Figure 3. Total synthesis of Methanophenazine a) $\mathrm{LiTMP}, \mathrm{THF},-78^{\circ} \mathrm{C} ; \mathrm{ClP}=\mathrm{O}(\mathrm{OEt})_{2},-78^{\circ} \mathrm{C} \rightarrow \mathrm{rt}$; LiTMP, THF, $-78^{\circ} \mathrm{C} \rightarrow \mathrm{rt}, \mathrm{H}_{2} \mathrm{O}, 75 \%$; b) cat. $\mathrm{Cp}_{2} \mathrm{ZrCl}_{2}, \mathrm{Me}_{3} \mathrm{Al}, \mathrm{CH}_{2} \mathrm{Cl}_{2} ; \mathrm{I}_{2}, \mathrm{THF},-30^{\circ} \mathrm{C} \rightarrow \mathrm{rt} ; \mathrm{K}_{2} \mathrm{CO}_{3}$, $\mathrm{H}_{2} \mathrm{O}, 0^{\circ} \mathrm{C}, 74 \%$; c) $\mathrm{NaH}$, TBDMSCl, THF, $83 \%$; d) $\mathrm{NEt}_{3}, \mathrm{MsCl} \mathrm{CH}_{2} \mathrm{Cl}_{2}, 0^{\circ} \mathrm{C}$; e) NaI, acetone, reflux, $93 \%$ for 2 steps; f) $\underline{\underline{8}}+\mathrm{ZnCl}_{2}, \mathrm{Et}_{2} \mathrm{O}, \mathrm{rt} \rightarrow-100^{\circ} \mathrm{C}$, tert-BuLi; $\underline{\underline{4}}+\mathrm{Pd}\left(\mathrm{PPh}_{3}\right)_{4},(0.05$ equiv. $),-70^{\circ} \mathrm{C} \rightarrow \mathrm{rt}, 65 \%$; $\left.\mathrm{g}\right)$ TBAF, THF, rt; h) $\mathrm{NEt}_{3}, \mathrm{MsCl}, \mathrm{CH}_{2} \mathrm{Cl}_{2}, 0^{\circ} \mathrm{C}$; i) $\mathrm{KOH}$, Aliquat, THF $90 \%$ for 3 steps. $\mathrm{Ms}=$ methanesulphonyl, TBDMS $=\underline{\text { tert }}$-butyldimethylsilyl. 


\section{Results}

Methanosarcina mazei Gö1 was grown according to an earlier report ${ }^{[7]}$ and the preparation of cytoplasmic membranes was performed as previously described. ${ }^{[7]}$ Photometrical analysis to determine enzymatic activities were carried out at room temperature in glass cuvettes (1.7 ml) that were gassed with $\mathrm{N}_{2}$ or $\mathrm{H}_{2}$ and closed with rubber stoppers. The optical-enzymatic determination of the $\mathrm{F}_{420} \mathrm{H}_{2}$ dependent reduction of MP and the dihydro-MP dependent heterodisulfide reduction was performed under a nitrogen atmosphere. The cuvette was flushed with hydrogen in order to determine the hydrogen dependent reduction of MP. The reactions were started by adding the respective electron acceptors. Final concentrations of the reactants were: $\mathrm{F}_{420}: 25 \mu \mathrm{M}$; $\underline{\underline{12}}: 25 \mu \mathrm{M}$; MP: $24 \mu \mathrm{M}$ (stock solution in dimethylformamide) and CoB-S-S-CoM: $38 \mu \mathrm{M}$. Protein concentration was $7.5 \mu \mathrm{g}$ membrane protein per $\mathrm{ml}$ assay. Extinction coefficients: $\mathrm{F}_{420}: \varepsilon_{420}=40 \mathrm{mM}^{-1} \mathrm{~cm}^{-1}$; MP: $\varepsilon_{414}=3.17 \mathrm{mM}^{-1} \mathrm{~cm}^{-1} ; \underline{\underline{\mathbf{1 2}}} \varepsilon_{425}=$ $4.5 \mathrm{mM}^{-1} \mathrm{~cm}^{-1}$.

\section{References and Footnotes}

[1] C. R. Woese, O. Kandler, M. L. Wheelis, Proc. Natl. Acad. Sci. USA $\underline{\underline{\mathbf{1 9 9 0}}}$, 87, 45764579 .

[2] R. Conrad, Microbiol. Rev. $\underline{\underline{\mathbf{1 9 9 6}}}, \underline{60}, 609-640$.

[3] R. K. Thauer, Microbiology $\underline{\underline{\mathbf{1 9 9 8}}}, \underline{144}, 2377-2406$.

[4] R. K. Thauer, R. Hedderich, R. Fischer in Methanogenesis (ed.: J. G. Ferry), Chapman \& Hall, New York and London, 1993, p. 209-252.

[5] J. Ellermann, R. Hedderich, R. Böcher, R. K. Thauer, Eur. J. Biochem. 1988, 172, 669677.

[6] U. Deppenmeier, T. Lienard, G. Gottschalk, FEBS Lett. 1999, 457, 291-297.

[7] H.-J. Abken, M. Tietze, J. Brodersen, S. Bäumer, U. Beifuss, U. Deppenmeier, J. Bact. $\underline{\underline{\mathbf{1 9 9 8}}}, \underline{180}, 2027-2032$.

[8] E. Negishi, A. O. King, W. L. Klima, J. Org. Chem. 1980, 45, 2526-2528. 
[9] a) S. V. Ley, A. Armstrong, D. Diez-Martin, M. J. Ford, P. Grice, J. G. Knight, H. C. Kolb, A. Madin, C. A. Marby, S. Mukherjee, A. N. Shaw, , A. M. Z. Slawin, S. Vile, A. D. White, D. J. Williams, M. Woods, J. Chem. Soc. Perkin Trans. I 1991, 667-692.

b) E. Negishi, D. E. Van Horn, A. O. King, N. Okukado, Synthesis 1979, 501-502. c)

D. E. Van Horn, E. Negishi, J. Am. Chem. Soc. $\underline{\underline{\mathbf{1 9 7 8}}}, \underline{100}, 2252-2254$.

[10]P. J. McDougal, J. G. Rico, Y. Oh, B. D. Condon, J. Org. Chem. 1986, 51, 3388-3390.

[11]A. B. Smith III, Y. Qiu, D. R. Jones, K. Kobayashi, J. Am. Chem. Soc. 1995, 117, 1201112012.

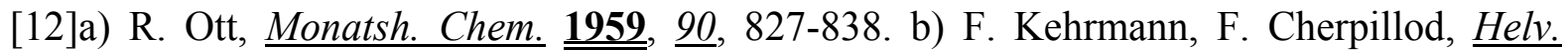

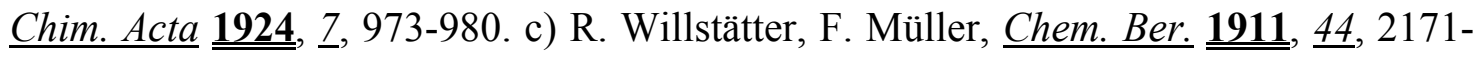
2185.

[13]A. Loupy, J. Sansoulet, F. Vaziri-Zand, Bull. Soc. Chim. Fr. 1987, 1027-1035.

$[14] \mathrm{R}_{\mathrm{f}}=0.51$ (diethyl ether/hexane $\left.=1: 1\right) ;{ }^{1} \mathrm{H}-\mathrm{NMR}\left(500 \mathrm{MHz}, \mathrm{C}_{6} \mathrm{D}_{6}, \mathrm{TMS}\right): \delta=0.83\left(\mathrm{~d},{ }^{3} \underline{J}\right.$ $\left.=6.6 \mathrm{~Hz}, 3 \mathrm{H} ; 3^{\prime}-\mathrm{CH}_{3}\right), 1.14-1.23\left(\mathrm{~m}, 1 \mathrm{H} ; 4^{\prime}-\mathrm{H}_{\mathrm{A}}\right), 1.32-1.39\left(\mathrm{~m}, 1 \mathrm{H} ; 4^{\prime}-\mathrm{H}_{\mathrm{B}}\right), 1.44\left(\mathrm{dt},{ }^{2} \underline{J}\right.$ $\left.=13.5 \mathrm{~Hz},{ }^{3} \underline{J}=6.4 \mathrm{~Hz}, 1 \mathrm{H} ; 2^{\prime}-\mathrm{H}_{\mathrm{A}}\right), 1.56\left(\mathrm{~s}, 3 \mathrm{H} ; 19^{\prime}-\mathrm{CH}_{3}\right), 1.60-1.65\left(\mathrm{~m}, 1 \mathrm{H} ; 3^{\prime}-\mathrm{H}\right)$ superimposed by $1.61,1.62,1.64\left(3 \mathrm{~s}, 3 \mathrm{H}\right.$ each; 7' $\left.-\mathrm{CH}_{3}, 11^{\prime}-\mathrm{CH}_{3}, 15^{\prime}-\mathrm{CH}_{3}\right), 1.68\left(\mathrm{~d},{ }^{4} \underline{J}\right.$ $\left.=0.8 \mathrm{~Hz}, 3 \mathrm{H} ; 20^{\prime}-\mathrm{H}_{3}\right), 1.72\left(\mathrm{ddt},{ }^{2} \underline{J}=13.5 \mathrm{~Hz},{ }^{3} \underline{J}=5.4 \mathrm{~Hz},{ }^{3} \underline{J}=6.8 \mathrm{~Hz}, 1 \mathrm{H} ; 2^{\prime}-\mathrm{H}_{\mathrm{B}}\right)$, 1.97-2.27 (m, 14H; 5'- $\left.\mathrm{H}_{2}, 8^{\prime} \mathrm{H}_{2}, 9^{\prime} \mathrm{H}_{2}, 1^{\prime}{ }^{\prime}-\mathrm{H}_{2}, 13^{\prime}-\mathrm{H}_{2}, 16^{\prime}-\mathrm{H}_{2}, 17^{\prime}-\mathrm{H}_{2}\right), 3.79$ (dt, ${ }^{2} \underline{J}=$ $10.7 \mathrm{~Hz},{ }^{3} \underline{J}=6.8 \mathrm{~Hz}, 1 \mathrm{H} ; 1$ '- $\left.-\mathrm{H}_{\mathrm{A}}\right), 3.81\left(\mathrm{dt},{ }^{2} \underline{J}=10.7 \mathrm{~Hz},{ }^{3} \underline{J}=6.4 \mathrm{~Hz}, 1 \mathrm{H} ; 1^{\prime}-\mathrm{H}_{\mathrm{B}}\right), 5.25$ $\left(\mathrm{tt},{ }^{3} \underline{J}=6.9 \mathrm{~Hz},{ }^{4} \underline{J}=1.4 \mathrm{~Hz}, 1 \mathrm{H} ; 18^{\prime}-\mathrm{H}\right), 5.28-5.38$ (m, 3H; 6’-H, 10'-H, 14'-H), 7.29 $\left(\mathrm{ddd},{ }^{3} \underline{J}=8.6 \mathrm{~Hz},{ }^{3} \underline{J}=6.8 \mathrm{~Hz},{ }^{4} \underline{J}=1.6 \mathrm{~Hz}, 1 \mathrm{H} ; 7-\mathrm{H}\right.$ or $\left.8-\mathrm{H}\right), 7.32\left(\mathrm{dd},{ }^{3} \underline{J}=9.6 \mathrm{~Hz}, \underline{J}=\right.$ $2.8 \mathrm{~Hz}, 1 \mathrm{H} ; 3-\mathrm{H}), 7.35\left(\mathrm{ddd},{ }^{3} \underline{J}=8.6 \mathrm{~Hz},{ }^{3} \underline{J}=6.8 \mathrm{~Hz},{ }^{4} \underline{J}=1.6 \mathrm{~Hz}, 1 \mathrm{H} ; 8-\mathrm{H}\right.$ or $\left.7-\mathrm{H}\right)$, $7.53\left(\mathrm{~d},{ }^{4} \underline{J}_{1,3}=2.8 \mathrm{~Hz}, 1 \mathrm{H} ; 1-\mathrm{H}\right), 8.12\left(\mathrm{~d},{ }^{3} \underline{J}=9.6 \mathrm{~Hz}, 1 \mathrm{H} ; 4-\mathrm{H}\right), 8.30\left(\mathrm{dd},{ }^{3} \underline{J}=8.6 \mathrm{~Hz}\right.$, ${ }^{4} \underline{J}=1.6 \mathrm{~Hz}, 1 \mathrm{H} ; 6-\mathrm{H}$ or $\left.9-\mathrm{H}\right), 8.31\left(\mathrm{dd},{ }^{3} \underline{J}=8.6 \mathrm{~Hz},{ }^{4} \underline{J}=1.6 \mathrm{~Hz}, 1 \mathrm{H} ; 6-\mathrm{H}\right.$ or $\left.9-\mathrm{H}\right) ;{ }^{13} \mathrm{C}-$ NMR (125 MHz, $\left.\mathrm{C}_{6} \mathrm{D}_{6}\right): \delta=16.12,16.13,16.15\left(7^{\prime}-\mathrm{CH}_{3}, 11^{\prime}-\mathrm{CH}_{3}, 15^{\prime}-\mathrm{CH}_{3}\right), 17.73$ $\left(19^{\prime}-\mathrm{CH}_{3}\right), 19.56\left(3^{\prime}-\mathrm{CH}_{3}\right), 25.78$ (C-20'), 25.83 (C-5'), 27.11, 27.12, 27.23 (C-9', C13', C-17'), 29.80 (C-3'), 36.01 (C-2'), 37.45 (C-4'), 40.20, 40.23 (C-8', C-12', C16'), 66.91 (C-1'), 105.80 (C-1), 124.73, 124.77, 124.93, (C-10', C-14', C-18'), 125.04 (C-6’), 126.29 (C-3), 128.29 (C-7 or C-8), 129.58 (C-8 or C-7), 130.15 (C-6 or C-9), 130.27 (C-9 or C-6), 131.08 (C-19'), 131.30 (C-4), 134.99, 135.04, 135.09 (C-7', C11', C-15'), 141.36 (C-4a), 142.63 (C-5a or C-9a), 144.12 (C-9a or C-5a), 145.89 (C- 
10a), 160.78 (C-2); IR(film): $\widetilde{v}=3059 \mathrm{~cm}^{-1}$ (CH, olefinic), 2954, 2924, 2853 (CH, aliphat.), 1632, 1605, 1560, $1518(\mathrm{C}=\mathrm{C}), 1483,1445\left(\mathrm{CH}_{2}, \mathrm{CH}_{3}\right), 1380,1360\left(\mathrm{CH}_{3}\right)$, 1196 (C-O-C), 828, 757 (C=C, arom.); UV(CH $3 \mathrm{CN}): \lambda_{\max }(\lg \varepsilon)=388$ (3.72), 355 (3.78), $256 \mathrm{~nm}$ (4.71); $\mathrm{MS}(70 \mathrm{eV}): \underline{m / z}(\%): 538(100)\left[\underline{M}^{+}\right], 470(6)\left[\left(\underline{M}^{+}-\mathrm{C}_{5} \mathrm{H}_{8}\right], 402\right.$ (8) $\left[470-\mathrm{C}_{5} \mathrm{H}_{8}\right], 334$ (20) [402- $\left.\mathrm{C}_{5} \mathrm{H}_{8}\right], 265$ (4) [334- $\left.\mathrm{C}_{5} \mathrm{H}_{9}\right], 196(82)\left[\mathrm{C}_{12} \mathrm{H}_{8} \mathrm{~N}_{2} \mathrm{O}^{+}\right], 168$ (7) [196-CO]; HR-MS: calculated for $\mathrm{C}_{37} \mathrm{H}_{50} \mathrm{~N}_{2} \mathrm{O}$ : 538.3923; found: 538.3923 . 


\title{
Chapter 5
}

\section{Identification and analysis of proton-translocating pyrophosphatases in the methanogenic archaeon Methanosarcina mazei}

\begin{abstract}
Genome sequence data from the methanogenic archaeon Methanosarcina mazei Gö1 revealed the existence of two different open reading frames encoding proton-translocating pyrophosphatases (PPases). They are linked by a 750-bp intergenic region containing TC rich stretches and are transcribed in opposite directions. The corresponding polypeptides were referred to as Mvp1 and Mvp2 consisting of 671 and 676 amino acids, respectively. Both enzymes represent extremely hydrophobic, membrane integral proteins with 15 predicted transmembrane segments and an overall amino acid sequence similarity of $50.1 \%$. Multiple alignments revealed that the PPase isoenzymes from Ms. mazei might have different phylogenetic backgrounds. Mvp1 is closely related to eukaryotic PPases whereas Mvp2 belongs to the bacterial PPase lineage. Northern blot experiments using RNA from methanolgrown cells harvested in the mid-log growth phase indicated that only Mvp2 was produced under these conditions. The enzyme had a specific activity of $0.34 \mathrm{U} / \mathrm{mg}$ protein when washed membranes were analyzed. Proton translocation experiments with inverted membrane vesicles prepared from methanol-grown cells showed, that pyrophosphate hydrolysis was coupled to the translocation of about one proton across the cytoplasmic membrane. Conditions for the expression of $m v p 1$ could not be found so far. The pyrophosphatases of Ms. mazei Gö1 represent the first examples of this class of enzymes in methanogenic archaea and might be part of their energy conserving system.
\end{abstract}




\section{Introduction}

Inorganic pyrophosphate (PPi) is formed in several enzymatic reactions of various metabolic pathways (e.g. deoxyribonuleic acid and ribonuleic acid polymerisation, amino acid- and fatty acid activation). PPi is supposed to be hydrolyzed subsequently by the catalytic activity of pyrophosphatases to shift the overall reaction equilibrium towards product formation. According to Rea and Sanders (1) this assumption may be too restrictive because a considerable amount of metabolic energy is lost and released as heat. Instead, it might be possible that the pyrophosphatases provide a portion of the anhydride bond energy for the generation of a transmembrane proton gradient.

Two families of pyrophosphate cleaving enzymes were identified in the three domains of life. The first class encompasses a wide variety of soluble, cytoplasmic enzymes which are not involved in energy conservation (2). The second class comprises tightly membrane-bound pyrophosphatases, which were first isolated from vacuole membranes of higher plants and alga (3). These enzymes translocate protons across the vacuolar membrane thereby maintaining the acidic vacuolar interior millieu. Proton-translocating pyrophosphatases were also found in the cytoplasmic membrane of several bacteria such as Rhodospirillium rubrum (4), Thermotoga maritima (5), Streptomyces coelicolor (6), Synthrophus gentiana (7) and in the hyperthermophilic archaeon Pyrobaculum aerophilum (8).

In this report we show that proton-translocating pyrophosphatases are also present in the methanogenic archaeon Methanosarcina mazei Gö1. This organism derives its metabolic energy from the conversion of $\mathrm{H}_{2} / \mathrm{CO}_{2}$, acetate, methanol or methylamines to methane. Redox-reactions involved in the process of methanogenesis are partly catalyzed by membrane-bound enzymes that generate or use electrochemical ion gradients (9). The $\mathrm{H}_{2}$ :heterodisulfide oxidoreductase and the $\mathrm{F}_{420} \mathrm{H}_{2}$ :heterodisulfide oxidoreductase are novel electron transport systems which are able to generate a proton motive force by redox-driven $\mathrm{H}^{+}$-translocation (10). The electrochemical proton gradient is used for ATP-synthesis by a membrane-bound $\mathrm{A}_{1} \mathrm{~A}_{0}$-ATP synthase (11). The pyrophosphatases found in Ms. mazei Gö1 
represent a further class of proton translocating enzymes in methanogens and might be involved in a new energy conserving system.

\section{Materials and Methods}

Growth of cells and preparation of washed vesicles. Ms. mazei Gö1 (DSM 3647) was grown in 1-1 glass bottles or, for mass culturing, in 20-1 carboys on $150 \mathrm{mM}$ methanol in a medium described previously (12), supplemented with $1 \mathrm{~g} / 1$ of sodium acetate. Washed inverted vesicles of strain Gö1 were prepared according to Ide et al. (13) with the exception that the final protein concentration was $10-15 \mathrm{mg} / \mathrm{ml}$.

Preparation of washed membranes. Washed membranes from Ms. mazei were prepared according to Abken and Deppenmeier (14).

Measurement of Proton translocation. Proton translocation was monitored as described previously (13). In principal a nitrogen-gassed reaction vessel $(11 \mathrm{ml})$ was filled with $3 \mathrm{ml} 40$ $\mathrm{mM}$ KSCN solution containing $0.5 \mathrm{M}$ sucrose, $1 \mathrm{mg} / \mathrm{ml}$ resazurin and $10 \mathrm{mM}$ dithioerythritol, followed by the addition of 50-80 $\mu$ l washed inverted vesicles $(1-1.4 \mathrm{mg}$ protein/assay). Proton uptake coupled to pyrophosphate cleavage was followed by the addition of 5 - $40 \mathrm{nmol}$ Na-pyrophosphate (20 $\mathrm{mM}$ aqueous stock solution) using a sensitive $\mathrm{pH}$ electrode connected to a chart recorder. After finishing the experiments the $\mathrm{pH}$ changes were calibrated with standard solutions of $\mathrm{HCl}$ or $\mathrm{NaOH}$. The uncoupler SF6847 was added as an ethanolic solution to final conc. of $12 \mathrm{nmol} / \mathrm{mg}$ membrane protein where indicated.

Determination of the cytoplasmic phosphate concentration. 5-ml cultures of Ms. mazei were harvested in the exponential growth phase and washed three times with $25 \mathrm{mM}$ MOPS plus $0.5 \mathrm{M}$ sucrose to remove phosphate contaminations. After sonication the protein was precipitated by heating at $100{ }^{\circ} \mathrm{C}$ for $5 \mathrm{~min}$ and removed by centrifugation. The supernatant was used for determination of the cytoplasmic phosphate concentration. 
Enzyme Activity Assays. Enzyme activity of the PPase was determined in $1.8 \mathrm{ml}$ glass vessels containing $25 \mathrm{mM}$ MOPS buffer $\mathrm{pH} 7$ and washed membranes (approx. $1 \mathrm{mg}$ membrane protein). $\mathrm{Na}$ pyrophosphate and $\mathrm{MgCl}_{2}$ were added from a $0.1 \mathrm{M}$ aqueous stock solution. Membranes and $\mathrm{MgCl}_{2}$ were preincubated at $37{ }^{\mathrm{O}} \mathrm{C}$ and the reaction was started by the addition of pyrophosphate. To examine PPi hydrolysis $50 \mu l$ samples were withdrawn and added to $10 \mu \mathrm{l}$ conc. $\mathrm{HClO}_{4}$ to stop enzyme activity. Precipitated protein was removed by centrifugation. The release of free phosphate due to a pyrophosphate hydrolysis was monitored by a method described by Saheki (15) with the following specifications: $25-\mu 1$ samples prepared as described above were added to $750 \mu 1$ of a $15 \mathrm{mM}$ ammonium molybdate / $70 \mathrm{mM}$ zinc acetate solution $(\mathrm{pH} 5.0 \mathrm{HCl}$ ) and reduced by $250 \mu \mathrm{l}$ of a freshly prepared $10 \%$ sorbic acid solution $(\mathrm{pH} 5.0 \mathrm{NaOH})$. After incubation for $20 \mathrm{~min}$. the samples were measured at $850 \mathrm{~nm}$ against a phosphate blank sample. Concentrations were calculated from a standard curve $0-250 \mu \mathrm{M} \mathrm{KH}{ }_{2} \mathrm{PO}_{4}$.

Construction of ${ }^{32}$ P-labeled probes and northern blot analysis. For the construction of specific DNA probes for expression studies of the pyrophosphatases from Ms. mazei Gö1 non-homologous sequence regions of $m v p 1$ (probe 1: bp 743-1089) and $m v p 2$ (probe 2: bp 710-1035) were amplified by PCR, respectively, using chromosomal DNA as template. The DNA fragments were isolated from a $0.8 \%$ agarose gel and purified by a gel extraction kit (Qiaex II, Qiagen). Radiolabeling with [ $\alpha-32$ P]dATP (Hartmann, Braunschweig, Germany) was done by using a random primer labeling kit (Boehringer, Mannheim, Germany), and the labeled probes were purified by gel chromatography (NAP 10, Pharmacia, Uppsala, Sweden). Total cellular RNA was prepared from methanol-grown Ms. mazei strain Gö1 (harvested in the mid-log phase) using a RNA isolation kit (RNeasy, Qiagen) according to the manufacturer's instructions. Northern blot analysis was done as described previously (16). 


\section{Results}

Molecular biological analysis. DNA sequence data from the Ms. mazei Gö1 genome project (Göttingen Genomics Laboratory) revealed two different open reading frames encoding hypothetical plant V-type pyrophosphatase homologues ${ }^{2}$. The genes were designated $m v p 1$ and $m v p 2$ ( $m v p$ for Methanosarcina vacuolar-type pyrophosphatase). They are linked by a 750-bp intergenic region containing TC rich stretches and are transcribed in opposite directions (Fig. 1). Typical archaeal promoter sequences of the TATA-box initiator type (17) were found upstream of both genes. Bacterial-type ribosomal binding sites immediately preceded the genes.
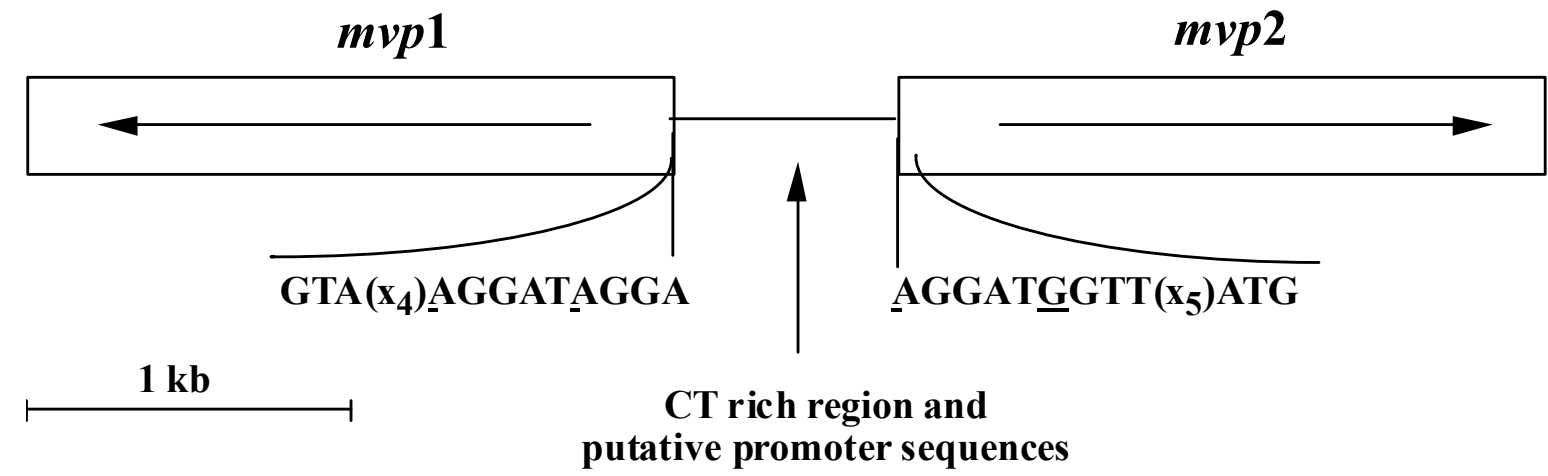

Figure 1: Organization of genes encoding $\mathbf{H}^{+}$-translocating pyrophosphatases in $M$ s. mazei Gö1. Base pairs contributing to the RBS are underlined $\left({ }^{\mathrm{A}} / \mathrm{GGG}^{\mathrm{A}} / \mathrm{GGGTG}^{\mathrm{A}} / \mathrm{G}=\right.$ consensus sequence of the ribosome binding site in Ms. mazei); black arrows indicate the direction of transcription of $m v p 1$ and $m v p 2$.

The deduced polypeptides of $m v p 1$ (N-terminus MERLIFT) and $m v p 2$ (N-terminus MDMLIY) consist of $671(69.1 \mathrm{kDa})$ and 676 amino acids $(69.2 \mathrm{kDa})$, respectively. Both enzymes represent extremely hydrophobic, membrane integral proteins with 15 predicted transmembrane segments. The overall amino acid sequence similarity was $50.1 \%$. The deduced amino acid sequences of $m v p 1$ and $m v p 2$ were compared to $\mathrm{H}^{+}$-PPases from other 
organisms. Alignments indicated similarities in the range of 35.5 to $50.6 \%$. For Mvp1 highest scores were obtained for the gene products of the eukaryotes Acetabularia mediterana (50.6\%), Nicotiana tabacum (45.1\%) and Chara corallina (45.4\%). In contrast, Mvp2 showed highest similarities to the PPases from the bacterium Rhodospirillium rubrum (45.6 \%) and the archaeon Pyrobaculum aerophilum (42.9\%).

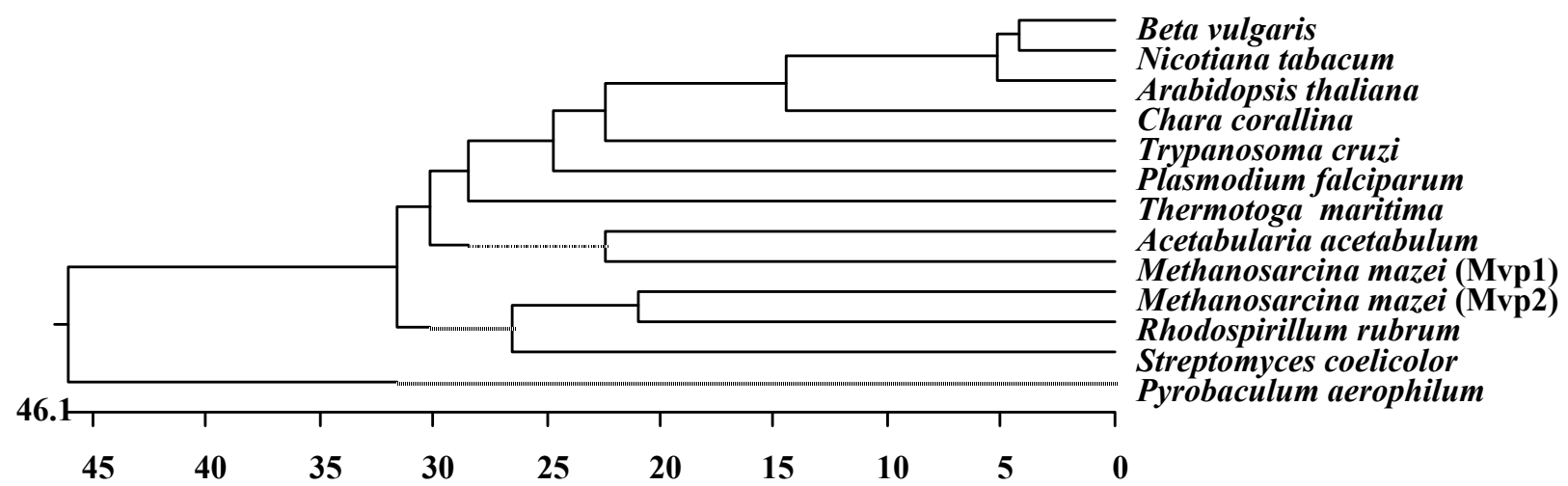

Figure 2: Sequence distances of proton-translocating pyrophosphatases. The phylogenetic tree was generated with the program MegAlign using the Clustal method (residue weight table PAM 250). NCBI accession No.: Acetabularium mediterrana, D88820; Arabidopsis thaliana, AB015138; Beta vulgaris, L32791; Plasmodium falciparum, AF115766; Pyrobaculum aerophilum AF182812; Rhodospirillum rubrum, AF035636; Streptomyces coelicolor, AL035636; Thermotoga maritima, D72409; Trypanosoma cruzi, AF159881.

To obtain information about the possible evolution of the Ms. mazei PPases the phylogenies of the protein sequences were estimated using the program ClustalX. As is apparent from Fig. 2 the PPases from eukarya and Thermotoga maritima cluster together with Mvp1, the nearest relative being the marine algae Acetabularia. The isoenzyme Mvp2 branches off separately and is located in the same cluster as the PPase from the bacterial organisms Rhodospirillum rubrum and Streptomyces coelicolor. The enzyme from Pyrobaculum represents the deepest branch and is separated form all other proteins analyzed. These 
findings might indicate that the $\mathrm{H}^{+}$-PPase isoenzymes form Ms. mazei have different phylogenetic backgrounds with Mvp1 closely related to eukaryotic PPases and Mvp2 falling into the bacterial lineage.

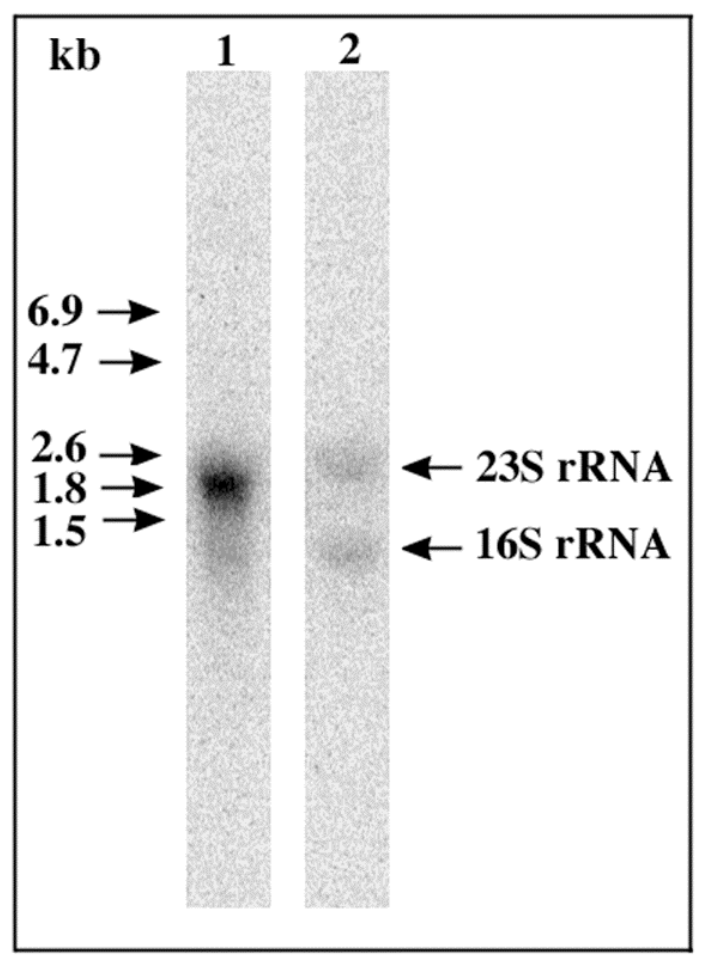

Figure 3: Analysis of expression of mvp1 and mvp2 from Ms. mazei Gö1. Northern blotting was performed using total RNA from methanol grown cells. Each lane contained $5 \mu \mathrm{g}$ RNA. The blots were hybridized with probes specific for $m v p 2$ (lane 1) and $m v p 1$ (lane 2), respectively.

Expression analysis. For analysis of the expression pattern of $m v p 1$ and $m v p 2$ specific DNA probes from both genes were synthesized by polymerase chain reaction using chromosomal DNA as template. In parallel, total RNA was isolated from methanol-grown cells and was used for northern blots analysis. One major signal with a size of $1.8 \mathrm{~kb}$ was obtained when RNA from these cells was hybridized with the mvp2-specific probe (Fig. 3). No specific signals were found with the $m v p 1$-probe. The weak signals at 2.5 and $1.4 \mathrm{~kb}$ are probably caused by an unspecific binding to the $23 \mathrm{~S}$ rRNA and the 16s rRNA, respectively (16). 
Because the transcript of $m v p 2$ has a length of $1.8 \mathrm{~kb}$, it is evident that only this gene is expressed with methanol as growth substrate. It is to note that the following experiments were performed exclusively with methanol-grown cells harvested in the mid-log phase. As described above only Mvp2 was produced under these conditions. Thus, pyrophosphatase activity was caused by this enzyme and an interference with Mvp1 took not place.

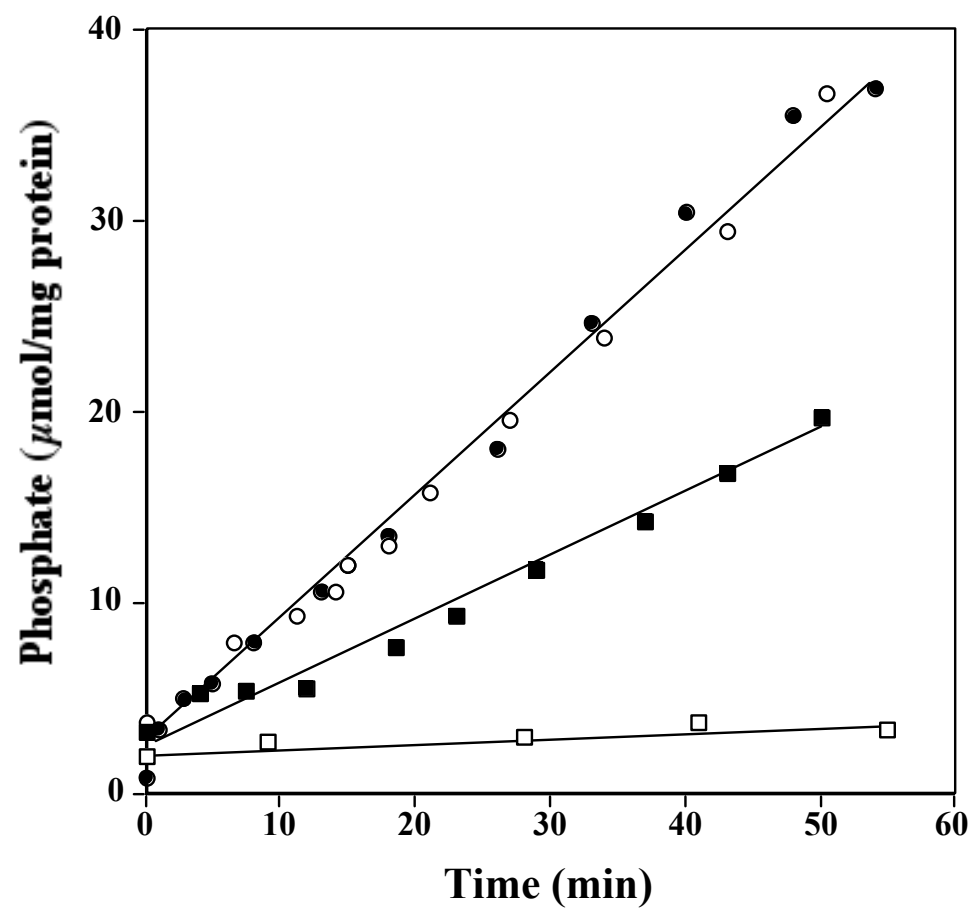

Figure 4: Magnesium ion dependence of Pi formation from PPi hydrolysis as catalyzed by washed cytoplasmic membranes from Ms. mazei Gö1. The amount of PPi hydrolyzed was determined by analysis of the phosphate concentration in the reaction mixture as described in Materials and Methods. ( $\square$ ) no addition of $\mathrm{Mg}^{2+}$. Addition of $\mathrm{Mg}^{2+}$ to a final concentration of $1 \mathrm{mM}(\square), 2 \mathrm{mM}(\mathrm{O})$ and $3 \mathrm{mM}(\bigcirc)$. 
Biochemical analysis. To determine the cellular localization of the pyrophosphatase cell-free extracts of Ms. mazei Gö1 were centrifuged at 120.000 x g for two hours. It was found that almost $100 \%$ of the PPase activity was present in the pellet which was resuspended and centrifuged at $100000 \mathrm{x}$ g. Again almost $100 \%$ of the PPi-hydrolyzing activity was detected in the membraneous fraction, indicating that the enzyme is located in the cytoplasmic membrane. The activity of the membrane-bound PPase depended linearly on the concentration of membrane protein up to $1 \mathrm{mg} / \mathrm{ml}$ (not shown). Furthermore, the enzyme was air-stable for several hours. The protein showed maximal activity $(0.34 \mu \mathrm{mol}$ PPi hydrolyzed $\mathrm{x} \min ^{-1} \mathrm{x} \mathrm{mg}$ membrane protein ${ }^{-1}$ ) when $4 \mathrm{mM} \mathrm{PPi}$ and at least $2 \mathrm{mM} \mathrm{Mg}{ }^{2+}$ were added to the reaction mixture (Fig. 4). Lower concentrations of these ions led to a decrease of the reaction rate. As already described for other PPases (18) the Mvp2 protein was inhibited by DCCD indicated by $\mathrm{IC}_{50}$ values of $1.5 \mu \mathrm{mol}$ DCCD per mg membrane protein (not shown).

In addition to $m v p 1$ and $m v p 2$ the genome sequencing of $M s$. mazei revealed the presence of a gene encoding a soluble pyrophosphatase (GenBank Acc-No. AF312700). However, the cytoplasmic fraction did not contain any PPase activity. Thus, a soluble PPi-hydrolyzing enzyme was obviously not produced when cells were grown on methanol and harvested in the mid-log phase.

Multialignments and the biochemical analysis indicated that Mvp2 is a membrane-bound, proton translocating pyrophosphatase. To verify this hypothesis washed inverted vesicles from Ms. mazei Gö1 were tested for their ability to couple PPi hydrolysis with the transfer of protons across the cytoplasmic membrane. Therefore, concentrated vesicles were diluted with a sucrose/thiocyanate solution under an atmosphere of molecular nitrogen and were pulsed with PPi as shown in Fig. 5. When the substrate was added, a short period of alkalinization of the medium was monitored which is due to a rapid proton movement into the lumen of the inverted vesicles. In the second phase a reacidification was observed until a stable $\mathrm{pH}$-value was reached again. It is thought that the consumption of PPi is responsible for this effect leading to a decay of the generated $\Delta \mu_{\mathrm{H}^{+}}$by passive diffusion of protons back to the medium. 
The addition of the protonophore SF 6847 led to a complete inhibition of reversible alkalinization, indicating that protons function as coupling ions (Fig. 5). After calibration of the system the extent of $\mathrm{H}^{+}$transfer was calculated from more than 30 experiments resulting in an average ratio of $0.47 \pm$

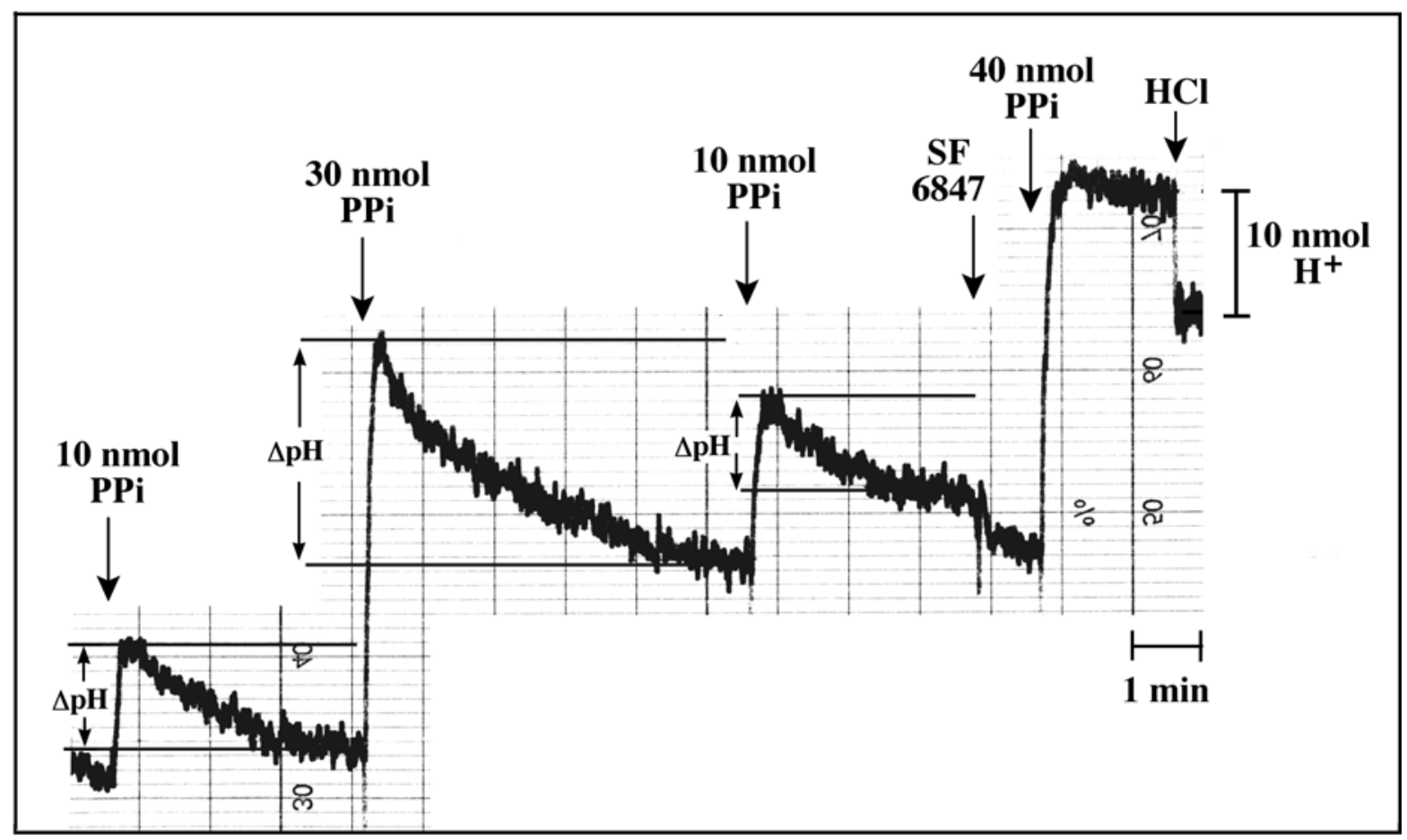

Figure 5: Proton translocating activity of washed inverted vesicles of Ms. mazei in the presence of PPi. The experiments were performed as described in Materials and Methods. The amount of translocated protons was calculated from the difference between maximal alkalinization and the final base line after reacidification as indicated for each experiment (small black arrows). The difference between the starting baseline and the final baseline was due to alkalinization by the addition of PPi to the weakly buffered reaction mixture. The system was calibrated by injection of $10 \mathrm{nmol} \mathrm{HCl}$

0.12 protons translocated per PPi hydrolyzed. Taking into account that about $50 \%$ of the membrane structures present in the vesicle preparations are unable to establish a proton gradient (10), the hydrolysis of one mol PPi is coupled to the translocation of about $1 \mathrm{~mol}$ of protons. 


\section{Discussion}

Energetic considerations. The process of methanogenesis in Ms. mazei is not coupled to substrate-level phosphorylation. Instead, it has been shown that energy is conserved by a chemiosmotic mechanism (10). The membrane-bound electron transport system of this organism is able to translocate four mol of protons in the course of the generation of one mol $\mathrm{CH}_{4}$. Thus, it is evident that Ms. mazei has only limited abilities for the generation of electrochemical ion gradients. In 1988 Keltjens et al. (19) reported that methane formation is coupled to PPi synthesis in Methanobacterium thermoautotrophicum. However, later on it was shown by Ellermann et al. (20) that these experiments were not reproducible. In accordance to the latter findings methanogenesis from methanol $+\mathrm{H}_{2}$ as catalyzed by washed cells suspensions of Ms. mazei Gö1 was not coupled to the synthesis of PPi (not shown). Irrespective of this controversy it is evident that several core biosynthetic pathways generate PPi (e. g. DNA and RNA synthesis, amino acid activation, polysaccharide synthesis and formation of fatty acyl-CoA (3)). Thus, the idea that PPi may function as an energy-rich intermediate for ATP synthesis is reasonable. This hypothesis is supported by the finding that the PPi concentration in the cytoplasm of Ms. mazei Gö1 is very low $(<0.2 \mathrm{mM})$ despite the fact that soluble PPase activity is lacking. Thus, the membrane-bound PPases might be the only enzymes responsible for the disposal of cytosolically produced PPi, thereby pulling the biosynthetic reactions to completion. In addition, the enzymes salvage a portion of the free energy of PPi hydrolysis by proton translocation. The actual free energy change for PPi hydrolysis in the cytoplasm has been calculated to be $27.3 \mathrm{~kJ} / \mathrm{mol}$ at $\mathrm{pH} 7.3$ (21). The proton potential that can be established by a given proton pump depends on the free-energy change of the driving reaction and on the number of protons transported per cycle $(\Delta \mathrm{G}=\mathrm{n} \cdot \mathrm{F} \cdot \Delta \mathrm{p})$. It was shown that $\Delta \mathrm{p}$ of Ms. mazei is in the range of $-150 \mathrm{mV}$ (22). Thus, for the translocation of $1 \mathrm{~mol} \mathrm{H}^{+}$a free energy change of at least $14.6 \mathrm{~kJ}$ is necessary. Taking the above-mentioned $27.3 \mathrm{~kJ} / \mathrm{mol}$ into account, PPi hydrolysis coupled to $\mathrm{H}^{+}$-transfer is still an exergonic process which is able to function as a driving force for biosynthetic reactions. The advantage of a membrane-integral PPase is that some of the energy is conserved as a 
transmembrane electrochemical proton gradient in comparison to soluble PPases which merely thermally dissipate all free energy.

Putative enzyme structure and sequence characteristics. Sequence comparison, computerassisted topological and functional analysis, demonstrate that the $m v p 2$ encoded enzyme of Ms. mazei belongs to the membrane-associated $\mathrm{H}^{+}$-translocating type of PPases. The gene $m v p 1$ was not expressed in methanol-grown cells but multiple alignments of the deduced amino acid sequence showed that the protein also belongs to this class of enzymes. The most thoroughly investigated $\mathrm{H}^{+}$-translocating PPases are those found in the vacuolar membranes of plant cells (3) and the cytoplasmic membranes of the photosynthetic bacterium Rhodospirillum rubrum (4). Structural studies indicate that these enzymes are composed of only one subunit with a molecular mass of 67.5 to $80.8 \mathrm{kDa}$ (3). Evidence for the presence of $\mathrm{H}^{+}$-translocating PPases were also found in several other organisms such as the thermophilic bacterium Thermotoga maritima (5), the marine algae Acetabularia mediterranea (23), the parasitic protist Trypanosoma cruzi (NCBI Acc. No. AAF80381), the malaria parasite Plasmodium falciparum (24), the synthrophic bacterium Syntrophus gentianae (7) and the soil bacterium Streptomyces coelicolor (6). Recently, Drozdowicz et al. described a vacuolartype membrane pyrophosphatase from the hyperthermophilic archaeon Pyrobaculum aerophilum (8). It is the first report about this category of pump in an archaeon indicating that these proteins are distributed among all three domains of live. Support in favor of this assumption is the discovery of PPase-orthologs in the methanogenic archaeon Ms. mazei. Interestingly, genes encoding $\mathrm{H}^{+}$-PPases are not present in the genomes of Methanobacterium thermoautotrophicum and Methanococcus jannaschii $(25,26)$. Moreover, it is not found in the sulfate-reducing archaeon Archaeoglobus fulgidus (27) which is a close relative of Ms. mazei.

The deduced amino acid sequences of $m v p 1$ and $m v p 2$ possess most of the structural features characteristic of PPases (Fig. 6). Because of the evolutionary distance of methanogenic archaea and other organisms containing PPases the evaluation of highly conserved amino 
acid sequences might contribute to the identification of sequence motifs likely involved in core catalysis by all V-PPases.

Using the TopPredII program 16 transmembrane helices for both Mvp1 and Mvp2 were predicted. The residues 656 to 676 at the C-terminus first fulfilled the requirements of a transmembrane $\alpha$-helix. However, as pointed out by Drozdowicz et al. (8) this structure is unlikely because protein fusions with apoaequorin and the C-terminus of the vacuolar PPase in transgenic Arabidopsis plants indicated that this part of the enzyme is located in the cytoplasm (28). Moreover, antibody binding to this segment caused hindrance of PPi hydrolysis. Therefore, it was supposed that it is close to the catalytic site of the cytoplasmic loop 3 (29). Considering the fundamental correspondence of the putative topology of Mvp1 and Mvp2 to that of other V-PPases a basic uniformity of secondary structure is most possible (30). Therefore, the C-terminus of the methanogenic proteins may also form a helixlike structure in the cytoplasm. In summary, Mvp2 (Fig. 6) is predicted to form 15 transmembrane spans which are connected by large cytoplasmic loops and relatively small outside loops. A multiple alignment of PPase sequences from eukarya (Arabidopsis, Beta, Acetabularia, Plasmodium), bacteria (Rhodospirillum, Streptomyces, Thermotoga) and archaea (Pyrobaculum, Ms. mazei Mvp1 and Mvp2) was performed (not shown) and conserved residues are shown in white on a black background in Fig. 6.

The greatest similarities between the enzymes were detected within the hydrophilic loops III and VI with cytoplasmic orientation and the C-terminal tail which are probably part of the substrate-binding and hydrolysis domain or contribute to it (29). Moreover, there are highly conserved Gly residues in Helix 3, 4, 5, 9, 13 and 15 which might be responsible for a tight localization of the corresponding helices.

Furthermore, several sequence motifs and residues assumed or demonstrated to be essential for catalysis by plant PPases are also present in the methanogenic enzymes. By comparison of 

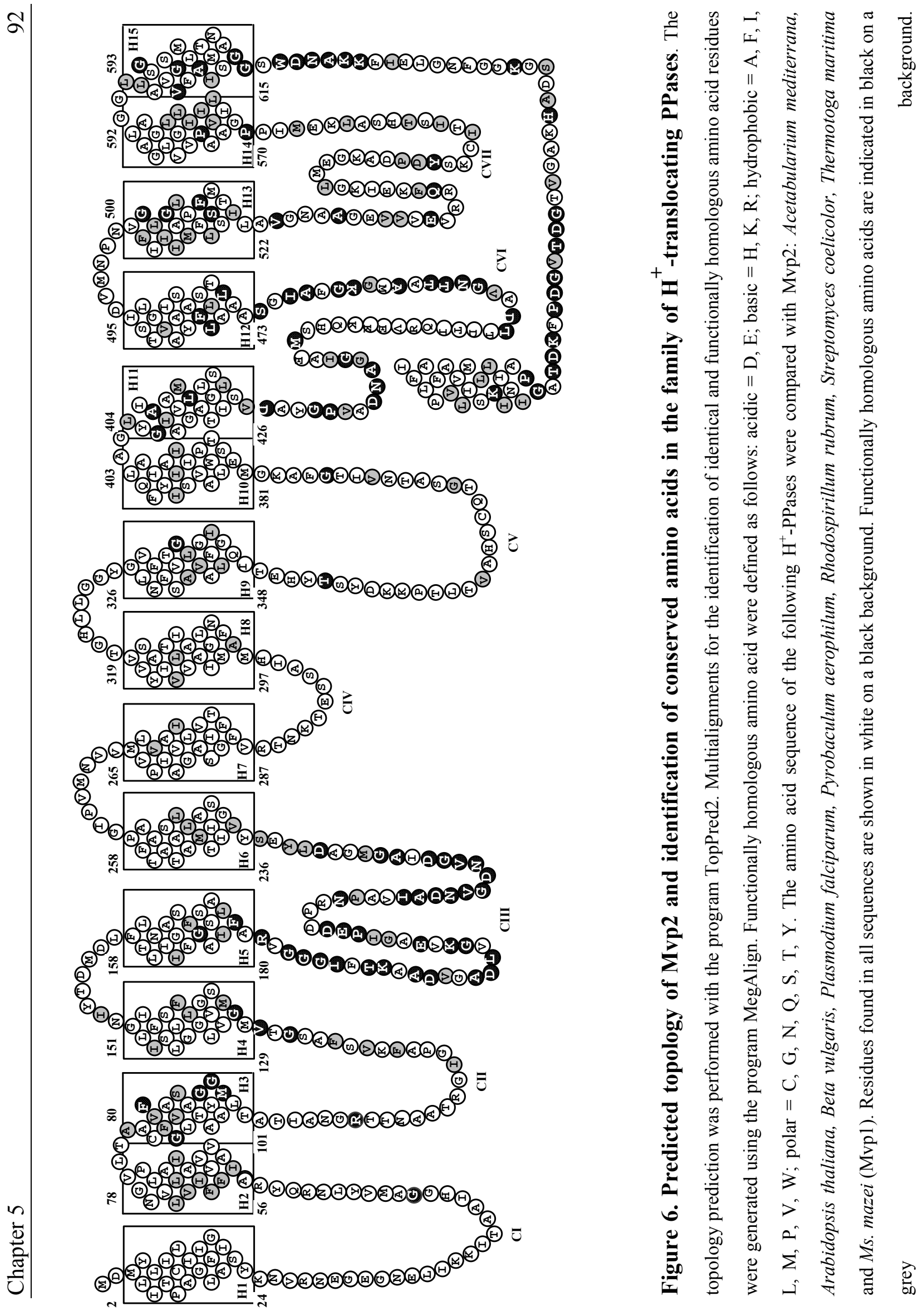
$\mathrm{H}^{+}$-PPases one remarkably conserved segment has been detected (3). It is located in the cytosolic loop III and contained the putative catalytic motif $\mathrm{Dx}_{7} \mathrm{KxE}$ found in soluble and membrane-associated PPases (31). The sequence TKAADVGADLVGKVEEA from Mvp2 corresponds to this region and exactly matches the respective segment in vacuolar PPases of land plants. Is has been proposed that this subdomain participates directly in substrate and $\mathrm{Mg}^{2+}$ binding (32). Mutational analysis using the $\mathrm{H}^{+}$-PPase from mung bean showed (3) that the underlined charged residues are essential for enzymatic activity (in Mvp2: D191, K199, E201 see Fig. 6).

In addition other residues may be essential to form the catalytic site: i) the substitution of E305 and D504 in the $\mathrm{H}^{+}$-PPase from Arabidopsis (30) resulted in loss of hydrolyzing activity and $\mathrm{H}^{+}$-translocation (E235 and D426 in the methanogenic enzymes). ii) The cytoplasmic loop $\mathrm{V}$ of many plant $\mathrm{H}^{+}$-PPases contains the span-loop interface motif TEYYTS (in Mvp2: TEHYTS). This sequence encompasses a Glu residue also implicated in coupling PPi hydrolysis and $\mathrm{H}^{+}$-translocation (30). iii) A carbodiimide-reactive Glu residue has been identified within the C-terminal part of the enzyme from pumpkin (33). It was proposed that the DCCD-sensitive residue is near by the $\mathrm{Mg}^{2+}$-binding site. However, this amino acid is not conserved in the prokaryotic enzymes. iv) Another DCCD reactive site (D283) has been detected in the $\mathrm{H}^{+}$-PPase from Vigna radiata which could be involved in the catalytic cycle (34). This residue is part of a sequence block (IADNVGDNVGD; loop CIII) which is conserved throughout all $\mathrm{H}^{+}$-PPases.

In summary, it is evident that the amino acid sequences of Mvp1 and Mvp2 from the methylotrophic methanogen Ms. mazei contain all the residues believed to be essential for PPi hydrolysis and $\mathrm{H}^{+}$-translocation. This finding was verified by biochemical experiments which indicated that at least Mvp2 is able to catalyze the aforementioned reactions. Further experiments are aimed to find conditions under which $m v p 1$ is expressed and to analyze the function the corresponding protein in the metabolism of Ms. mazei. 


\section{REFERENCES}

1. Rea, P. A. and Sanders, D. (1987) Physiol. Plantarum 71, 131-141.

2. Silvula, T., Salminen, A., Parfenyev, A. N., Pohjanjoki, P., Goldman, A., Cooperman, B. S., Baykov, A. A., and Lahti, R. (1999) FEBS Lett. 454, 75-80.

3. Maeshima, M. (2000) Biochim. Biophys. Acta 1465, 37-51.

4. Baltscheffsky, M., Nadanaciva, S., and Schultz, A. (1998) Biochim. Biophys. Acta 1364, 301-306.

5. Nelson, K. E., Clayton, R. A., Gill, S. R., Gwinn, M. L., Dodson, R. J., Haft, D. H., Hickey, E. K., Peterson, J. D., Nelson, W. C., Ketchum, K. A., McDonald, L., Utterback, T. R., Malek, J. A., Linher, K. D., Garrett, M. M., Stewart, A. M., Cotton, M. D., Pratt, M. S., Phillips, C. A., Richardson, D., Heidelberg, J., Sutton, G. G., Fleischmann, R. D., White, O., Salzberg, S. L., Smith, H. O., Venter, J. C., and Fraser, C. M. (1999) Nature 399, 323-329.

6. Redenbach, M., Kieser, H. M., Denapaite, D., Eichner, A., Cullum, J., Kinashi, H., and Hopwood, D. A. (1996) Mol. Microbiol. 21, 77-96.

7. Schöcke, L., and Schink, B. (1998) Eur. J. Biochem. 256, 589-594.

8. Drozdowicz, Y. M., Lu, Y. P., Patel, V., Fitz-Gibbon, S., Miller, J. H., and Rea, P. A. (1999) FEBS Lett. 460, 505-512.

9. Deppenmeier, U., Müller, V., and Gottschalk, G. (1996) Arch. Microbiol. 165, 149-163.

10. Deppenmeier, U., Lienard, T., and Gottschalk, G. (1999) FEBS Lett. 457, 291-297.

11. Müller, V., Ruppert, C., and Lemker, T. (1999) J. Bioenerg. Biomemb. 31, 15-27.

12. Hippe, H., Caspari, D., Fiebig, K., and Gottschalk, G. (1979) Proc. Natl. Acad. Sci. USA. 76, 494-498.

13. Ide, T., Bäumer, S., and Deppenmeier, U. (1999) J. Bacteriol. 181, 4076-4080.

14. Abken, H. J., and Deppenmeier, U. (1997) FEMS Lett. 154, 231-237.

15. Saheki, S., Takeda, A., and Shimazu, T. (1985) Anal. Biochem. 148, 277-281.

16. Deppenmeier, U., Blaut, M., Lentes, S., Herzberg, C., and Gottschalk, G. (1995) Eur. J. Biochem. 227, 261-269. 
17. Brown, J. W., Daniels, C. J., and Reeve, J. N. (1989) Crit. Rev. Microbiol. 16, 287-338.

18. Maeshima, M., and Yoshida, S. (1989) J. Biol. Chem. 264, 20068-20073.

19. Keltjens, J. T., Van Erp, R., Mooijaart, R. J., Van der Drift, C., and Vogels, G. D. (1988) Eur. J. Biochem. 172, 471-476.

20. Ellermann, J., Rospert, S., Thauer, R. K., Klein, A., Voges, M., and Berkessel, A. (1989) Eur. J. Biochem. 184, 63-68.

21. Davis, J. M., Poole, R. J., and Sanders, D. (1993) Biochim. Biophys. Acta 1141, 29-36.

22. Peinemann, S. (1989) PhD Thesis, University of Göttingen.

23. Ikeda, M., Tanabe, E., Rahman, M., Kadowaki, H., Moritani, C., Akagi, R., Tanaka, Y., Maeshima, M., and Watanabe, Y. (1999) J. Exp. Bot. 50, 139-140.

24. Luo, S., Marchesini, N., Moreno, S. N. J., and Docampo, R. (1999) FEBS Lett. 460, $217-$ 220.

25. Bult, C. J., White, O., Olsen, G. J., Zhou, L., Fleischmann, R. D., Sutton, G. G., Blake, J. A., FitzGerald, L. M., Clayton, R. A., Gocayne, J. D., Kerlavage, A. R., Dougerty, B. A., Tomb, J.-F., Adams, M. D., Reich, C. I., Overbeek, R., Kirkness, E. F., Weinstock, K. G., Merrick, J. M., Glodek, A., Scott, J. L., Geoghagen, N. S. M., Weidman, J. F., Fuhrmann, J. L., Nguyen, D., Utterback, T. R., Kelley, J. M., Peterson, J. D., Sadow, P. W., Hanna, M. C., Cotton, M. D., Roberts, K. M., Hurst, M. A., Kaine, B. P., Borodovsky, M., Klenk, H.-P., Fraser, C. M., Smith, H. O., Woese, C. R., and Venter, J. C. (1996) Science 273, 1058-1073.

26. Smith, D. R., Doucette-Stamm, L. A., Deloughery, C., Lee, H., Dubois, J., Aldrege, T., Bashirzahdeh, R., Blakely, D., Cook, R., Gilbert, K., Harrison, D., Hoang, L., Keagle, P., Lumm, W., Pothier, B., Qiu, D., Spadafora, R., Vicaire, R., Wang, Y., Wierzbowski, J., Gibson, R., Jiwani, N., Caruso, A., Bush, D., Safer, H., Patwell, D., Prabhakar, S., McDougall, S., Shimer, G., Goyal, A., Pietrokovski, S., Church, G.M., Daniels, C. J., Mao, J., Rice, P., Nölling, J., and Reeve, J. N. (1997) J. Bacteriol. 179, 7135-7155.

27. Klenk, H.-P., Clayton, R. A., Tomb, J. F., White, O., Nelson, K. A., Dodson, R. J., Gwinn, M., Hickey, E. K., Peterson, J. D., Richardson, D. L., Kerlavage, A. R., Graham, 
D. E., Kyrpides, N. C., Fleischmann, R. D., Quackenbusch, J., Lee, N. H., Sutton, G. G., Gill, S., Kirkness, E. F., Dougherty, B. A., McKenny, K., Adams, M.D., Loftus, B., Venter, J. C., et al., (1997) Nature 390, 364-370.

28. Knight, H., Trewavas, A. J., and Knight, M.R. (1996) Plant Cell 8, 489-503.

29. Takasu, A., Nakanishi, Y., Yamauchi, T., and Maeshima, M. (1997) J. Biochem. 122, 883-889.

30. Zhen, R. G., Kim, E. J., and Rea, P. A. (1997) J. Biol. Chem. 272, 22340-22348.

31. Rea, P. A., Kim, Y., Sarafian, V., Poole, R. J., Davies, J. M., and Sander, D. (1992) Trends Biochem. Sci. 17, 348-353.

32. Rea, P. A., and Poole, R. J. (1993) Ann. Rev. Plant Physiol. Plant Mol. Biol. 44, 157180.

33. Maruyama, C., Tanaka, Y., Takeyasu, K., Yoshida, M., and Sato, M. H. (1998) Plant Cell Physiol. 39, 1045-1053.

34. Yang, S. J., Jiang, S. S., Kuo, S. Y., Hung, S. H., Tam, M. F., and Pan, R. L. (1999)

Biochem. J. 342, 641-646. 


\section{Conclusions}

Methane is the major end product of the microbiological decomposition of organic matter under anaerobic, sulfate limiting conditions. Typical habitats of methanogenic microorganisms are freshwater sediments or the intestinal tract of animals. It has been calculated that more than $10^{9}$ tons of the combustible gas is generated per year. Most of the gas escapes into aerobic zones, where it is oxidized by methanotrophic bacteria or is released to the atmosphere, where it is photochemically converted to $\mathrm{CO}_{2}$. However, the atmospheric concentration of methane had risen significantly over the last 300 years, probably due to expanded agricultural activities such as rice cultivation and the rising number of cattles around the world. This fact is of major importance since methane as well as carbon dioxide are potent greenhouse gases (Conrad 1996).

The enzymatic breakdown of organic matter is not catalyzed by a single microorganism, but by syntrophic associations of different species. Large amounts of organic material (polysaccharides, proteins, nucleic acids, lipids) that reach anoxic environments are hydrolyzed and fermented by anaerobic bacteria to acetate, $\mathrm{CO}_{2}, \mathrm{H}_{2}$, formate and other simple $\mathrm{C}_{1}$-compounds. These substances are used by methanogenic archaea as carbon and energy sources resulting in the formation of methane and $\mathrm{CO}_{2}$ as end products of the anaerobic food chain.

The methanogenic organisms belong to the domain Archaea and are classified in five orders. Members of the orders Methanobacteriales, Methanococcales, Methanomicrobiales and Methanopyrales are referred to as obligate hydrogenotroph organisms able to use $\mathrm{H}_{2}+\mathrm{CO}_{2}$ as substrate. Most of them can also oxidize formate to form methane. The Methanosarcinales are most versatile with respect to their substrate spectrum because many species use $\mathrm{H}_{2}+\mathrm{CO}_{2}$, acetate, methanol and other methylated $\mathrm{C}_{1}$ compound such as methylamines (mono-, di-, or trimethylamine) and methylated thiols (dimethylsulfide, methanethiol or methylmercaptopropionate). 


\section{Mechanisms of ATP synthesis in methanogenic archaea}

The principal mechanisms of ATP generation fall into just two classes namely substrate level phosphorylation (SLP) and ion gradient driven ATP synthesis. SLP occurs during the degradation of organic substrates where a small number of intermediates is formed containing high-energy phosphoryl-bonds (e. g. acetyl phosphate, phosphoenolpyruvate and 1,3-bisphosphoglycerate). Further metabolism of such compounds is coupled to the transfer of the phosphate group to ADP. The second mechanism of ATP synthesis is effected by the interaction of ion translocating enzymes and ATP synthases, both tightly associated with the inner mitochondrial membrane in eukarya or the cytoplasmic membrane of bacteria and archaea. Ion translocating proteins can be divided into two classes: i) The translocation of ions is coupled to redox reactions as catalyzed by membrane bound electron transport systems (respiratory chains or photosynthesis) or ii) the generation of an ion gradient is independent of these rections. Examples of this type of ion translocases are product/proton symporters (Konings et al 1997) or primary sodium ion translocating decarboxylases (Dimroth et al 1997, Dimroth and Schink 1998) as well as $\mathrm{Na}^{+}$translocating methyl transferases (Gottschalk and Thauer, 2000). The ion motive force generated by these enzymes is thought to be the driving force for ATP synthesis from ADP and Pi as catalyzed by ATP synthases.

In former times it was a matter of debate how methanogenic archaea regenerate ATP. Although it became clear that there was no obvious site for ATP formation by substrate level phosphorylation, it took a long time to find experimental proofs for a chemiosmotic mechanism of ATP synthesis . A major breakthrough was the preparation of subcellular vesicles from Methanosarcina mazei strain Gö1 (Peinemann, 1989) and the generation of washed inverted vesicles of this organism which contained closed membrane structures with definite inside out orientation (Mayer et al. 1987). These vesicles were found to be capable of energy transduction by proton translocation (Deppenmeier et al, 1990). The great advantage of such a system is that the active centers of the enzyme involved in energy transduction face the outside and are accessible for highly charged substrates.

In the following sections the major energy conserving enzyme systems in methanogenic archaea, especially that of Methanosarcina strains will be discussed: 1) three different anaerobic respiratory chains present in these organisms and 2) three primarily ion 
translocases: namely a proton translocating pyrophosphatase, the $\mathrm{Na}^{+}$translocating methyl transferase and the ATP synthase.

\section{Anaerobic respiratory chains in Ms. mazei}

During growth on hydrogen and carbon dioxide $\mathrm{CO}_{2}$ is reduced to formyl-MF by the catalytic activity of the formyl-MF dehydrogenase. The endergonic reaction is driven by an electrochemical ion gradient. The formyl group is then transferred to $\mathrm{H}_{4} \mathrm{MPT}$ and stepwise reduced to methyl- $\mathrm{H}_{4} \mathrm{MPT}$. Reduction equivalents are derived from reduced cofactor $\mathrm{F}_{420}$ which in turn is produced by the cytoplasmic $\mathrm{F}_{420}$-reducing hydrogenase. The next step is the transfer of the methyl group from $\mathrm{H}_{4} \mathrm{MPT}$ to coenzyme $\mathrm{M}$, an exergonic reaction catalyzed by the methyl- $\mathrm{H}_{4} \mathrm{MPT}: \mathrm{HSCoM}$ methyltransferase. It was shown that this reaction is coupled to the generation of an electrochemical $\mathrm{Na}^{+}$gradient. The final step in methanogenesis is the reduction of methyl CoM using HS-CoB as a reductant. The reaction results in the formation of methane and a heterodisulfide (CoM-SS-CoB) from coenzyme $\mathrm{M}$ and coenzyme $\mathrm{B}$.

During the last years, the energy conserving systems of Ms. mazei Gö1 have been analyzed comprehensively. It was shown that this organism possesses at least two membrane bound electron transport systems both of which are able to use the heterodisulfide as an electron acceptor and either molecular hydrogen or reduced cofactor $\mathrm{F}_{420}$ as electron donors for the reductive cleavage of CoM-S-S-CoB.

\section{The $\mathrm{H}_{2}$ :heterodisulfide oxidoreductase}

When methanogens grow on $\mathrm{H}_{2}$ and $\mathrm{CO}_{2}$, molecular hydrogen is used for the reduction of CoB-S-S-CoM. In Methanosarcina strains this reaction is catalyzed by the membrane bound $\mathrm{H}_{2}$ :heterodisulfide oxidoreductase (Deppenmeier et al. 1990, see also CHAPTER 2). The initial step is the oxidation of molecular hydrogen by the $F_{420}$-nonreducing hydrogenase, an enzyme which was purified from Ms. barkeri (Kemmner and Zeikus, 1996) and Ms. mazei (Deppenmeier et al. 1996). The purified enzyme consists of two different subunits with molecular masses of 60 and $40 \mathrm{kDa}$ and contains one nickel ion in the $\mathrm{Ni} / \mathrm{Fe}$ active site and several Fe/S clusters, but no flavins. Ms. mazei contains two sets 
of genes, the vho and vht operons, both of which encode $\mathrm{F}_{420}$-nonreducing hydrogenases. The VhoGAC enzyme is believed to be part of the membrane bound $\mathrm{H}_{2}$ :heterodisulfide oxidoreductase (Deppenmeier et al., 1995, Deppenmeier et al., 1996) Interestingly, the $v h o G A$ products showed homologies to bacterial NiFe hydrogenases while $v h o C$ encoded a b-type cytochrome which probably functions as an initial electron acceptor of the core NiFe enzyme (Brodersen et al., 1999).

The heterodisulfide reductase is the second component of the $\mathrm{H}_{2}$ :heterodisulfide oxidoreductase. The enzyme of Methanosarcina species is composed of two subunits (Hdr D E), HdrE is a membrane integral b type cytochrome containing two heme groups, while $\mathrm{HdrD}$ is the catalytic center harbouring two $\mathrm{Fe}_{4} \mathrm{~S}_{4}$ clusters (Hedderich et al., 1999; Simianu et al., 1998).

After the elucidation of the composition and properties of the key proteins of the $\mathrm{H}_{2}$ :heterodisulfide oxidoreductase the most interesting question concerned the nature of the carrier mediating electron transfer from the hydrogenase to the heterodisulfide reductase. It is important to note that quinones were not detected in Methanosarcina strains. Fortunately, the mechanisms of membrane bound electron transport could be further analyzed with the discovery of methanophenazine (Abken et al, 1998, see also CHAPTER 4). Because the component is very hydrophobic, it cannot be used for in vitro assays in aqeous buffer systems. However, a hydrophilic analogon, 2-hydroxy phenazine was found to be an effective substitute for methanophenazine. It was shown that washed inverted vesicles of Ms. mazei catalyze the $\mathrm{H}_{2}$-dependend 2-OH phenazine reduction and the dihydro-2-OH phenazine-dependend heterodisulfide reduction. Both reactions are coupled to the transfer of two protons across the cytoplasmic membrane.

\section{The $\mathbf{F}_{420}$ : heterodisulfide oxidoreductase}

During growth on methanol or methylated substrates, part of the methyl groups of the substrates are oxidized and reduction equivalents are transferred to cofactor $\mathrm{F}_{420}$. Hence, $\mathrm{F}_{420} \mathrm{H}_{2}$ and the heterodisulfide CoM-S-S-CoB are generated under these conditions. Using the above mentioned inverted vesicle preparatios from Ms. mazei Gö1, it became evident that $\mathrm{F}_{420} \mathrm{H}_{2}$ is reoxidized in the presence of CoM-S-S-CoB by a membrane bound electron transport system named $\mathrm{F}_{420} \mathrm{H}_{2}$ :heterodisulfide oxidoreductase (see also CHAPTER 3). This system consists of a $\mathrm{F}_{420} \mathrm{H}_{2}$ dehydrogenase and the aforementioned heterodisulfide reductase. Furthermore, the $\mathrm{F}_{420}$-dependent $\mathrm{CoM}-\mathrm{S}-\mathrm{S}-\mathrm{CoB}$ reduction has been shown to be competent in driving proton translocation across the cytoplasmic membrane 
(Deppenmeier et al., 1996, Bäumer et al., 2000). Similar to the $\mathrm{H}_{2}$-dependend oxidoreductase system, electron transport and proton translocation are strictly coupled as indicated by stoichiometries of $4 \mathrm{H}^{+}$transferred per 2 electrons transported from $\mathrm{F}_{420} \mathrm{H}_{2}$ to the heterodisulfide. It was also shown that the electron transfer between the $\mathrm{F}_{420} \mathrm{H}_{2}$ dehydrogenase and the heterodisulfide reductase is mediated by phenazine derivatives (Bäumer et al., 1998). The water soluble analogue of methanophenazine, 2-OH phenazine was reduced in the presence of $\mathrm{F}_{420} \mathrm{H}_{2}$ and dihydro-2-OH phenazin was able to act as an electron donor for the heterodisulfide reductase. Washed inverted vesicles of Ms. mazei Gö1 couple both exergonic processes with the transfer of protons across the cytoplasmic membrane. The maximal $\mathrm{H}^{+} / 2 \mathrm{e}^{-}$ratio was 2.0 for each reaction. The resulting electrochemical proton gradient $\left(\Delta \mu \mathrm{H}^{+}\right)$was the driving force for ATP synthesis from ADP $+\mathrm{P}_{\mathrm{i}}$. Thus, the $\mathrm{F}_{420} \mathrm{H}_{2}$ :heterodisulfide oxidoreductase system comprises two different proton-translocating segments. The first involves the 2-OH-phenazinedependent $\mathrm{F}_{420} \mathrm{H}_{2}$ dehydrogenase and the second one the heterodisulfide reductase.

Also the key enzymes of this methanogenic electron transport chain have been isolated and characterized: The $\mathrm{F}_{420} \mathrm{H}_{2}$ dehydrogenase from $M s$. mazei was purified as an $115 \mathrm{kDa}$ enzyme containing iron sulphur clusters and FAD (Deppenmeier et al., 1996). It became evident that the enzyme is very similar to the corresponding enzyme from Methanolobus tindarius (Haase et al., 1992). The complex of the latter organism is composed of five different subunits with molecular masses of 43, 37, 22, 20 and $16 \mathrm{kDa}$.

In the course of the Ms. mazei Gö1 genome-sequencing project a DNA fragment was identified which encodes the subunits of the purified enzyme. The proposed name for this gene locus is fpo for $\underline{F}_{420}$ phenazine oxidoreductase. The fragment comprises 12 genes designated fpo $A B C D H I J K L M N O$ that are organized in one operon. The gene encoding subunit Fpo $\mathrm{F}$ of the purified enzyme is not part of the operon and is located at a different locus on the chromosome. Taking into account that the fpo operon contains 12 genes and that the purified $\mathrm{F}_{420} \mathrm{H}_{2}$ dehydrogenase is composed of only five subunits it is obvious that only a subcomplex of protein has been purified so far.

It is notably that the $\mathrm{F}_{420} \mathrm{H}_{2}$ dehydrogenase is functionally homologous to the NADH:ubiquinone oxidoreductase 1 (NADH-DH) since both enzymes reveal a complex subunit composition and contain FeS-clusters and flavins (Yagi et al., 1998). $\mathrm{F}_{420} \mathrm{H}_{2}$ and NADH are reversible hydride donors with similar mid-point potentials. Electrons derived from the oxidation process are transferred to quinones and methanophenazine, 
respectively, which are similar in possessing isoprenoid side chains that enable them to diffuse into the hydrocarbon phase of the cytoplasmic membrane. It has been shown that mitochondrial and bacterial NADH:ubiquione oxidoreductases as well as $\mathrm{F}_{420} \mathrm{H}_{2}$ dehydrogenase are inhibited by diphenyleneiodonium chloride. Moreover, the comparison of the deduced amino acid sequences of the subunits revealed that the enzymes are also structurally related. For eleven polypeptides encoded by fpoA to $f p o N$ related counterparts exist in bacterial NADH-Dehydrogenase and mitochondrial complex I. Alignments indicated similarities of $42-71 \%$ and identities of $37-60 \%$ to the corresponding subunits of the above-mentioned enzyme complexes.

\section{Fd $d_{\text {red }}$ :heterodisulfide oxidoreductase}

Methanogenesis from acetate is coupled to the smallest change of free energy of all methanogenic substrates: Since 1 ATP is invested in acetate activation

Acetate + ATP $\longrightarrow \quad$ Acetyl-phosphate + ADP

Acetylphosphate + CoenzymeA $\longrightarrow \quad$ Acetyl-CoenzymeA $+\mathrm{Pi}$

it is necessary that methanogenesis from acetate gives rise to the generation of more than one ATP per $\mathrm{CH}_{4}$ formed for obvious reasons. As mentioned in the introduction, the $\mathrm{CO}$ dehydrogenase/ acetylCoA synthase complex catalyzes the acetylCoA cleavage and forms methyl- $\mathrm{H}_{4} \mathrm{MPT}, \mathrm{CO}_{2}$ and reduced ferredoxin. The cofactor-bound methyl group is subsequently transferred to coenzyme $\mathrm{M}$. An exergonic reaction is catalyzed by the methyl- $\mathrm{H}_{4} \mathrm{MPT}: \mathrm{HSCOM}$ methyltransferase and gives rise to the generation of an electrochemical $\mathrm{Na}^{+}$gradient. After this reaction methyl-CoM is reduced to $\mathrm{CH}_{4}$ with the help of the reductive agent HS-CoB resulting in the formation of the heterodisulfide. The remaining intermediates, reduced ferredoxin and the heterodisulfide have to be regenerized by a third membrane bound electron transport system, which is referred to as the $\mathrm{Fd}_{\text {red }}$ :heterodisulfide oxidoreductase.

The composition of this system is still a matter of debate. Strong evidence has been provided by the group of Rainer Hedderich (MPI f. terrestrische Mikrobiologie, Marburg) that a so called Ech hydrogenase and the heterodisulfide reductase are involved in 
electron transfer and proton translocation. The Ech hydrogenase was discovered in acetate grown cells of $M s$. barkeri and showed homologies to hydrogenase 3 from E. coli and the $\mathrm{CO}$ induced hydrogenase from Rhodospirillium rubrum. Biochemical and genetical analysis revealed that the Ech hydrogenase is composed of six subunits (Ech A B C D E F) which are encoded by the ech operon. The Ech E protein reveals homologies to the catalytic subunit of classical NiFe hydrogenases while Ech $\mathrm{C}$ contains a conserved motif for a iron sulfur cluster and may function as an electron acceptor of Ech E. Ech A and B are membrane integral proteins. With the exception of Ech D all polypeptides of the Ech hydrogenase show distinct homologies to subunits of energy conserving NADH dehydrogenases. Therefore, it was proposed that this enzyme also functions as a proton pump.

The Ech hydrogenase is most likely involved in the membrane bound electron transfer of acetate grown Methanosarcina cells, because Hedderich et al. (1999) showed that reduced ferredoxin, as produced by the CO-Dehydrogenase, is reoxidized by the purified Ech hydrogenase. Two different mechanisms of electron transfer to the heterodisulfide are possible:

1. The oxidation of the reduced ferredoxin by the Ech hydrogenase results in the formation of molecular hydrogen, which is in turn oxidized by the above mentioned $\mathrm{H}_{2}$ :heterodisulfide oxidoreductase systems and electrons are channeled to the heterodisulfide. An argument against mechanism 1 is that the overall process would include three proton translocating coupling sites, namely the Ech hydrogenase itself, the $\mathrm{F}_{420}$-nonreducing hydrogenase and the heterodisulfide reductase. Because of thermodynamical reasons this possibility is not very likely.

2. Another hypothesis is that molecular hydrogen is not an intermediate of the $\mathrm{Fd}_{\text {red }}$ :heterodisulfide oxidoreductase. Instead the electrons derived from the oxidation of reduced ferredoxin could be channeled directly to methanophenazine and further on to the heterodisulfide. An argument against this mechanism is the fact, that the purified Ech hydrogenase catalyzes a ferredoxin dependent 2-OH phenazine reduction only at very low rates, but this finding might depend on the state of the purified enzyme or the possibility that 2-OH phenazine might be not the suitable electron acceptor in contrast to methanophenazine. 


\section{The formyl-MF dehydrogenase system}

The conversion of $\mathrm{CO}_{2}$ and $\mathrm{H}_{2}$ to formyl-MF is an endergonic process which involves a membrane bound hydrogenase, the formyl-MF dehydrogenase and probably several electron carriers. The driving force for this reaction is the electrochemical ion gradient.

The formyl-MF dehydrogenase from Ms. barkeri is composed of five different subunits containing a molybdenum cofactor, molybdopterin and several Fe/S clusters (Thauer, 1998). The genes encoding the subunits are organized in one operon that comprises the genes fmd $E F A B C$ and $D$. Subunit Fmd B harbours the molybdopterin active site and probably one $\mathrm{Fe}_{4} \mathrm{~S}_{4}$ cluster. FmdF is predicted to be a polyferredoxin containing eight $\mathrm{Fe}_{4} \mathrm{~S}_{4}$ clusters. Since the formyl-MF dehydrogenase cannot use $\mathrm{H}_{2}$ directly for $\mathrm{CO}_{2}$ reduction, a separate hydrogenase has to be involved in the initial reaction of methanogenesis from $\mathrm{H}_{2}$ and $\mathrm{CO}_{2}$. It was found that the formyl-MF dehydrogenase as well as the above mentioned Ech hydrogenase are able to interact with ferredoxins. From these findings it is reasonable to assume that the formyl-MF formation takes place in the following manner:

In the first reaction, $\mathrm{H}_{2}$ is oxidized by the membrane bound Ech hydrogenase and electrons are transferred to a ferredoxin. Taking into account that the redox potential of the $\mathrm{CO}_{2}+\mathrm{MF} /$ formyl-MF couple is in the range of $-500 \mathrm{mV}$, the potential difference between $\mathrm{H}_{2} / 2 \mathrm{H}^{+}(-414 \mathrm{mV})$ and the required low-potential ferredoxin could be overcome by the influx of protons through the Ech hydrogenase. Thus, the endergonic reduction of $\mathrm{CO}_{2}$ would finally be driven by the electrochemical proton gradient.

During growth on methylated substrates the hydrogenase/formyl-MF dehydrogenase system should catalyze the reverse reaction: Formyl-MF would be oxidized to $\mathrm{CO}_{2}$ and part of the free energy released would be stored by reducing the low potential ferredoxin. Reduced ferredoxin would in turn be oxidized by the Ech hydrogenase thereby releasing molecular hydrogen that could function as an electron donor for the $\mathrm{H}_{2}$ :heterodisulfide oxidoreductase.

As ferredoxins with a midpoint potential of $-500 \mathrm{mV}$ have not been characterized in methanogens, the final support for this hypothesis is still missing. But it is to note that more than 20 open reading frames coding for possible ferredoxins were identified during the Ms. mazei genome project. One of these could fulfill the function described above. 


\section{Proton translocating pyrophosphatases}

In the course of the Ms. mazei genome sequencing project a DNA fragment was identified that encodes for two different proton translocating pyrophosphatases (see also CHAPTER 5). The genes ( $m v p 1$ and $m v p 2$ ) were found to be oriented in opposite directions and were linked by a $750 \mathrm{bp}$ intergenic region. The corresponding polypeptides Mvp1 and Mvp2 represent extremely hydrophobic, membrane integral proteins. Furthermore, a membrane bound pyrophosphatase activity in washed membranes of Ms. mazei was determined and further experiments using inverted membrane vesicles revealed that pyrophosphate hydrolysis was coupled to the transfer of one proton across the cytoplasmic membrane. Several biosynthetic pathways generate pyrophosphate (PPi), for instance amino acid activation, polysaccharide synthesis, DNA and RNA assembly and the formation of fattyacyl coenzyme A (Maeshima, 2000). Thus, PPi may function as an high energetic substrate of the membrane bound pyrophosphatases that saves a portion of the free energy of PPi hydrolysis for the generation of an electrochemical proton gradient. This assumption is also logical from the thermodynamic point of view: The free energy of PPi hydrolysis in the cytoplasm was calculated to be about $-30 \mathrm{~kJ} / \mathrm{mol}$ (Davis et al., 1993). Taking into account that the membrane potential $\Delta \mathrm{p}$ ist in the range of $-150 \mathrm{mV}$ (Peinemann, 1989b), the energy of $-14.6 \mathrm{~kJ} / \mathrm{mol}$ would be neccesary to translocate one proton across the cytoplasmic membrane. Thus, PPi hydrolysis coupled to the translocation of one mol protons per mol of PPi would still be an exergonic process capable of driving biosynthetic reactions towards completion. This is the main advantage of the proton translocating pyrophosphatases in contrast to the soluble type of enzymes, which merely thermally dissipate all the free energy of the pyrophosphate bond. 


\section{The membrane bound methyltransferase in methanogenic archaea: A primary sodium pump}

All methanogenic archaea have in common that their growth is dependent on the presence of sodium ions. It was shown that methanogenesis from acetate, $\mathrm{H}_{2}$ and $\mathrm{CO}_{2}$ and methanol as catalyzed by whole cells is $\mathrm{Na}^{+}$dependent (Perski et al., 1981 and 1982)

A major breakthrough was the finding that methanogenesis from methanol and $\mathrm{H}_{2}$ was not sodium dependent (Blaut et al., 1984). This led to the discovery that one special reaction, the methyl group transfer from $\mathrm{H}_{4} \mathrm{MPT}$ to coenzyme $\mathrm{M}$ required the presence of sodium ions.

Using washed inverted vesicle preparations of strain Gö1 it was shown that the methyl$\mathrm{H}_{4} \mathrm{MPT}$ :SCoM methyltransferase acts as an primary sodium ion pump translocating two $\mathrm{Na}^{+}$ions across the cytoplasmic membrane in the course of methyl-group transfer from $\mathrm{H}_{4} \mathrm{MPT}$ to coenzyme $\mathrm{M}$. In contrast, during growth on methylated $\mathrm{C}_{1}$ compounds the methyltransferase takes advantage of the sodium ion potential in order to drive the endergonic methyl transfer from methyl-SCoM to $\mathrm{H}_{4} \mathrm{MPT}$.

Thauer and co-workers detected eight different subunits in the purified methyl- $\mathrm{H}_{4} \mathrm{MPT}$ : $\mathrm{CoM}$ methyltransferase from Methanobacterium thermoautothrophicum designated as Mtr A B C D E F G H (Gärtner et al., 1993). Later on, a similar enzyme was purified from Ms. mazei Gö1 (Lienard et al., 1999). Biochemical charcterisation of the enzyme revealed the presence of a $\mathrm{Fe}_{4} \mathrm{~S}_{4}$ cluster and 5-hydroxybenzimidazol cobamide with a midpoint potential of $-426 \mathrm{mV}$ (Lu et al., 1995).

Finally, the purified enzyme was reconstituted into ether lipid liposomes prepared from membrane fractions of $M s$. mazei Gö1 and was shown to couple methyl-group transfer and $\mathrm{Na}^{+}$translocation across the artificial membrane structures.

Recent studies on the structure and catalytic properties of the membrane bound methyltransferases allow to speculate on a rection mechanism: The subunits Mtr A and $\mathrm{H}$ are located at the inner side of the cytoplasmic membrane. Mtr A is the corrinoid harbouring subunit where the methylation and demethylation process takes place. Subunits $\mathrm{H}$ and $\mathrm{E}$ are probably involved in the methyl transfer reactions. The methylation of the $\operatorname{Cob}(\mathrm{I})$ amide is believed to be associated with the ligation of a additional histidine to the methylcob(III)amide. In this state, methylcob(III)amide is exposed to a nucleophilic attack probably from the ${ }^{-} \mathrm{S}-\mathrm{CoM}$ ion (Mattews and Goulding, 1997). The following demethylation reaction is thought to result in the dissociation of the additional histidine 
bond from the cobamide, which in turn would lead to a dramatic conformational change of the enzyme. This conformational change might be the driving force for the sodium ion translocation.

\section{ATP synthases}

The synthesis of ATP driven by electrochemical ion gradients is carried out by ATP synthases. Three different subclasses of ATPases can be distinguished. The first example is the vacuolar type $\mathrm{V}_{1} \mathrm{~V}_{\mathrm{o}}$ ATPase which is located at endomembrane systems of eucaryota. The proteins exhibit only ATP hydrolase activity (Forgac, 1999). Based on structural similarities, it has been shown that the archaeal type $A_{1} A_{o}$ ATPase is closely related to the vacuolar type enzyme. However, the $A_{1} A_{o}$ enzyme differs significantly from the $V_{1} V_{0}$ type enzyme because it is able to synthesize ATP. This feature is in turn shared with the best studied subclass of ATPases, the $\mathrm{F}_{1} \mathrm{~F}_{\mathrm{o}}$ type ATPase from mitochondria and most bacteria.

All ATPases are composed of two subcomplexes: A membrane integral, ion translocting module $\left(\mathrm{A}_{\mathrm{o}}, \mathrm{F}_{\mathrm{o}}\right.$ and $\left.\mathrm{V}_{\mathrm{o}}\right)$ and a peripheral ATP hydrolyzing/synthesizing module $\left(\mathrm{A}_{1}, \mathrm{~F}_{1}\right.$ and $\mathrm{V}_{1}$ ). The $\mathrm{F}_{1}$ module of the $E$. coli enzyme has been studied on basis of X-ray crystallography and NMR spectroscopy. It is composed of five different subunits with the stoichiometry $\alpha_{3} \beta_{3} \delta \gamma \varepsilon$. The membrane integral $\mathrm{F}_{\mathrm{o}}$ part is constructed from three different subunits in various stoichiometries $\left(\mathrm{ab}_{2} \mathrm{c}_{10-14}\right)$.

According to the current model the subunits of the $F_{1}$ part are arranged in a hexagonal ring, the $\alpha_{3} \beta_{3}$ hexamer. Together with subunits a, $b_{2}$ and $\delta$ the hexamer forms the stator of the enzyme. The rotor comprises subunits $\mathrm{c}, \varepsilon$ and $\gamma$. It is belived that the $\gamma$ subunit is able to rotate in the center of the $\alpha_{3} \beta_{3}$ stationary ring. Together with the $\varepsilon$ subunit it forms the „traditional stalk“ that connects $F_{1}$ and $F_{0}$. The second connection between the modules is the so called ,second stalk“ consisting of subunit $\delta$ and two copies of subunit b which most probably holds the hexamer in place.

According to a widely accepted model the electrochemical ion gradient is the driving force for a rotational movement of the ring formed by the assembly of the hydrophobic $\mathrm{c}$ units. The rotational energy is then conducted to the asymmetrical $\gamma$ subunit which rotates inside the stationary hexamer of the catalytic $\alpha_{3} \beta_{3}$ subunits that carry out the formation of ATP in three consecutive steps. The first step is the binding of the substrates ADP plus Pi, 
the second the formation of the phosphoanhydride bound and the third the release of the ATP molecule. This process would be in accordance with results showing a very fine tuned succession of differing binding affinities towards the substrates and the product (for review see BBA Bioenergetics 1458, 2000).

The $\mathrm{H}^{+}$translocating $\mathrm{A}_{1} \mathrm{~A}_{0}$ ATPase from Ms. mazei has been studied comprehensively. The enzyme was purified and the coresponding genes have been sequenced. The complex was shown to be composed of ten different subunits designated Aha H I K E C F A B D and $\mathrm{G}$ that are encoded by the aha operon. The $\mathrm{A}_{1}$ part consists of 5 different subunits with a stoichiometry of $\mathrm{A}_{3} \mathrm{~B}_{3} \mathrm{CDF}$ (Gruber et al., 1999). Structural determinations revealed that Aha D probably represents the ,traditional stalk“ while the stator might be constructed of Aha $\mathrm{E}$ and $\mathrm{I}$. The subunit Aha $\mathrm{K}$ represents the very hydrophobic proteolipid with significant homologies to subunit c in F-type ATPases (Müller et al., 1999). Similar to the F-type enzyme an ion flux through subunit Aha I would result in a rotation of the Aha $\mathrm{K}$ ring which transfers the rotational movement to Aha $\mathrm{D}$. The latter subunit interacts directly with the catalytic subunits (Aha A) that synthesize and release ATP.

In methanoarchaea, as outlined in the conclusions of this thesis, ATP is synthesized by a chemiosmotic mechanism. The electrochemical proton gradient is generated by at least three different anaerobic respiratory chains, the $\mathrm{H}_{2}$ :hetrodisulfide oxidoreductase, the $\mathrm{F}_{420} \mathrm{H}_{2}$ :heterodisulfide oxidoreductase and the $\mathrm{Fd}_{\text {red }}$ :heterodisulfide oxidoreductase each of them revealing unique mechanisms of proton translocation. Another mechanism of $\mathrm{H}^{+}$ translocation is coupled to the hydrolysis of PPi as catalyzed by membrane bound pyrophosphatases.

Furthermore, the membrane bound methyltransferase gives rise to the generation of a electrochemical sodium ion gradient. How ATP regeneration from a transmembrane $\mathrm{Na}^{+}$ gradient is achieved is still a matter of discussion. A sodium dependent $\mathrm{F}_{1} \mathrm{~F}_{0}$ type ATPase was formerly postulated, but in the course of the Ms. mazei genome project it became clear that Methanosarcina is equipped only with A-type ATPases, which use protons as coupling ions. Hence, the most reasonable explanation is that the electrochemical sodium gradient established by the methyltransferase is converted to a secondary proton gradient by $\mathrm{Na}^{+} / \mathrm{H}^{+}$antiporters. This secondary proton gradient is then the driving force for ATP generation by the proton dependent $\mathrm{A}_{1} \mathrm{~A}_{\mathrm{o}}$ ATPase. 


\section{References}

Abken, H. J., Tietze, M., Brodersen, J., Bäumer, S., Beifuss, U., Deppenmeier, U.: J. Bacteriol. 180, 2027-2032 (1998).

Bäumer, S., Ide, T., Jacobi, C. Johann, A. Gottschalk G., Deppenmeier, U.: J. Biolog. Chem. 275, 17968-17973 (2000)

Bäumer, S., Murakami, E., Brodersen, J. Gottschalk, G., Ragsdale, S.W., Deppenmeier, U.: FEBS Lett. 428, 295-298 (1998).

Blaut, M., Gottschalk, G.:. Eur. J. Biochem. 141, 217-222 (1984).

Brodersen, J., Bäumer, S., Abken, H.J., Gottschalk, G., Deppenmeier, U.: Eur. J. Biochem. 259, 218-224 (1999).

Conrad, R.: Microbiol. Rev. 60, 609 - 640 (1996)

Davis, J. M., Poole, R. J., and Sanders, D.: (1993) Biochim. Biophys. Acta 1141, 29-36.

Deppenmeier, U., Blaut, M., Mahlmann, A., Gottschalk, G.: Proc. Natl. Acad. Sci. USA 87, 9449-9453 (1990).

Deppenmeier, U., Blaut, M., Lentes, S., Herzberg, C., Gottschalk, G.: Eur. J. Biochem. 227, 261-269 (1995).

Deppenmeier, U., Müller, V., Gottschalk, G.: Arch. Microbiol. 165, 149-163 (1996).

Dimroth P, Kaim G, Matthey U.: Biochim Biophys Acta;1365(1-2):87-92 (1998)

Dimroth P, Schink B.: Arch Microbiol 170(2):69-77(1998

Forgac M.: J Biol Chem;274(19):12951-4 (1999)

Gärtner, P., Ecker, A., Fischer, R., Linder, D., Fuchs, G., Thauer, R. K.: Eur. J. Biochem. 213, 537-545 (1993).

Gottschalk, G. and Thauer, R.K.: Biochim. Biophys. Acta 1505, 28-36 (2001)

Gruber G, Svergun DI, Coskun U, Lemker T, Koch MHJ, Schägger H, Müller V.: Biochemsitry 40 (7): 1890-1896 (2001).

Haase, P., Deppenmeier, U., Blaut, M., Gottschalk, G.: Eur. J. Biochem. 203, 527-531 (1992).

Kemner, J.M., Zeikus, J.G.: Arch. Microbiol. 161, 47-54 (1994)

Lienard T, Gottschalk G.: FEBS Lett 425(2):204-208 (1998)

Lu, W.P , Becher, B., Gottschalk, G. Ragsdale, S.W.: J. Bacteriol 177, 2245-2250 (1995)

Maeshima, M.: Biochim. Biophys. Acta 1465, 37-51. (2000)

Mayer, F., Jussofie, A., Salzmann, M., Lübben, M. Rohde,. M., Gottschalk, G.:. J. Bacteriol. 169, 2307-2309. (1987) 
Müller V, Ruppert C, Lemker T.: J Bioenerg Biomembr (1):15-27 (1999)

Peinemann, S., Hedderich, R., Blaut, M. Thauer, R.K., Gottschalk, G. Eur. J. Biochem. $186,175-180$ (1989a)

Peinemann, S.: PhD Thesis, University of Göttingen (1989b)

Perski, H.J., Moll, J., Thauer, R.K.: Arch. Microbiol. 130, 319-321 (1981)

Perski, H.J., Schönheit, P. Thauer, R.K.: FEBS Lett. 143, 323-326 (1982)

Simianu, M., Murakami, E., Brewer, J. M., Ragsdale, S. W.: Biochemistry 37, $10027-$ 10039 (1998).

Thauer, R.K.: Microbiology. 144, 2377-2406 (1998).

Yagi T, Yano T, Di Bernardo S, Matsuno-Yagi A.:Biochim Biophys Acta 1364(2):125-33 (1998) 


\section{Curriculum vitae}

\section{Sebastian Andreas Bäumer, Dipl. Biol.}

\section{Born on October, $24^{\text {th }} 1970$ in Münster, Germany}

\section{Education:}

$1977-1981$

$1981-1990$

May 1990

Scientific Background:

Oct. 1992- Feb.1995

Mar. 1995- July 1998

June 1997-July 1998

since September1998
Primary education in Münster

Secondary education at the Johann-Conrad Schlaun Gymnasium in Münster

Abitur
Study of Biology at the Westfälische-Wilhelms University Münster

Study of Biology at the Georg-August University, Göttingen

Diploma Thesis in Microbiology: Rekonstitution der $\mathrm{F}_{420} \mathrm{H}_{2}:$ Heterodisulfid-Oxidoreduktase aus Methanosarcina mazei Gö1 und Untersuchungen zur Protonentranslokation im Zuge von 2-Hydroxyphenazin abhängigen Redox Reaktionen“"

Scientific Assistant at the Institute of Microbiology and Genetics, Georg-August University Göttingen 


\section{Danksagungen}

Mein besonderer Dank gilt PD Dr. Uwe Deppenmeier für die Überlassung des hochinteressanten Themas. Seine Zielstrebigkeit, Genauigkeit und auch eine Portion Skepsis haben zum Gelingen dieser Arbeit wesentlich beigetragen. Ausserdem Danke ich ihm für die stete Diskussions- und Hilfsbereitschaft sowie die gewissenhafte Korrektur dieses (und vieler anderer) Manuskripte. Lehrreich war es auch, bei so vielen nationalen und internationalen Meetings, Tagungen und Symposien teilnehmen zu dürfen.

Herrn Prof. Gottschalk danke ich für die Ermöglichung dieser Arbeit und die mir in jeder Hinsicht gewährte Unterstützung.

Ein besonderer Dank an meine „methanogenen“ Lehrmeister Hans-Jörg Abken und Jens Brodersen: Ohne Eure stete und prompte Hilfe (ich sage nur: Fermenter, Photometer und GradiFrac!) hätte es häufig finster ausgesehen!

Ein herzliches Dankeschön möchte ich allen jetzigen und ehemaligen Mitgliedern der „Labor 206-Crew“ Andrea, Anja, Caro, Claudi, Frank, Holger, Kai, Marc, Sabine, Sonja, Tina, und Vera ausprechen. Eure fröhliche und hilfsbereite Art wird mir immer in guter Erinnerung bleiben.

Ein großes Dankeschön an alle Mitarbeiter des Lehrstuhls II, die ich hier nicht erwähnt habe: Es gab immer für jedes Problem einen kompetenten Ansprechpartner! Darüber hinaus möchte ich Herrn M. Hoppert für seine unerlässliche Hilfe am EM danken.

Auch den Mitgliedern des Genomlabors sei für ihre rege Sequenzierarbeit gedankt.

Nicht ungenannt soll die Werkstatt mit Charly, Gerd und Jürgen bleiben, die in allen kleinen und großen technischen Problemen immer ein offenes Ohr für mich hatten und stets echt eine tolle Arbeit geleistet haben. Außerdem Danke an Herrn Hellwig (beispielsweise für all die Tricks beim Pipettenreparieren!).

Nicht zuletzt möchte ich meinen Eltern danken, die mir dieses Studium ermöglicht haben.

Für ihre unendliche Geduld, die tausenden fachlichen und nichtfachlichen Diskussionen, für ihren unverbesserlichen Optimismus und die vielen schönen Stunden möchte ich mich ganz herzlich bei meiner Nicole bedanken. 